Neylor Stevo

\title{
Registro Múltiplo de Sequências Temporais Coronais e Sagitais Obtidas por Ressonância Magnética Baseada em Transformada de Hough
}

\author{
Dissertação apresentada à Escola Poli- \\ técnica da Universidade de São Paulo \\ para obtenção do Título de Mestre em \\ Engenharia.
}


Neylor Stevo

\section{Registro Múltiplo de Sequências Temporais Coronais e Sagitais Obtidas por Ressonância Magnética Baseada em Transformada de Hough}

Dissertação apresentada à Escola Politécnica da Universidade de São Paulo para obtenção do Título de Mestre em Engenharia.

Área de concentração:

Engenharia Mecatrônica

Orientador:

Prof. Dr. Marcos de Sales Guerra Tsuzuki 
Este exemplar foi revisado e alterado em relação à versão original, sob responsabilidade única do autor e com a anuência de seu orientador.

São Paulo, 14 de Setembro de 2010.

Assinatura do autor.

Assinatura do orientador.

Ficha Catalográfica

Stevo, Neylor

Registro Múltiplo de Sequências Temporais Coronais e Sagitais Obtidas por Ressonância Magnética Baseada em Transformada de Hough. / N. Stevo. - São Paulo, 2010.

p. 74

Dissertação (Mestrado) — Escola Politécnica da Universidade de São Paulo. Departamento de Engenharia de Mecânica.

1. Ressonância Magnética 2. Pulmão 3. Imageamento (Bioengenharia) (Registro) I. Universidade de São Paulo. Escola Politécnica. Departamento de Engenharia de Mecânica. II. t. 


\section{Agradecimentos}

Ao Prof. Marcos Tsuzuki, por acreditar em mim e estar sempre disposto a me ajudar, desde o início deste projeto com idéias e propostas.

Aos meus pais, por todo apoio que sempre me deram.

E também à parceria dos colegas de laboratório e aos professores da Poli, que são empenhados como mestres e abertos ao diálogo como amigos. 
Dedico esta monografia à minha querida esposa que sempre me apoiou e à Deus que me ensinou que nenhum conhecimento tem valor se não estiver a serviço da vida. 
"Adquire sabedoria, adquire inteligência, e não te esqueças nem te apartes das palavras da minha boca. Não a abandones e ela te guardará; ama-a, e ela te protegerá. A sabedoria é a coisa principal; adquire pois a sabedoria, emprega tudo o que possuis na aquisição de entendimento. Exalta-a, e ela te exaltará; e, abraçando-a tu, ela te honrará. Dará à tua cabeça um diadema de graça e uma coroa de glória te entregará." 


\section{Resumo}

Este trabalho discute a determinação de padrões respiratórios em sequências temporais de imagens obtidas por Ressonância Magnética (RM) e o seu uso no registro temporal de imagens coronais e sagitais. O registro é feito sem o uso de qualquer informação de sincronismo e qualquer gás especial para reforçar o contraste. As sequências temporais de imagens são adquiridas em respiração livre. O movimento real do pulmão nunca foi diretamente visto, pois é totalmente dependente dos músculos que o rodeiam. A visualização do pulmão em movimento é um tema atual de pesquisa na medicina. O movimento do pulmão não possui intervalos regulares e é suscetível a variações na respiração. Comparado à Tomografia Computadorizada (TC), a RM necessita de um maior tempo de aquisição e é preferível porque não envolve radiação. Como as sequências de imagens coronais e sagitais são ortogonais entre si, a sua intersecção corresponde a um segmento de reta no espaço tridimensional. O registro se baseia na análise deste segmento interseccional. A variação deste segmento de interseção no tempo pode ser enfileirada, definindo uma imagem espaço-temporal em duas dimensões (2DST). Supõe-se que o movimento diafragmático é o movimento principal e todas as estruturas do pulmão se movem quase que totalmente sincronicamente. A sincronização deste movimento é feita através de um padrão chamado função respiração. Este padrão é obtido através do processamento de uma imagem 2DST. Um algoritmo da transformada de Hough intervalar procura movimentos sincronizados na função respiração. O algoritmo de contornos ativos ajusta pequenas discrepâncias originadas por movimentos assíncronos nos padrões respiratórios. A saída é um conjunto de padrões respiratórios. Finalmente, a composição de imagens coronal e sagital que estão na mesma fase respiratória é realizada através da comparação de padrões respiratórios provenientes das superfícies de contorno superior e diafragmática. Quando disponíveis, os padrões respiratórios associados às estruturas internas do pulmão também são usados. Vários resultados e conclusões são apresentados. 


\section{Abstract}

This work addresses the determination of the breathing patterns in time sequence of images obtained from Magnetic Resonance (MR) and their use in the temporal registration of coronal and sagittal images. The registration is done without the use of any triggering information and any special gas to enhance the contrast. The temporal sequences of images are acquired in free breathing. The real movement of the lung has never been seen directly, as it is totally dependent on its surrounding muscles and collapses without them. The visualization of the lung in motion is an actual topic of research in medicine. The lung movement is not periodic and it is susceptible to variations in the degree of respiration. Compared to Computerized Tomography (CT), MR imaging involves longer acquisition times and it is preferable because it does not involve radiation. As coronal and sagittal sequences of images are orthogonal to each other, their intersection corresponds to a segment in the three dimensional space. The registration is based on the analysis of this intersection segment. A time sequence of this intersection segment can be stacked, defining a two-dimension spatio-temporal (2DST) image. It is assumed that the diaphragmatic movement is the principal movement and all the lung structures move almost synchronously. The synchronization of this motion is performed through a pattern named respiratory function. This pattern is obtained by processing a 2DST image. An interval Hough transform algorithm searches for synchronized movements with the respiratory function. A greedy active contour algorithm adjusts small discrepancies originated by asynchronous movements in the respiratory patterns. The output is a set of respiratory patterns. Finally, the composition of coronal and sagittal images that are in the same breathing phase is realized by comparing of respiratory patterns originated from diaphragmatic and upper boundary surfaces. When available, the respiratory patterns associated to lung internal structures are also used. Several results and conclusions are shown. 


\section{Conteúdo}

$\begin{array}{ll}\text { Lista de Figuras } & \text { ix }\end{array}$

Lista de Tabelas $\quad$ xiv

Lista de Abreviações e Siglas $\quad$ xv

1 Introdução 1

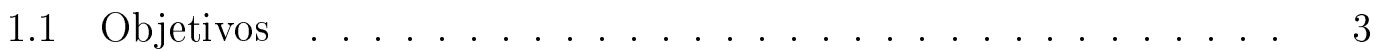

1.2 Estrutura do Trabalho . . . . . . . . . . . . . . . . . 4

2 Conceitos Básicos 5

2.1 A Pleura e o Pulmão . . . . . . . . . . . . . . . . . . 5

2.1.1 O Movimento Respiratório . . . . . . . . . . . . . 6

2.2 A Ressonância Magnética Nuclear . . . . . . . . . . . . . . . . 7

2.2.1 Princípios Físicos de RM . . . . . . . . . . . . . . . 8

2.2.2 Sequência de pulsos . . . . . . . . . . . . . . . . . 12

2.2 .3 Qualidade da Imagem . . . . . . . . . . . . . 17

2.3 Imageamento por RM do pulmão . . . . . . . . . . . . . . . . 20

2.4 O Arquivo DICOM . . . . . . . . . . . . . . 21

3 Padrão Respiratório Temporal 23

3.1 Função Respiratória Padrão . . . . . . . . . . . . . . . . . . . . . 24

3.1.1 Obtenção da Função Respiratória Padrão . . . . . . . . . . 27

3.2 Detector de Bordas . . . . . . . . . . . . . . . . . . . . 28

3.3 Transformada de Hough Modificada . . . . . . . . . . . . . . . 29

3.3.1 Busca por outros pares (Re-amostragem negativa) . . . . . 31 
3.3.2 Uma explicação sobre a Transformada de Hough Modificada 32

3.3.3 Transformada de Hough Modificada Intervalar (Tavares et al. ${ }^{[1]} \ldots \ldots \ldots \ldots \ldots \ldots \ldots \ldots$

3.4 Algoritmo de Contornos Ativos (Snakes) . . . . . . . . . . . 35

3.4.1 Aplicando ao Padrão Respiratório . . . . . . . . . . . 36

4 Mapeamento Coronal-Sagital $\quad 39$

4.1 Intersecção do Plano Sagital x Coronal . . . . . . . . . . . . . . . 39

4.2 A matriz inversa .................... . . . 40

4.3 Cálculo da Intersecção das Imagens . . . . . . . . . . . . . . . . . 42

5 Registro Temporal $\quad 46$

6 Resultados e Discussões $\quad 51$

$\begin{array}{llc}7 & \text { Conclusões } & 63\end{array}$

Apêndice A - Aritmética Intervalar $\quad 64$

Apêndice B - Algoritmo de Contornos Ativos (Snakes) 67

B.1 Formulação Clássica . . . . . . . . . . . . . . . . . 67

B.2 Greedy Snake . . . . . . . . . . . . . . . 69

$\begin{array}{ll}\text { Referências } & 71\end{array}$ 


\section{Lista de Figuras}

2.1 Esquema das pleuras, pulmão e mediastino, corte frontal ${ }^{[2]}$. . . 6

2.2 Espectro de onda da radiação eletromagnética ${ }^{[3]}$. . . . . . . . 7

2.3 Fenômeno da ressonância ${ }^{[4]} \ldots \ldots \ldots \ldots$

2.4 Intensidade do vetor magnetização transversal $\left(\vec{M}_{x y}\right)$ em função do tempo ${ }^{[4]} \ldots \ldots \ldots \ldots \ldots \ldots$

2.5 Tempo T1 - tempo necessário para a recuperação da magnetização longitudinal dos prótons do tecido ${ }^{[4]}$. . . . . . . . . . . . . 11

2.6 Contraste por $\mathrm{T}^{[4]}{ }^{[4]} \ldots \ldots \ldots \ldots \ldots$

2.7 Com o passar do tempo os prótons vão saindo do alinhamento de fase e a magnetização transversal $\left(\vec{M}_{x y}\right)$ vai diminuindo de amplitude ${ }^{[4]}$............................. 12

2.8 Sequência Spin-eco, onde exibe-se o pulso de RF de 90 graus seguido do pulso de refasamento (180 graus) ${ }^{[4]}$. . . . . . . . . . . 14

2.9 Sequência FSE - fast spin-eco ${ }^{[4]} \ldots$. . . . . . . . . . . . . . . 15

2.10 Sequência SSFSE ${ }^{[4]}$. . . . . . . . . . . . . . . . . . . 16

2.11 Ruído em imagem gradiente ${ }^{[4]}$. . . . . . . . . . . . . . . . . 19

3.1 Exemplos de imagens de RM, coronal e sagital. . . . . . . . . . . 23

3.2 Duas imagens do mesmo pulmão que se interseccionam. A diferença de registro é mais evidente na superfície diafragmática. A intersecção entre as imagens é um segmento de linha. . . . . . . . . 24

3.3 Um exemplo de STV criado por 10 imagens de RM de uma fatia coronal do pulmão. . . . . . . . . . . . . . . . . . 25

3.4 Ilustração de uma intersecção arbitrária paralela ao eixo do tempo com um STV. . . . . . . . . . . . . . . . . . . 25

3.5 Exemplo de imagem de RM do tórax e uma imagem espaço temporal bidimensional (2DSTI) vertical. . . . . . . . . . . . . . 26 
3.6 Uma função respiratória padrão $f_{s}(t) \ldots \ldots \ldots$. . . . . .

3.7 Processo realizado na obtenção da função respiração padrão. Primeiramente o usuário define uma imagem 2DST e em seguida um algoritmo detecta os maiores gradientes nesta imagem. . . . . .

3.8 Ilustração do método de detecção de bordas. Conjuntos superior e inferior de pixels em torno do ponto considerado são usados para calcular o gradiente. . . . . . . . . . . . . .

3.9 Exemplo de imagem 2DST com o detector de bordas aplicado, uma imagem aresta. . . . . . . . . . . . . .

3.10 A transformada de Hough, a imagem 2DST está à esquerda e o espaço de quantização está à direita. O padrão respiratório na imagem 2DST é mapeado como uma célula no espaço de quantização. 30

3.11 A região que precisa ser re-amostrada é exibida em verde. Esta região contém todas as linhas que passam pela célula de maior intensidade selecionada pelo algoritmo e possui coeficiente angular interno ao intervalo $\left[0, f_{\max }\right] \ldots \ldots \ldots \ldots$

3.12 (a) Um padrão respiratório incoerente detectado pela transformada de Hough modificada é apontado por uma seta. (b) O espaço quantizado é exibido e o padrão respiratório relevante $f_{k}(t)=(a, b)$ é apontado por uma seta. . . . . . . . . . . . . .

3.13 A transformada de Hough após a substituição da variável, a nova imagem está na esquerda e o espaço quantizado está na direita. Uma linha projetada como uma célula no espaço quantizado. . . .

3.14 A região que deve ser re-amostrada é exibida em verde. Esta região engloba todas as linhas que atravessam a célula com maior intensidade selecionadas pelo algoritmo e que tem um coeficiente angular dentro do intervalo $\left[0, f_{\max }\right] \ldots \ldots \ldots \ldots$

3.15 A transformada de Hough intervalar, a imagem 2DST está à esquerda e o espaço quantizado a direita. Um pixel na imagem 2DST está mapeado com uma faixa no espaço quantizado. . . . . . . . . 
3.16 (a) A imagem 2DST e o padrão respiratório encontrado pela transformada de Hough modificada (acima), e o padrão respiratório encontrado pelo método intervalar (abaixo). (b) O espaço quantizado e o padrão respiratório relevante para a transformada de Hough modificada. (c) O espaço de quantização e o padrão respiratório relevante à transformada de Hough intervalar. . . . . . . . . . . .

3.17 Um padrão respiratório resultante da transformada de Hough intervalar. O algoritmo de contornos ativos procura por uma posição de menor energia na adjacência vertical dos pixels pertencentes ao padrão respiratório. . . . . . . . . . . . . . . . .

3.18 (a) A imagem 2DST original. (b) A imagem de arestas. (c) O padrão respiratório detectado pela transformada de Hough intervalar. (d) O padrão respiratório detectado pelo algoritmo de contornos ativos.

4.1 O segmento de linha comum exibido nas imagens coronal e sagital. O segmento de linha vertical comum é localizado na $i_{c}=89$ (imagem coronal) e $i_{s}=146$ (imagem sagital) . . . . . . . . . .

4.2 O segmento de linha comum em função do tempo: imagens (a) coronal, (b) sagital e (c) coronal cortada.

5.1 A arquitetura do sistema desenvolvido com os três módulos principais: extrair a matriz de mapeamento, determinar arestas através de Hough intervalar e contornos ativos e registro temporal e visualização tridimensional. . . . . . . . . . . . . . . . . .

5.2 Determinação de arestas pelos módulos de Hough intervalar e contornos ativos. A transformada de Hough intervalar corresponde aos seguintes módulos: criação da imagem da aresta, criação do espaço quantizado, seleção do pixel mais brilhante e re-amostragem negativa do padrão respiratório. . . . . . . . . . . . . .

5.3 (a) Imagem coronal com uma linha vertical exibindo a posição da sequência sagital exibida em (c) e (d). (b) Imagem 2DST da sequência coronal com a linha vertical exibindo o instante da imagem exibida em (a). (c)-(d) Imagens sagitais com uma linha vertical exibindo a posição da sequência coronal exibida em (a). (e) Imagem 2DST da sequência sagital com duas linhas verticais exibindo os instantes das imagens exibidas em (c) e (d). . . . . . . . 
5.4 (a) Composição 3D da imagem coronal exibida na Fig. 5.3.(a) e da imagem sagital exibida na Fig. 5.3.(c). Ambas as imagens estão na mesma fase inalatória. (b) Composição tridimensional da imagem coronal exibida na Fig. 5.3.(a) e da imagem sagital exibida na Fig. 5.3.(d). As imagens estão em fases respiratórias distintas. . .

5.5 (a)Uma imagem sagital exibindo o local em que a imagem 2DST foi obtida. (b) Imagem 2DST. (c) 21 padrões respiratórios detectados. As setas indicam alguns padrões respiratórios detectados pela transformada de Hough que são a composição de estruturas internas diversas. . . . . . . . . . . . . . . . . 50

6.1 (a)-(b) A imagem coronal tem uma linha vertical mostrando onde uma imagem 2DST foi obtida. A transformada de Hough intervalar encontrou 21 padrões respiratórios e apenas 3 padrões foram selecionados para o registro temporal (c)-(d) A imagem sagital tem uma linha vertical que mostra onde uma imagem 2DST foi obtida. A transformada de Hough intervalar encontrou 21 padrões respiratórios e apenas 4 padrões respiratórios foram selecionados para o registro temporal. (e) Resultado do registro temporal. . . . . . .

6.2 Gráficos exibindo a diferença de intensidade dos pixels de toda imagem sagital na sequência temporal em relação a $7^{\mathrm{a}}$ imagem coronal.

6.3 Gráficos exibindo a diferença de intensidade dos pixels de toda imagem coronal na sequência temporal em relação a $36^{a}$ imagem sagital

6.4 Gráficos de comparação entre as $7^{\mathrm{a}}$ e $28^{\mathrm{a}}$ imagens coronais e a 36 imagem sagital.

6.5 Composição tridimensional dos pares das imagens obtidas a partir do método de comparação de pixel a pixel proposto por Neylor et al. ${ }^{[5]}$. (a) A $36^{a}$ imagem sagital e a $7^{a}$ imagem coronal. (b) A $36^{a}$ imagem sagital e a $28^{a}$ imagem coronal. . . . . . . . . . . . . 56 
6.6 Cada gráfico representa a diferença entre um valor constante representando o padrão respiratório associado à superfície diafragmática de uma imagem sagital (coronal) específica (37 ${ }^{a}$ sagital, $7^{a}$ coronal e $28^{a}$ coronal) e o padrão respiratório associado à superfície diafragmática de uma sequência temporal de imagens coronais (sagitais). . . . . . . . . . . . . . . 56

6.7 (a)-(f) Exemplos de pares de registro resultantes do algoritmo pro-

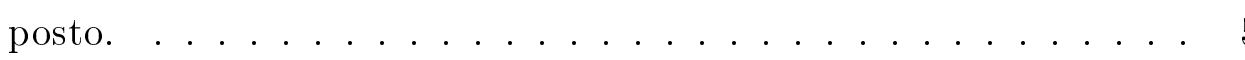

6.8 Determinação da superfície diafragmática através do registro múltiplo entre sequências coronais e sagitais. O algoritmo do registro múltiplo consiste em: seleção de uma sequência e imagem base, localização dos pontos da sequência base que interseccionam outras sequências e obtenção dos pontos intersectantes das melhores imagens correspondentes. . . . . . . . . . . . . . . 58

6.9 (a)-(d) Sequência de superfícies diafragmáticas tendo como base 4 imagens coronais sequenciais. A escala de cores representa o nível diafragmático. . . . . . . . . . . . . . . 60

6.10 (a)-(d) Sequência de superfícies diafragmáticas tendo como base 4 imagens sagitais sequenciais. A escala de cores representa o nível diafragmático. . . . . . . . . . . . . . . 61

6.11 (a)-(d) Superfície diafragmática da Fig. 6.10 (c) juntamente com a sua imagem sagital base e uma imagem coronal que possui o melhor registro para aquela intersecção. . . . . . . . . . . . . 62 


\section{Lista de Tabelas}

4.1 Dados DICOM para a utilização no exemplo mencionado. . . . . . 41

6.1 Caracterização das sequências de imagens de RM coronal e sagital utilizadas nos experimentos obtidos a partir de seis indivíduos saudáveis. Todas as sequências tem $256 \times 256$ pixels, tempo de repetição de $2.33 \mathrm{~ms}$, tempo de eco de $1.16 \mathrm{~ms}$, a espessura de corte de $10 \mathrm{~mm}$ e o número de imagens em cada sequência é de 50 


\section{Lista de Abreviações e Siglas}

TC - Tomografia Computadorizada

RM - Ressonância Magnética

SNR - Relação Sinal Ruído

RF - Radiofrequência

FOV - Campo de Visão

TR - Tempo de Repetição

T1 - Tempo de Relaxamento Longitudinal

T2 - Tempo de Relaxamento Transversal

FSE - Fast Spin Echo

SSFSE - Single Shot Fast Spin Echo

SSFP - Steady State Free Precession

TE - Tempo de Eco

ETL - Echo Train Length

NEX - Número de Excitações

DICOM - Digital Imaging Communication in Medicine 


\section{Introdução}

O pulmão apresenta algumas características que não permitem a sua observação direta, uma vez que se a caixa torácica for aberta, a sua estrutura não se mantém firme. O movimento do pulmão é majoritariamente passivo, e é o resultado do movimento dos músculos ao seu redor, tais como o diafragma e a caixa torácica, e de seus músculos interiores. Conclui-se que o uso de dispositivos de obtenção de imagens dos órgãos internos é a única forma de visualização do pulmão.

Métodos de diagnóstico pulmonares atuais ainda necessitam de diversos aprimoramentos. Por exemplo, espirometria e testes de função pulmonar apenas fornecem medidas globais do trabalho pulmonar. Sistemas de TC de raios-X de alta velocidade estão em desenvolvimento e permitem a visualização tridimensional das estruturas internas, em função do tempo, como descrito por Mori et al. ${ }^{[6]}$. Atualmente, várias técnicas de modelagem do movimento do pulmão durante a respiração, exclusivamente com base em imagens de TC, têm sido propostas [7-10]. O grande FOV (Campo de Visão) do pulmão, no entanto, faz com que o uso repetido destes sistemas seja proibitivo devido à alta exposição à radiação.

Independentemente do dispositivo de obtenção de imagens utilizado, as imagens obtidas dos órgãos internos sofrem de imperfeições características, pois, como as imagens são geradas de forma indireta, as intensidades de pixels derivam de uma média do volume, resultando em intensidades heterogêneas, baixa resolução e baixa relação sinal-ruído (SNR). A consequência direta dessa severa limitação na obtenção de imagens é que muitas vezes os limites dos órgãos internos não estão fechados, pois algumas partes não são visíveis e, portanto, desconectadas. Mangard e Hammersberg ${ }^{[11]}$ desenvolveram um método para determinar os limites de detecção em uma TC de alta resolução.

Considerando a segurança dos indivíduos sob observação, os dispositivos de RM são preferíveis. Por outro lado, a RM é dificultada por vários aspectos: a pouca quantidade de tecido se refere a um pequeno número de prótons levando a sinais de baixa qualidade, interfaces incontáveis de camadas de ar causam artefatos de susceptibilidade substancial, e os movimentos respiratório e cardíaco 
causam imagens desfocadas ${ }^{[12,13]}$. O sinal de RM é gerado a partir de prótons dentro de moléculas de água e material orgânico. O parênquima pulmonar contém apenas cerca de $800 \mathrm{~g}$ de tecido e sangue, que é distribuída em um volume de 4 a 6 litros. A densidade de prótons e intensidade do sinal são extremamente baixas em comparação a outras partes do corpo.

O rápido movimento das estruturas do corpo durante as medições resultam em inconsistências de fase e amplitude da magnetização, como o movimento pulsátil dos líquidos dentro dos vasos. Esse distúrbio na magnetização afeta a obtenção de imagens dessas estruturas, tornando-as visíveis apenas em alguns instantes (desfocamento e "fantasmas"). Sequências em precessão livre com estado estacionário (SSFP - Steady State Free Precession) balanceadas como a sequência TrueFISP (True Fast Imaging with Steady-state free Precession) são particularmente adequadas para a obtenção de imagens de RM do pulmão por causa de sua eficiência SNR ser elevada ${ }^{[13]}$. Eficiência SNR é a razão entre SNR e a raiz quadrada do tempo total na obtenção da imagem. O método TrueFISP tem eficiência SNR elevada, em comparação com outras técnicas convencionais, tais como gradiente e spin-eco, permitindo tempos de aquisição mais rápidos e/ou melhor resolução espacial.

Poucos trabalhos analisam o movimento do pulmão através de imagens de RM. Iwasawa et al. ${ }^{[14]}$ avaliaram quantitativamente o movimento do diafragma analisando a área de deslocamento em imagens obtidas por RM e o movimento total do diafragma em um ciclo respiratório. O movimento dos pulmões e sua variação no tempo é de especial interesse, e abordagens para obter este conhecimento foram propostas. Cluzel et al. ${ }^{[15]}$ conseguiram obter uma imagem de RM em 3D de um pulmão com a respiração presa, encurtando o tempo de exposição para cada imagem. Gauthier et al. ${ }^{[16]}$ avaliaram não apenas a área do diafragma, mas também a forma do diafragma em diferentes volumes pulmonares e Gierada et al. ${ }^{[17]}$ consideraram a mobilidade diafragmática utilizando imagens sequenciais de RM tomadas durante uma respiração serena. Nakamura et al. ${ }^{[18]} \mathrm{e}$ Tsuzuki et al. ${ }^{[19]}$ pesquisaram o registro temporal de silhuetas vetoriais coronais e sagitais do pulmão extraídas a partir de imagens de RM. A silhueta vetorial do pulmão é extraída através de diferentes abordagens, sendo assim, representações poligonais são obtidas para as silhuetas coronais e sagitais. Um modelo tridimensional animado dos pulmões é criado ao compor as silhuetas planares coronais e sagitais representando seções transversais. Haneishi et al. ${ }^{[20]}$ criaram um modelo tridimensional animado por um correlacionamento entre uma fatia sagital especialmente escolhida e várias fatias coronais através do casamento de 
padrões ("template matching") aplicado a imagens 2DST. Oechsner et al. ${ }^{[21]}$ propuseram uma técnica para a aquisição de sequências de imagens temporais livre de artefatos utilizando "navigator echos" que são colocados sobre o ápice do hemidiafragma, e a posição do diafragma é monitorada para determinar o nível da inflação. Singh et al. ${ }^{[22]}$ utilizou sequências dinâmicas de imagens de RM para criar uma representação 4D do processo de deglutição, no qual, fatias sagitais e coronais foram registradas em função do tempo.

Existem essencialmente duas abordagens diferentes para o registro de imagens do movimento respiratório. A abordagem estática usa sequências de imagens padrões, que são obtidas com a respiração presa em diversos momentos, sendo isto repetido para se obter imagens em pelo menos duas posições respiratórias diferentes (volumes). Tem a vantagem de prover um detalhe anatômico que é útil para uma análise mais aprofundada, como a aplicação de algoritmos de registro. A desvantagem é que o pulmão pode chegar a um estado de distribuição de pressão e tensão uniforme no momento em que a respiração for presa ${ }^{[13]}$. A segunda abordagem, a qual é utilizada neste trabalho, utiliza imageamento rápido para capturar imagens durante a respiração livre. Infelizmente, na obtenção de imagens de RM, os ganhos em velocidade sempre levam à redução do detalhe. Sequências tipicamente empregadas são sequências de gradientes de eco (abreviações: FLASH, Siemens; SPGR, General Electric; T1-FFE, Philips) e sequências de gradientes de eco em estado uniforme (abreviações: TrueFISP, Siemens; FIESTA, General Electric; FFE balanceado, Philips) . O primeiro tem a vantagem de maior resolução temporal, este último tem a vantagem de maior sinal dos vasos sanguíneos, que fornecem as principais informações espaciais na obtenção de imagens dinâmicas do pulmão através de RM ${ }^{[23]}$.

\section{$1.1 \quad$ Objetivos}

Este trabalho é uma contribuição às pesquisas com objetivo de aprimorar o registro temporal em imagens médicas. O propósito inicial deste trabalho é o de determinar o movimento diafragmático tridimensional no tempo associado a uma sequência de imagens de RM coronal ou sagital. Para este fim, será realizado o registro entre duas imagens, uma coronal e outra sagital, pelo casamento de padrões respiratórios associados à superfície diafragmática. Dadas $n$ sequências temporais coronais e $m$ sequências temporais sagitais; o algoritmo de registro entre duas imagens será aplicado $n \times m$ vezes e a superfície diafragmática será reconstruída tridimensionalmente. 


\subsection{Estrutura do Trabalho}

No capítulo 2, serão apresentados conceitos básicos para a compreensão do texto, salientando a fisiologia do pulmão, a RM, o imageamento do pulmão e o padrão DICOM. No capítulo 3 será apresentado o conceito de função respiração padrão, que será utilizada pela transformada de Hough para determinar padrões respiratórios temporais síncronos. Este método terá os seus resultados melhorados pela introdução da aritmética intervalar. Como o movimento pulmonar não é totalmente síncrono, o algoritmo de contornos ativos será utilizado para ajustar o padrão respiratório final. O capítulo 4 aborda a correspondência das imagens coronais e sagitais, determinando a correspondência de um pixel na imagem coronal para a imagem sagital, e vice-versa. O capítulo 5 aborda o registro temporal que será realizado pela análise de padrões respiratórios temporais associados principalmente à superfície diafragmática. O capítulo 6 apresenta alguns resultados e os compara com o método de registro temporal por intensidade de pixels. Finalmente, no capítulo 7, as conclusões são apresentadas. 


\section{Conceitos Básicos}

Neste capítulo serão apresentados alguns conceitos básicos sobre a fisiologia do pulmão, a RM, sobre o imageamento do pulmão por RM e sobre o padrão DICOM.

\section{$2.1 \quad$ A Pleura e o Pulmão}

Os pulmões, direito e esquerdo, órgãos principais da respiração, estão contidos na cavidade torácica e entre eles há uma região mediana denominada mediastino, ocupada pelo coração, os grandes vasos e alguns dos seus ramos proximais, o esôfago, parte da traquéia e brônquios principais, além de nervos e linfáticos. Cada pulmão está envolto por um saco seroso completamente fechado, a pleura, que apresenta dois folhetos: a pleura pulmonar que reveste a superfície do pulmão e mantém continuidade com a pleura parietal que recobre a face interna da parede do tórax (Fig. 2.1). Entre as pleuras pulmonar e parietal há um espaço virtual, a cavidade da pleura, contendo uma película de líquido de espessura capilar que permite o livre deslizamento de um folheto contra o outro nas constantes variações de volume do pulmão ocorridas nos movimentos respiratórios.

Os pulmões têm uma cor vermelho-escura, que se torna, com a idade, acinzentada, pela deposição de partículas de carbono no seu tecido conjuntivo. A sua consistência é mole e elástica, e, crepita pela saída de bolhas de ar dos alvéolos. O peso é de cerca de 800 gramas para o pulmão direito e de cerca de 700 gramas, para o pulmão esquerdo. No final da expiração normal, contém um volume de ar de cerca de 2,4 litros. Após uma inspiração forçada, têm um volume máximo, cerca de 6 litros. São órgãos de forma cônica, apresentando um ápice superior ("apex"), uma base inferior e duas faces: costal (em relação com as costelas) e medial (voltada para o mediastino). A base descansa sobre o diafragma, músculo que separa, internamente, o tórax do abdome ${ }^{[24]}$. 


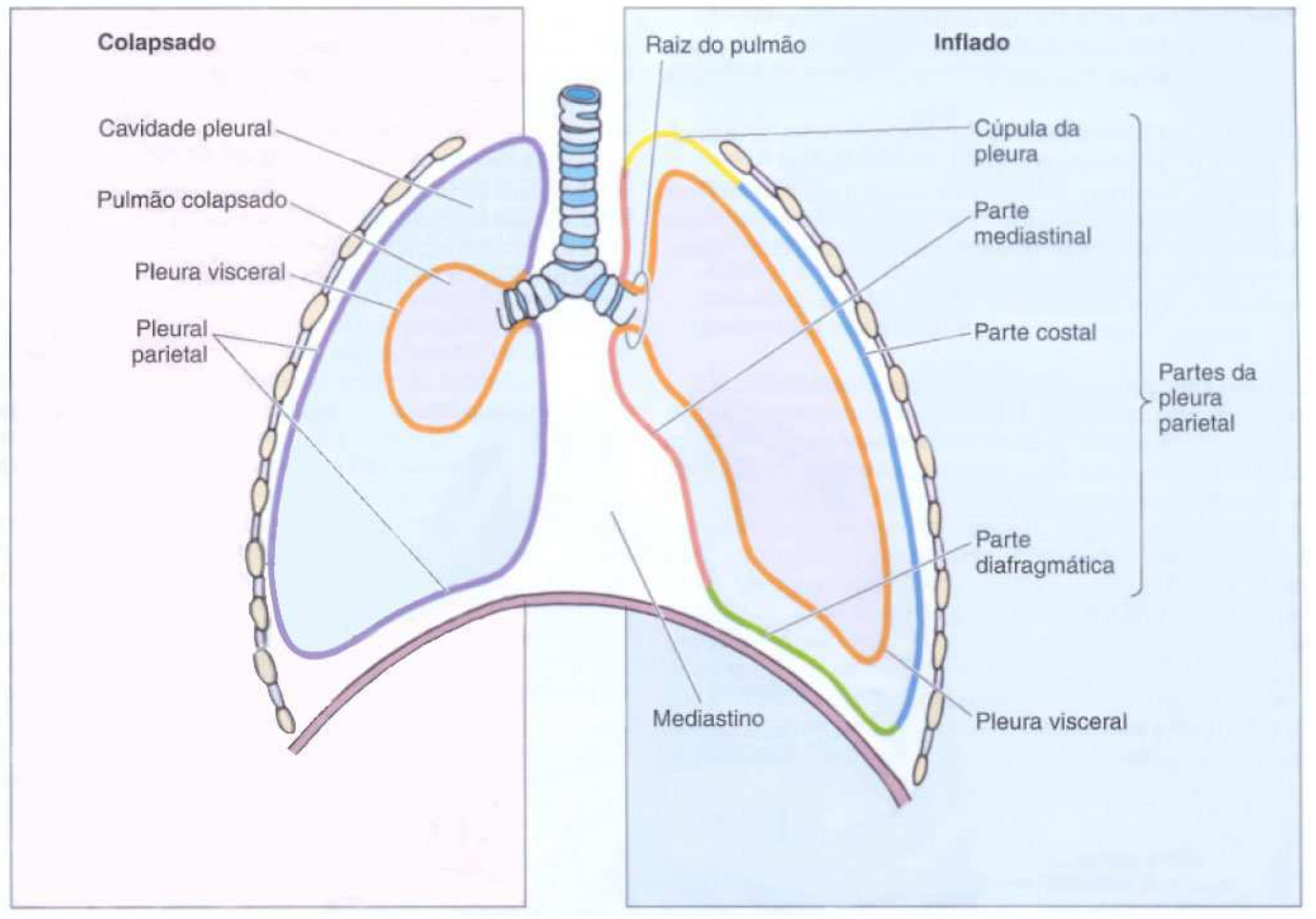

Figura 2.1: Esquema das pleuras, pulmão e mediastino, corte frontal ${ }^{[2]}$.

\subsubsection{O Movimento Respiratório}

No movimento respiratório, as costelas e o diafragma se movem, de tal maneira, que as dimensões da caixa torácica se alteram. Existem dois movimentos respiratórios básicos, que são:

1. Inspiração: a entrada de ar nos pulmões, dá-se pela contração da musculatura do diafragma, dos músculos intercostais (músculos que estão entre as costelas) e d. O diafragma abaixa e as costelas elevam-se, com isso ocorre um aumento do volume da caixa torácica (estrutura óssea que protege os pulmões e o coração), fazendo com que o ar entre nos pulmões.

2. Expiração: em seguida ocorre a saída de ar dos pulmões, acontece pelo relaxamento da musculatura do diafragma e dos músculos intercostais, eleva-se o diafragma e as costelas abaixam, diminuindo assim o volume da caixa torácica, expulsando o ar dos pulmões. Nem todo ar é expulso dos pulmões, ficando um pequeno volume que permanece dentro dos alvéolos, evitando que haja um colapso nas finas paredes dos alvéolos ${ }^{[25]}$. 


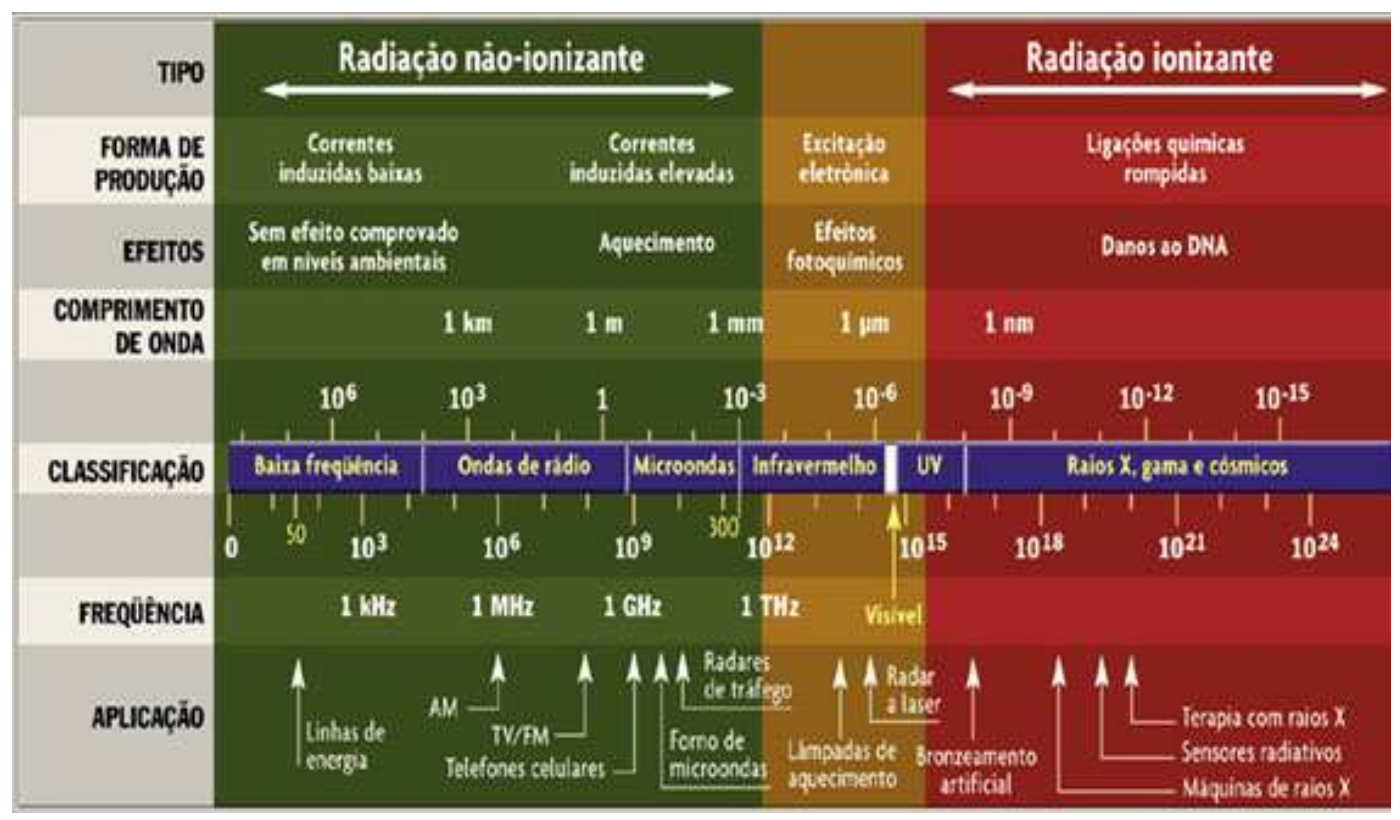

Figura 2.2: Espectro de onda da radiação eletromagnética ${ }^{[3]}$.

\subsection{A Ressonância Magnética Nuclear}

A RM é um fenômeno físico de troca de energia entre força periódica (ondas eletromagnéticas, Fig. 2.2) e corpos em movimento. A condição para que ocorra o fenômeno da ressonância é que a frequência periódica das ondas eletromagnéticas seja exatamente igual à frequência de movimento dos corpos.

Um dos exemplos mais conhecido de manifestação de ressonância é o som que ouvimos do rádio. Neste caso uma estação emite ondas eletromagnéticas em uma determinada faixa de frequência e, quando ajustamos o circuito eletrônico do nosso rádio na mesma faixa de frequência da estação emissora, ouvimos o sinal que está sendo transmitido.

O fenômeno da ressonância aplicado ao diagnóstico por imagem baseia-se na troca de energia entre núcleos de átomos de hidrogênio com ondas eletromagnéticas provenientes de campos magnéticos oscilatórios (Fig. 2.3). Sempre que a frequência oscilatória dos campos aplicados coincidirem com a frequência de Larmor dos núcleos de hidrogênio haverá o processo de troca de energia. Para que este processo ocorra de forma controlada, é necessário que os núcleos dos hidrogênios estejam alinhados. O campo magnético externo é o responsável por esse alinhamento; quanto maior for a potência do campo magnético externo, maior será a quantidade de hidrogênios que se alinharão com este. Nessa situação uma parcela de hidrogênios absorverá a energia das ondas eletromagnéticas externas e mudará de orientação em relação ao campo magnético. A "população de hidrogênios" que mudou de orientação assume um estado energizado e posteriormente 


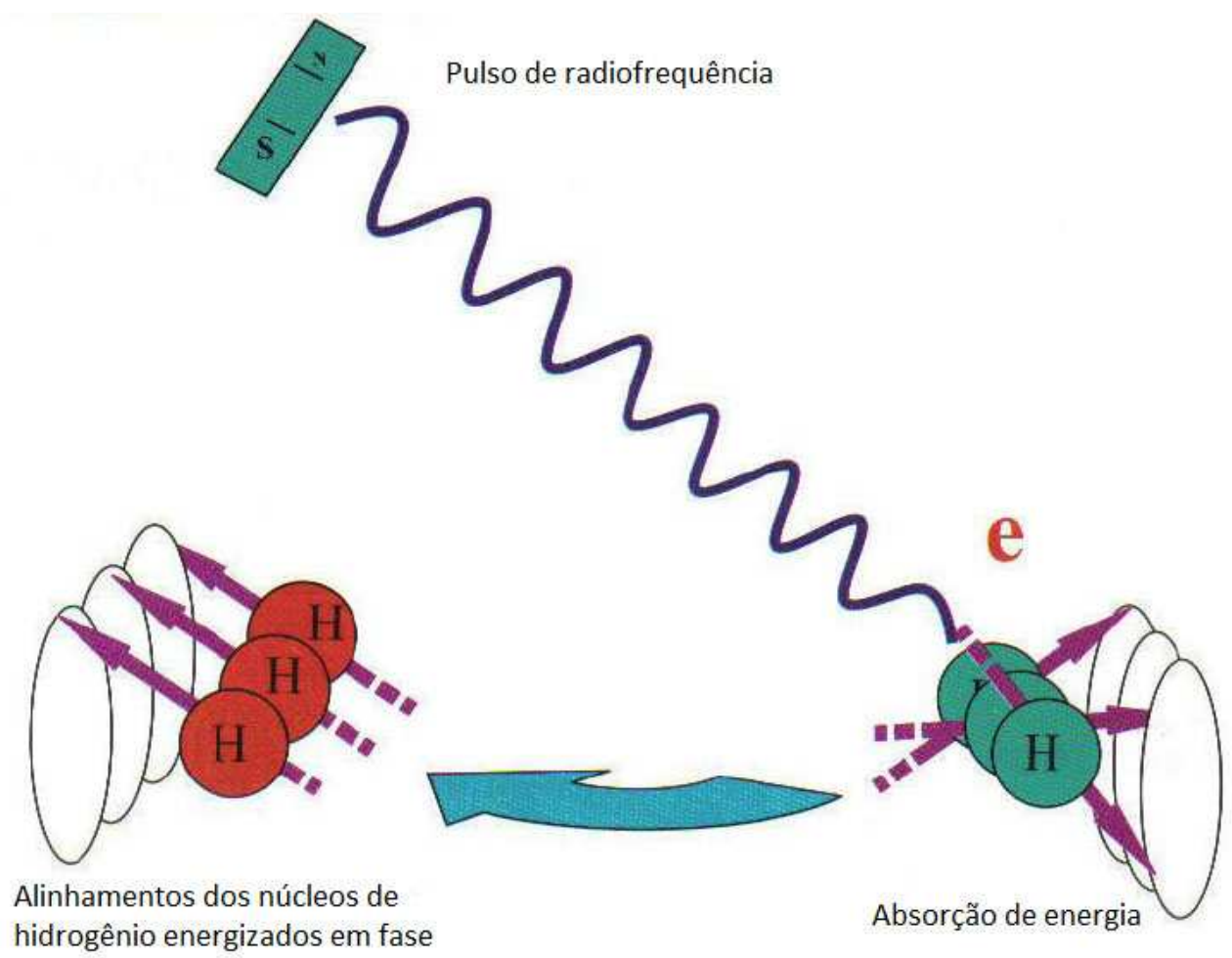

Figura 2.3: Fenômeno da ressonância ${ }^{[4]}$.

irá liberar esta energia na forma de sinal de RM nuclear.

A obtenção da imagem por ressonância a partir do hidrogênio se deve ao fato de este elemento estar amplamente distribuído nos tecidos biológicos e por suas características em responder a campos magnéticos externos como se fosse um pequeno ímã. A obtenção de imagens a partir de outros elementos, como o fósforo, o flúor e o sódio, também é possível, no entanto, a baixa constituição desses elementos no corpo humano inviabiliza o seu uso ${ }^{[26]}$.

\subsubsection{Princípios Físicos de RM}

O fenômeno da ressonância baseia-se em perturbar o equilíbrio dinâmico de tal forma que a resultante de polo magnético $\vec{M}_{z}$ (magnetização longitudinal é a força magnética resultante da somatória vetorial das forças magnéticas individuais de cada átomo de hidrogênio) mude a sua orientação no espaço e vá preferencialmente assumir uma posição no plano transversal $(X, Y)$. Para que isto ocorra, fazse necessário que corpos em movimento (núcleos de hidrogênio em precessão) troquem energia com uma força periódica externa (ondas eletromagnéticas de radiofrequência $(\mathrm{RF}))$.

Quando as ondas de RF oscilam na mesma frequência de precessão dos núcleos de hidrogênio observa-se o fenômeno da ressonância, em outras palavras, os 
núcleos de baixa energia absorvem a energia das ondas externas e "pulam" para o lado energético, conseguindo assim deslocar a resultante de polo magnético $\vec{M}_{z}$ de sua posição inicial.

Para que a resultante de polo magnético $\vec{M}_{z}$ possa se posicionar no plano transversal, é necessário que a energia seja transmitida especificamente para uma população de hidrogênios que se encontrem na mesma fase. Entende-se por fase a orientação espacial do momento magnético microscópico atribuído a cada átomo de hidrogênio.

A nova resultante de polo magnético que surge no plano transversal assume a denominação magnetização transversal $-\vec{M}_{x y}$. Este campo magnético é capaz de induzir corrente elétrica em condutores dispostos na forma de bobinas (antenas de RM). As correntes observadas nessas bobinas constituem-se, em última análise, no sinal de $\mathrm{RM}^{[4]}$.

\subsubsection{Sinal da Ressonância Magnética}

A magnetização transversal, o campo magnético $\vec{M}_{x y}$ que surge no plano transversal do equipamento, é de natureza oscilatória, ou seja, inverte a sua polaridade em relação à bobina, induzindo corrente elétrica alternada.

O sistema de RM está dimensionado para permitir que a magnetização transversal induza correntes elétricas apreciáveis em diferentes tipos de bobinas. As correntes geradas representam o sinal de ressonância proveniente de uma região particular do paciente. Cada pixel da imagem gerada terá uma graduação de cinza correspondente à corrente elétrica que contribuiu com o seu sinal.

As características das correntes elétricas geradas pela indução eletromagnética e o comportamento dessas correntes em função do tempo é fundamental para compreensão dos fatores que interferem na qualidade das imagens e da sua interferências na relação sinal/ruído ${ }^{[26]}$.

\subsubsection{Decaimento de Indução Livre (FID - Free Induction Decay)}

A magnetização transversal é obtida a partir da excitação de uma "população" de hidrogênios de mesma fase. Se a excitação for suficiente para desviar a magnetização longitudinal em 90 graus, portanto levando-a para o plano transversal, dizemos que foi aplicado um pulso de 90 graus ou $\pi / 2$. Se o pulso de excitação desviar a magnetização longitudinal de excitação em 45 graus, teremos uma magnetização parcial no plano transversal, suficiente para induzir corrente elétrica. 


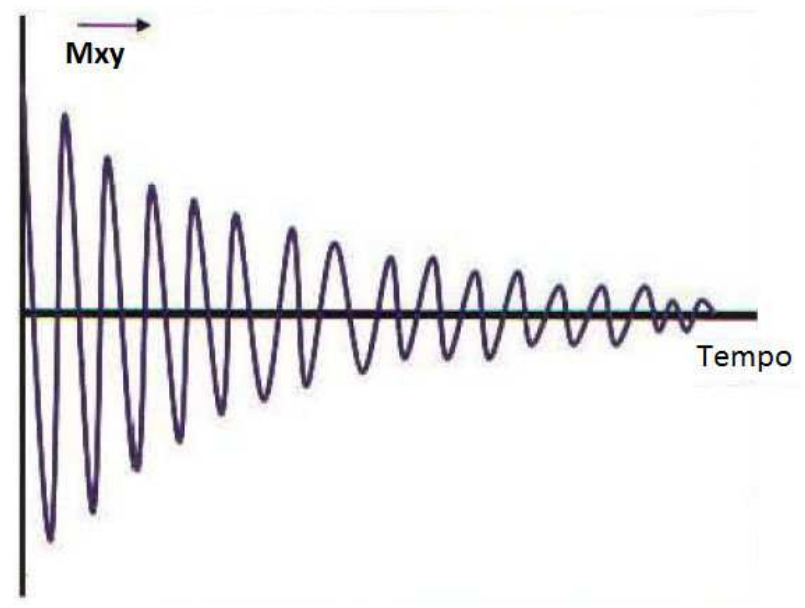

Figura 2.4: Intensidade do vetor magnetização transversal $\left(\vec{M}_{x y}\right)$ em função do tempo ${ }^{[4]}$.

Nota-se que no primeiro caso a amplitude do sinal será máxima, enquanto, no segundo, a amplitude será menor, resultado do componente transversal parcial dessa resultante.

Em ambos os casos porém, observa-se que as amplitudes das correntes elétricas geradas vão decrescendo com o tempo. Isto ocorre porque o vetor magnetização transversal também diminui de intensidade em função do tempo, em razão do retorno à condição de equilíbrio dos hidrogênios que passam a liberar a energia absorvida (recuperação da magnetização longitudinal) (Fig. 2.4).

O FID (free inducction decay), ou simplesmente "decaimento de indução livre", indica que o sinal de RM vai diminuindo de intensidade em função do tempo. Isto ocorre porque a população de hidrogênios que absorveu energia por ressonância libera a energia absorvida para o meio e retorna à condição de equilíbrio por meio da recuperação da magnetização longitudinal ${ }^{[26]}$.

\subsubsection{Tempo de Relaxamento Longitudinal (T1)}

Na busca da condição de equilíbrio, os prótons que absorveram energia no processo de excitação passam a liberá-la para o meio e assumem o estado de menor energia.

Os hidrogênios ligados aos diversos tecidos do corpo humano apresentam comportamentos diferentes quanto ao retorno à condição de equilíbrio, fenômeno este conhecido como recuperação da magnetização longitudinal. Hidrogênios ligados à água apresentam tempos longos de recuperação longitudinal, enquanto os ligados à gordura recuperam rapidamente esta condição. Tal característica dos tecidos biológicos possibilita o estudo da RM por contraste influenciado pela relaxação longitudinal produzindo imagens ponderadas em T1. 


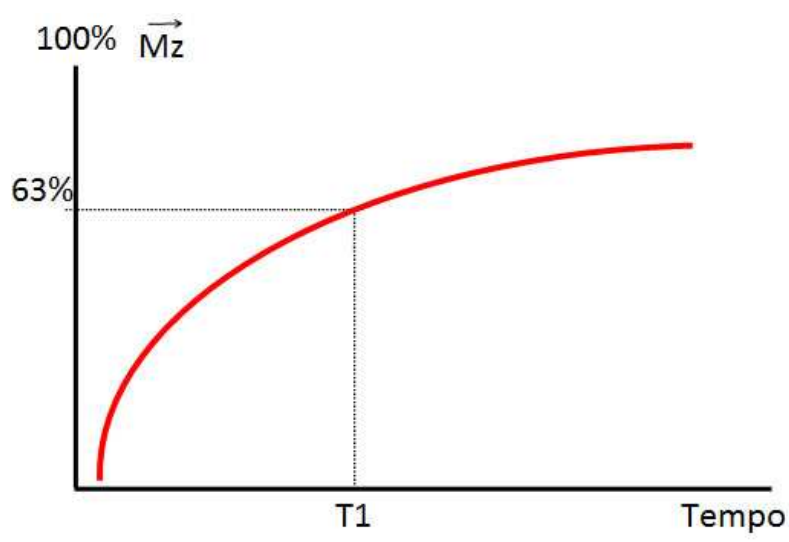

Figura 2.5: Tempo T1 - tempo necessário para a recuperação da magnetização longitudinal dos prótons do tecido ${ }^{[4]}$.

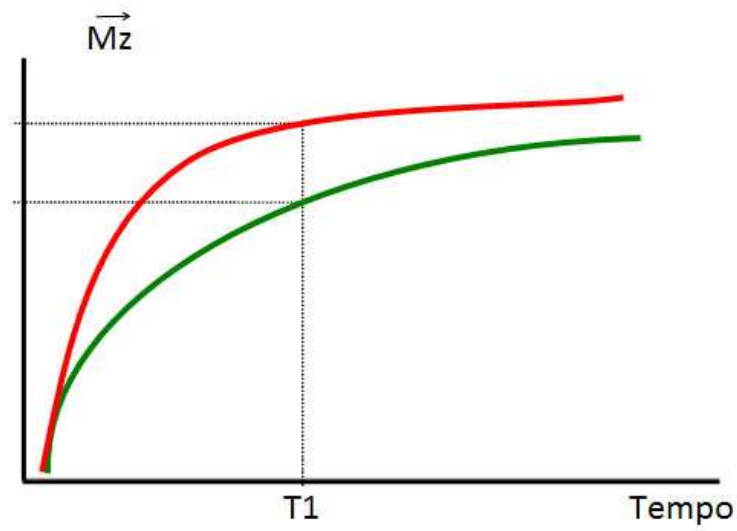

Figura 2.6: Contraste por $\mathrm{T} 1^{[4]}$.

Considera-se o T1 de um tecido o tempo necessário para a recuperação de aproximadamente $63 \%$ da magnetização longitudinal dos prótons deste tecido (Fig. 2.5).

Graficamente podemos visualizar o instante em que dois tecidos apresentam o melhor contraste por T1 (Fig. 2.6) . A obtenção da imagem neste momento produz uma imagem ponderada em $\mathrm{T} 1^{[4]}$.

\subsubsection{Tempo de Relaxamento Transversal (T2)}

Quando o pulso de RF é emitido, a sua frequência e o seu endereçamento quântico são feitos de forma tal que apenas a "população" de hidrogênios de mesma frequência e com as mesmas fases absorve a energia dessas ondas. A população de hidrogênios que absorve energia desloca-se para o lado de alta energia (spin down) e, com isto, uma magnetização resultante surge no plano transversal (magnetização transversal). Nessas condições, os hidrogênios que contribuem para a resultante transversal possuem a mesma fase e o valor da resultante magnética é máximo, porém, o contraste entre os tecidos é mínimo. 


\section{Relaxação transversal}
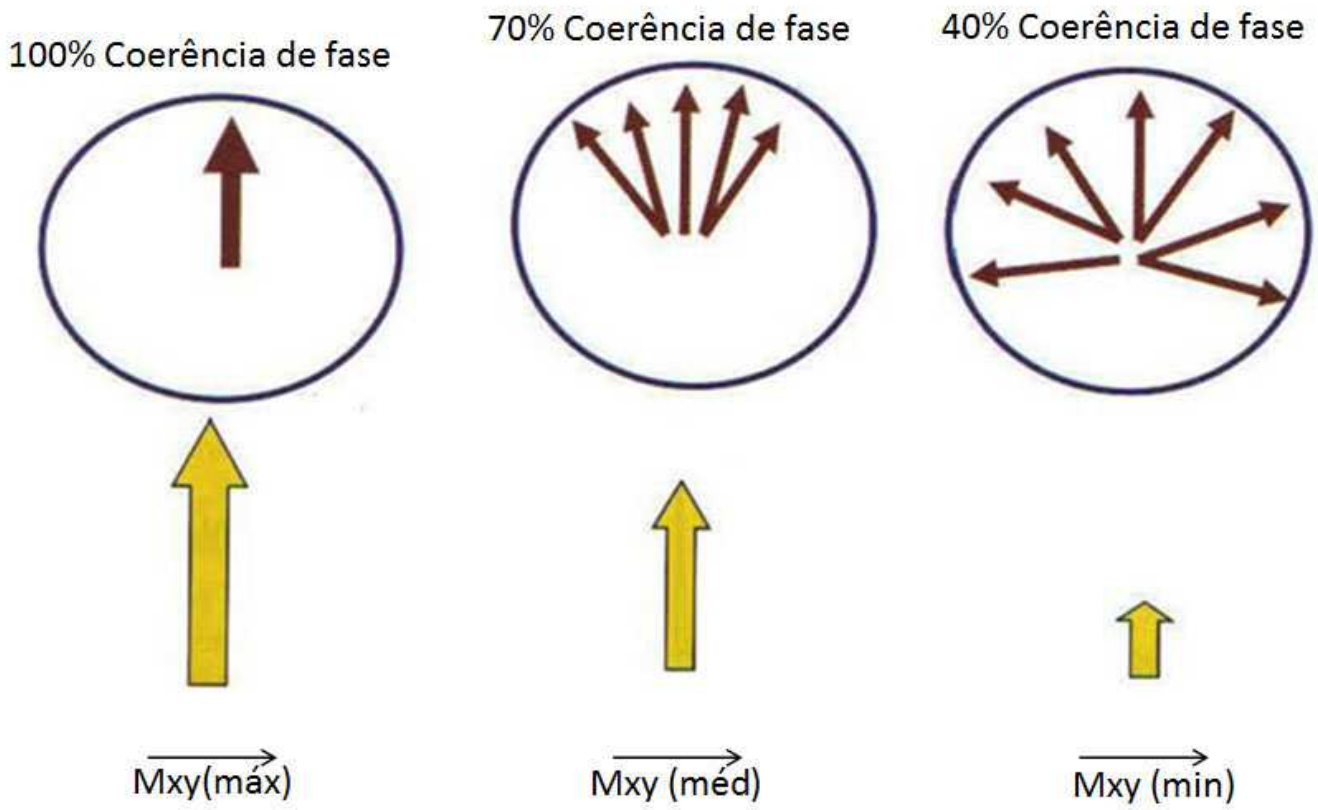

$\overrightarrow{\mathrm{Mxy}(\mathrm{med})}$

$\overrightarrow{\operatorname{Mxy}(\mathrm{min})}$

Tempo

Figura 2.7: Com o passar do tempo os prótons vão saindo do alinhamento de fase e a magnetização transversal $\left(\vec{M}_{x y}\right)$ vai diminuindo de amplitude ${ }^{[4]}$.

Após algum tempo, os átomos excitados alteram as suas fases, resultado da interação com átomos vizinhos e da falta de homogeneidade do campo magnético principal ocasionando uma redução na amplitude do vetor magnetização transversal (Fig. 2.7), no entanto, é possível obter contraste entre os tecidos nesse momento. O padrão de imagem estabelecido nestas condições é o que conhecemos por T2. Em outras palavras, podemos dizer que T2 é a ponderação de imagem influenciada pelas características de relaxação transversal dos hidrogênios ligados aos diversos tecidos biológicos. A principal característica da imagem T2 é que os líquidos se apresentam claros na imagem e tecidos musculares, vísceras, parênquimas em geral, fornecem um sinal baixo e se apresentam escuros.

O tempo de relaxação transversal (T2) de um tecido em particular é o tempo necessário para que o vetor magnetização transversal deste tecido decaia até aproximadamente $37 \%$ do seu valor original ${ }^{[4]}$.

\subsubsection{Sequência de pulsos}

A forma como os pulsos de RF são aplicados e a obtenção dos sinais de RM influenciam o contraste das imagens. É possível, a partir da aplicação de pulsos de diferentes ângulos, obter diferentes contrastes entre os tecidos. Várias sequências 
de pulsos foram desenvolvidas com este propósito e as principais sequências são abordadas a seguir ${ }^{[26]}$.

Para compreensão da estrutura dessas sequências e a sua dinâmica alguns conceitos precisam ser abordados:

1. Tempo de Eco (TE): é o tempo medido entre a aplicação do pulso de RF (90 graus) e a amplitude máxima do sinal de RM em uma sequência spin-eco.

2. Tempo de Repetição (TR): é o tempo medido entre dois pulsos de RF de 90 graus em uma sequência spin-eco.

3. Flip Angle (Ângulo de inclinação): é o ângulo formado pelo desvio da imagem da magnetização longitudinal pelo pulso de RF, para o plano de magnetização transversal. Controla o contraste nas imagens nas diferentes sequências de pulso.

4. Tempo de Aquisição: tempo de duração na aquisição de uma imagem.

5. Comprimento do trem de eco (ETL - Echo-Train Length): número de medições de eco após uma excitação.

6. Número de excitações/aquisições (NEX): número de vezes que a mesma fase e o sinal de frequência são adquiridos.

7. FOV: a área a qual se deseja obter a imagem utilizando o equipamento de RM.

8. Matriz: Rede utilizada para dividir o FOV. o número de pixels usados em cada dimensão linear da seção define o tamanho da matriz de aquisição da imagem (ex.: $256 \times 256,512 \times 512,1024 \times 1024,192 \times 256$, etc. $)$.

9. Espessura de Corte (Slice Thickness): a espessura do tecido da imagem obtida.

10. Amplitude do gradiente: é a robustez do campo de gradiente ou campo magnético. Estes campos são utilizados para alterar (coletivamente e sequencialmente) a influência do campo magnético estático $B_{O}$ sobre o objeto imageado. Medido em $m T / m$.

11. Taxa de Variação: é a taxa de velocidade da subida ou descida de um gradiente a partir do zero à sua amplitude máxima. É a amplitude do gradiente dividido pelo tempo de subida em $\mathrm{ms}$. 


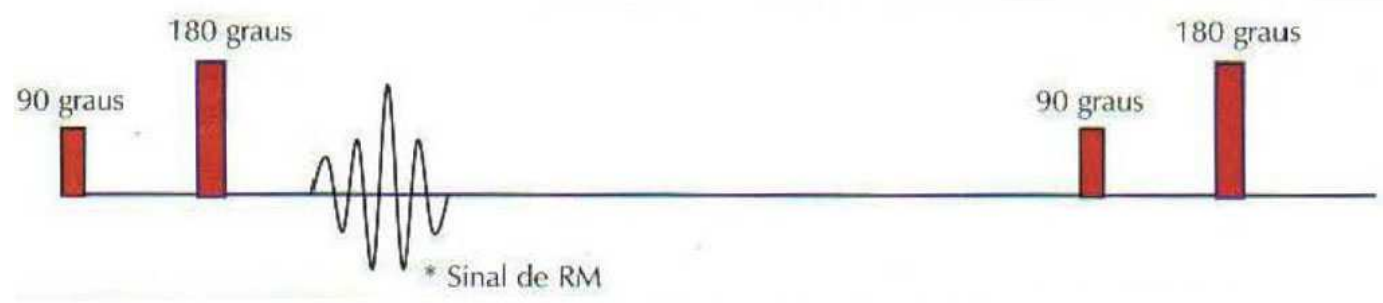

Figura 2.8: Sequência Spin-eco, onde exibe-se o pulso de RF de 90 graus seguido do pulso de refasamento (180 graus) ${ }^{[4]}$.

12. Espaço $\boldsymbol{K}$ : espaço de imagens temporárias no qual os dados a partir de sinais digitalizados de RM são armazenados durante a aquisição dos dados. Quando o espaço $K$ é completo (no final do imageamento), os dados são processados matematicamente através da transformada inversa de Fourier para produzir uma imagem final. Desta maneira, o espaço $K$ armazena os dados brutos antes da reconstrução.

Proposto por Tweig e Ljunggren como uma amostragem ao longo de trajetórias, $k=\left\{k_{x}(t), k_{y}(t), k_{z}(t)\right\}$, em um domínio de frequências espaciais. As trajetórias do espaço $K$ são descritas pelas seguintes equações: $k_{x}(t)=\gamma \int_{0}^{t} G_{x} d t, k_{y}(t)=\gamma \int_{0}^{t} G_{y} d t$ e $k_{z}(t)=\gamma \int_{0}^{t} G_{z} d t$. Por exemplo, na obtenção de imagens 2D um dos componentes de $K$ resultante do gradiente da codificação de fase é constante durante a aquisição, enquanto que o outro componentes resultante do gradiente de leitura muda linearmente em função do tempo.

No geral, trajetórias arbitrárias no espaço $K$ podem ser geradas a partir de gradientes de campo que variam em função do tempo aplicados durante a aquisição do sinal, desde que respeitando as limitações do equipamento tais como a amplitude do gradiente disponível máxima, $G_{\max }$ e a taxa de variação máxima, $(d G / d t)_{\max }$.

\subsubsection{Sequência Spin-Eco}

É a sequência mais comum em RM. Esta sequência inicia-se com um pulso de RF de 90 graus (pulso seletivo) seguido de um pulso de 180 graus (pulso de refasamento) (Fig. 2.8). Após o pulso de refasamento, observa-se uma recuperação do sinal da RM em resultado da recuperação das fases da população deslocada para o lado de maior energia ${ }^{[4]}$. 


\section{Sequência de Pulso}

FSE - Fast Spin-ECo

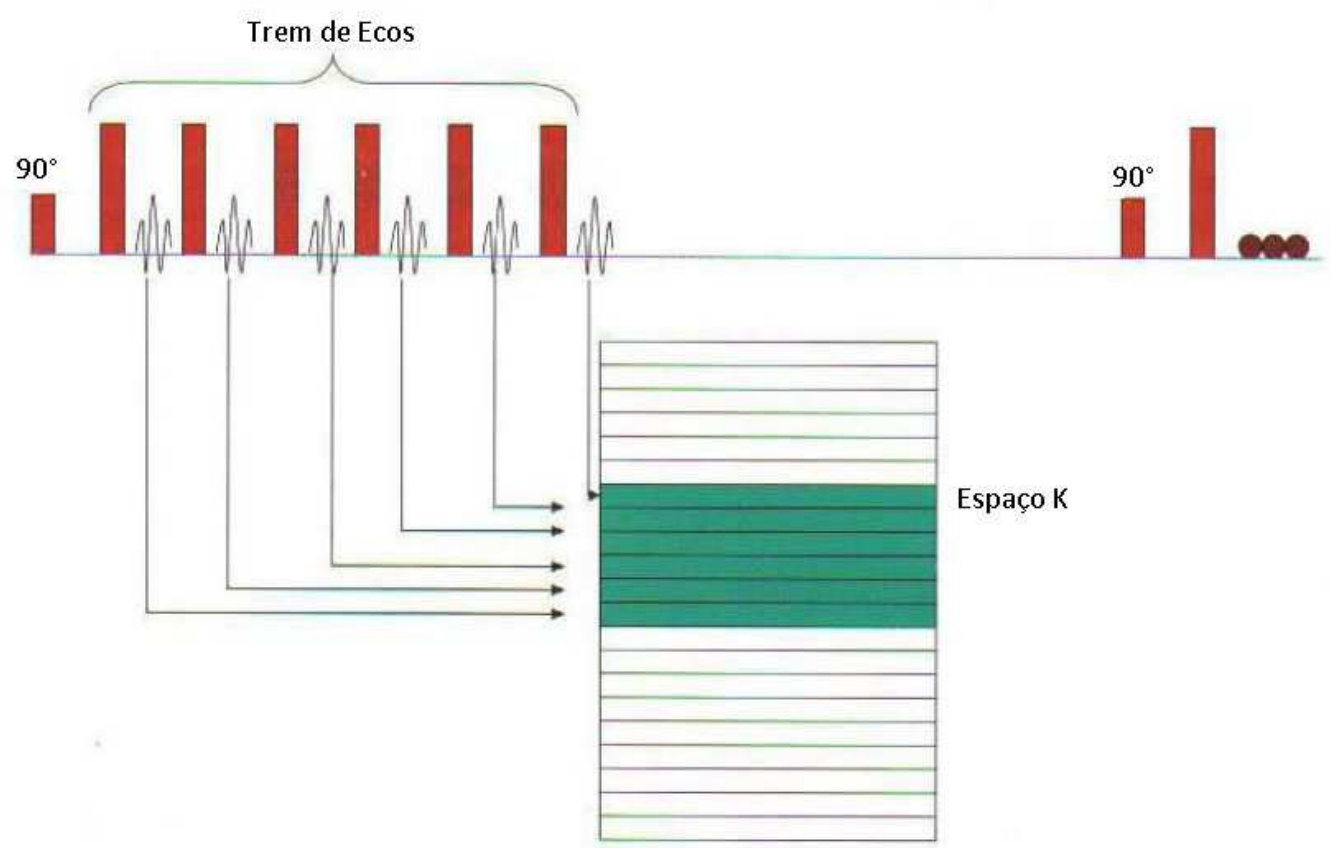

Figura 2.9: Sequência FSE - fast spin-eco ${ }^{[4]}$.

\subsubsection{Sequência Fast Spin-Eco (FSE)}

Um pulso de excitação de 90 graus, seguido por múltiplos pulsos de refasamento de 180 graus (Fig. 2.9) são aplicados à mesma imagem formando o que se conhece por "cadeia de ecos", "trem de ecos" ou "fator turbo". Após cada pulso de 180 graus da cadeia de ecos, o sinal gerado preenche uma linha do espaço $K$ e assim, mais rapidamente, o sistema pode reconstruir as imagens. Esta sequência reduz o tempo de aquisição das imagens na razão inversamente ao fator turbo utilizado. Como exemplo, uma sequência FSE com fator turbo 8 reduz o tempo de aquisição das imagens em oito vezes se comparada à sequência spin-eco, desde que mantidos os demais parâmetros ${ }^{[4]}$.

\subsubsection{Sequência Single Shot Fast Spin-Eco (SSFSE)}

Na sequência SSFSE todo o espaço $K$ é preenchido num único TR (Fig. 2.10).

A quantidade de pulsos de refasamento aplicados (180 graus) é equivalente ao número de linhas da matriz, de forma que o tempo total de aquisição da imagem é o mesmo do TR.

Para a obtenção de uma imagem de matriz, são utilizados 256 pulsos de 180 graus após o pulso inicial de 90 graus. Uma sequência completa dura apenas 


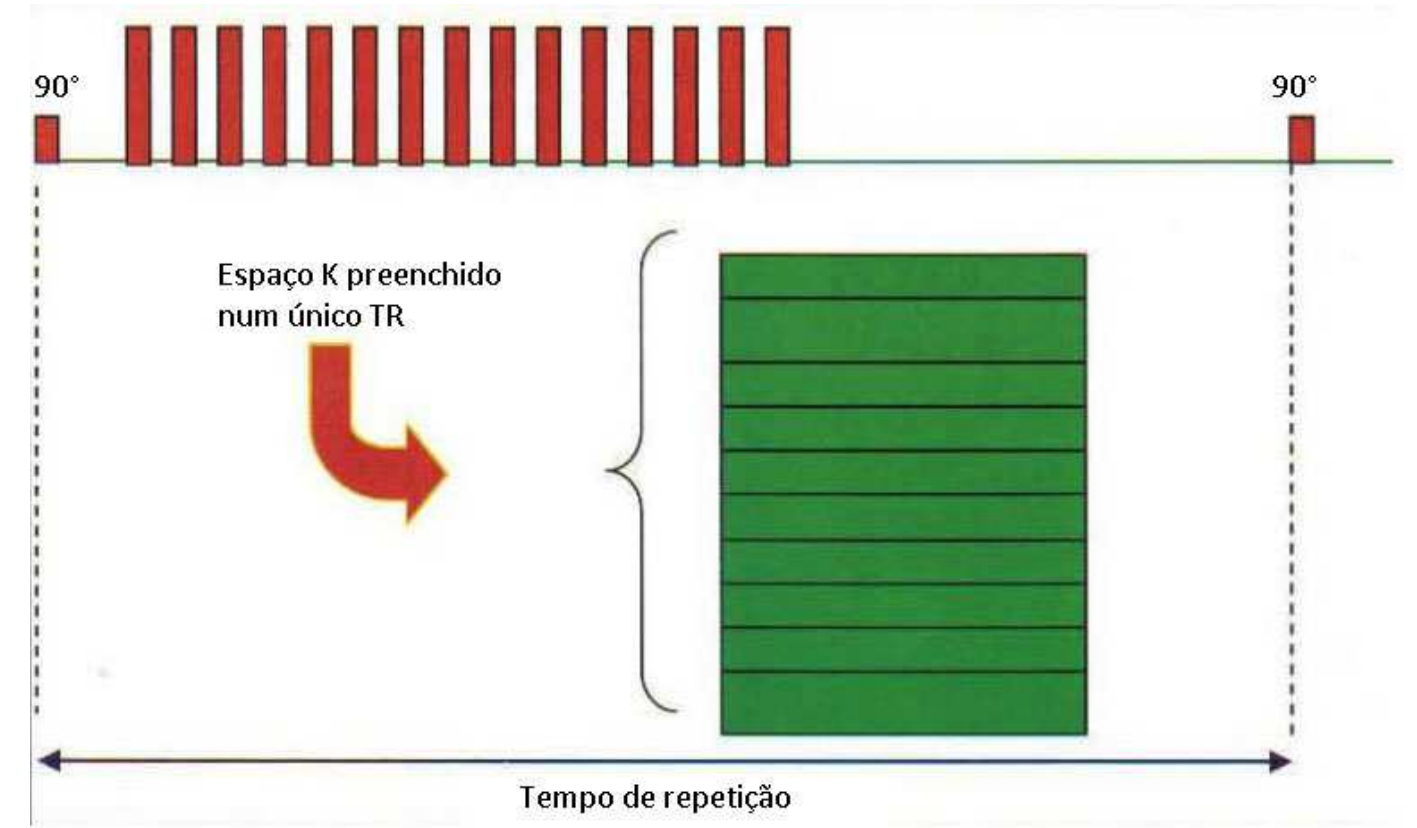

Figura 2.10: Sequência SSFSE ${ }^{[4]}$.

alguns segundos.

Como a cadeia de ecos é demasiado longa, ecos tardios tendem a influenciar a ponderação da imagem em T2 ${ }^{[4]}$.

\subsubsection{4 "Navigator echo"}

A técnica "navigator echo" utiliza um pré-pulso que mede a posição, por exemplo, do diafragma antes de recolher dados da imagem. Assim, estados respiratórios semelhantes do paciente podem ser identificados e usados para configurar a aquisição das imagens com o objetivo de que o desfocamento da imagem causado pela respiração seja minimizado.

Utilizando esta técnica, tem-se a vantagem das imagens possuírem uma maior precisão e não há a necessidade de nenhum equipamento sensorial adicional, pois o sistema de RM provê este sensoriamento ${ }^{[27]}$.

\subsubsection{Sequência Gradiente de Eco}

A sequência gradiente de eco utiliza-se de um pulso inicial de RF (flip angle) de ângulo variável entre 5 e 180 graus.

O refasamento dos prótons é obtido pela aplicação de um campo gradiente de polarização invertida, de forma muito mais rápida do que na sequência spin-eco.

Nesta sequência os tempos TR e TE são muito curtos, de forma que o tempo 
total da série fica drasticamente reduzido.

A ponderação da imagem na sequência gradiente de eco sofre forte influência do flip angle. Séries obtidas com menores flips ponderam a imagem em T2. A sequência em gradiente é muito sensível às imperfeições do campo magnético e a presença de artefatos nas imagens geradas são muito comuns ${ }^{[27]}$.

\subsubsection{Precessão Livre com Estado Estacionário (SSFP - Steady State Free Precession)}

Sequências SSFP são sequências eco de gradiente de estado uniforme, e de acordo com o fabricante e com as características da sequência de pulsos, possuem alguns dos seguinte nomes: TrueFISP, Siemens; FIESTA, General Electric; FFE balanceado, Philips) ${ }^{[27]}$.

\subsubsection{Qualidade da Imagem}

Em RM a qualidade da imagem pode ser medida pela SNR. Quanto maior o seu valor, menor será a influência dos fatores que contribuem para a degradação da imagem.

O ruído se caracteriza pela formação da imagem "granulada" que se sobrepõe à imagem real do objeto, dificultando a sua visualização. Imagens com baixos valores de SNR são pobres em detalhes.

\subsubsection{Principais Fatores que Afetam a SNR}

1. $B_{O}$ - Intensidade do Campo Magnético Principal: quanto maior o campo magnético, a principal característica de um sistema de ressonância, maior será a quantidade de núcleos de hidrogênios que se alinharão com o campo. Com mais hidrogênios "disponíveis", haverá um ganho proporcional no sinal gerado pelo paciente. Pode-se dizer, portanto, que altos campos magnéticos resultam em melhora direta do sinal de RM.

2. Tipo de Bobina Utilizada: as bobinas influenciam diretamente na qualidade das imagens. De forma geral, as bobinas de pequenas dimensões geram maior sinal.

3. FOV: quando se buscam imagens de grandes áreas de anatomia, mais hidrogênios tomam parte no processo de formação de imagem; consequentemente há um aumento de sinal, desde que os demais parâmetros não sofram 
alterações.

4. Espessura de Corte (Thickness): a espessura de corte também tem relação com com a quantidade de prótons que contribuem com o sinal. Quanto maior a espessura do corte, maior será o sinal da ressonância.

5. NEX: na formação da imagem por RM é possível excitar mais de uma vez um mesmo tecido e, assim, obter múltiplas respostas desta região. Quanto maior for o número de excitações, melhor será a SNR; no entanto, o tempo de aquisição das imagens aumentará numa razão diretamente proporcional ao número de excitações utilizado.

6. Matriz: quanto maior a resolução da matriz de imagem, menor será a área representada pelo pixel na imagem e, consequentemente, menor será a quantidade de prótons que terá contribuído para o seu sinal. Este fator afeta negativamente a SNR. Outro dado importante diz respeito à codificação da fase. Quanto maior a resolução da matriz na direção da fase, maior será o tempo de aquisição da imagem, pois para cada linha da imagem será alocado um gradiente de codificação com amplitude diferente, aumentandose o tempo de aquisição da imagem.

7. TR: aumentando-se o TR, permite-se que uma quantidade maior de prótons de hidrogênio recupere a magnetização longitudinal, aumentando-se assim a população disponível no lado de menor energia. Quando for aplicado novo pulso de excitação, uma quantidade maior de hidrogênios responderá a este estímulo, gerando, por conseguinte, intensificação do sinal.

8. TE: o tempo de eco pode ser entendido como o exato momento da coleta do sinal da ressonância. Considerando que o sinal da ressonância decai livremente em função do tempo (FID - free induction decay), podemos concluir que imagens obtidas com tempo de eco curtos, como as ponderadas por T1, apresentam maior amplitude de sinal, produzindo, por consequência, aumento da SNR.

9. Largura da Banda de Leitura (Bandwidth): os sinais de RM são analisados num espectro de frequências que pode variar para atender à codificação da frequência definida pela imagem. A faixa de frequências que serão analisadas constitui a banda de recepção do sinal ou, simplesmente, banda de leitura.

Quanto maior a banda de leitura, um número maior de frequências será analisado, inclusive frequências de baixa amplitude. 


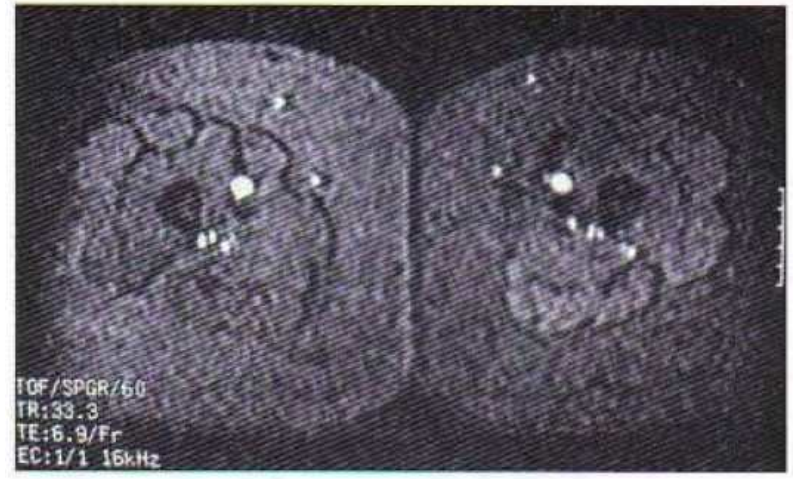

Figura 2.11: Ruído em imagem gradiente ${ }^{[4]}$.

Bandas de leitura larga coletam muito ruído e diminuem a SNR.

\subsubsection{Artefatos de Imagem em RM}

O fator que mais influencia a qualidade das imagens é o ruído eletrônico que se manifesta na forma da presença de granulação, diminuindo-se, assim, a SNR.

Os principais artefatos de imagem por RM são:

1. Ruído Eletrônico: presença do aspecto granuloso nas imagens de RM (Fig. 2.11). Pode ser causado pelos componentes eletrônicos do equipamento, pela intensidade do campo magnético não ser suficiente, causando uma redução da quantidade de núcleos de átomos de hidrogênios.

\section{Artefato de "Dobra da Imagem" - Aliasing - Foldover - Phase} Wrap: o artefato de dobra da imagem (aliasing/foldover) se caracteriza pela presença de parte da anatomia que não coube no campo de visão remontada sobre a própria imagem. Esses artefatos acontecem sempre que se trabalha com FOV de dimensões menores que o objeto. Na coleta de informações o processador de imagens adquire informações da anatomia fora do campo de visão e apresenta essa imagem remontada sobre a imagem principal . O artefato de dobra ocorre sempre na direção de codificação da fase.

3. Artefato de Movimento: no processo de aquisição da imagem por ressonância o paciente deverá permanecer imóvel durante toda a coleta dos dados. Caso o paciente se movimente durante esse processo a imagem será prejudicada pela presença de "fantasmas", "contornos repetidos", reduzindose, desta forma, a nitidez do tema principal.

4. Artefatos de Fluxo: o fluxo produzido pelo deslocamento sanguíneo no 
interior dos vasos costuma produzir imagens fantasmas desses vasos na direção da codificação da fase. É mais visível o artefato produzido pelo fluxo nas artérias do que nas veias.

5. Artefato de Suscetibilidade Magnética: a propriedade que tem diferentes objetos de responder a campos magnéticos externos pode ser definida com suscetibilidade magnética. A presença de metais no tecido biológico altera fortemente o campo magnético local, distorcendo a anatomia nesta região e provocando ao seu redor uma ausência de sinal. Mas não só metais causam artefatos desta natureza, alguns tecidos biológicos também apresentam suscetibilidade magnética. Esta condição se torna mais evidente quando dois tecidos com suscetibilidades diferentes estão muito próximos.

6. Artefato de Mapeamento Incorreto: estruturas que "pulsam", como as artérias, ou que apresentam movimentos que se repetem na direção da fase tendem a produzir um mapeamento incorreto da sua imagem nesta direção.

7. Artefatos Zebra (Zebra Stripes): artefatos "zebra" na imagem são obtidos quando se utilizam sequências gradiente de eco com grandes FOV.

\subsection{Imageamento por RM do pulmão}

Desenvolvido como uma ferramenta de pesquisa, o imageamento por RM do pulmão tem se tornado cada vez mais importante para aplicações clínicas específicas. As vantagens em comparação a TC não são apenas limitadas pela ausência de radiação ionizante, fator que é de grande interesse à avaliação de doenças pulmonares em crianças ou em pacientes que necessitam de frequentes exames de acompanhamento. Imagens de RM de alta qualidade podem contribuir significamente na tomada de decisão em numerosas doenças pulmonares. Apesar do atual nível de tecnologia da RM, ainda há diversas dificuldades na obtenção de imagens do pulmão. A principal delas são os artefatos de movimento, causados pelos movimentos contínuos do batimento cardíaco e respiração; outras dificuldades que existem na obtenção dessas imagens são a baixa intensidade de sinal devido à densidade de prótons ser pequena, comparada a outras partes do corpo, pois um pulmão contém apenas $800 \mathrm{~g}$ de tecido e sangue que são distribuídos em um volume de 4 a 6 litros e além do mais, inomogeneidades locais devido a artefatos de susceptibilidade nas camadas de ar ou nas interfaces ar-líquidas dos alvéolos resultando em uma rápida defasagem do sinal com um intervalo T2 muito curto ${ }^{[13]}$. 
Por causa de todas essas dificuldades, os pulmões normalmente aparecem sem nenhum sinal visível em imagens de RM convencionais. Porém, qualquer patologia com maior densidade de prótons e, portanto, um sinal maior aparece com um forte contraste inerente contra o fundo negro do tecido pulmonar aerado. Mudanças sutis no sinal do pulmão devido a pequenas lesões ou reticulações finas, ainda podem não ser notadas, em especial, se artefatos de movimento não forem suficientemente reprimidos.

\subsection{O Arquivo DICOM}

Comunicação de imagens digitais em medicina, DICOM (Digital Imaging Communications in Medicine), é conjunto de normas para tratamento, armazenamento e transmissão de informação médica num formato eletrônico, estruturando um protocolo ${ }^{[28]}$.

Foi criado, com a finalidade de padronizar a formatação das imagens diagnósticas como TC, RM, Radiografias, Ultrassonografias, etc. O padrão DICOM é uma série de regras que permite que imagens médicas e informações associadas sejam trocadas entre equipamentos de diagnóstico geradores de imagens, computadores e hospitais.

O padrão DICOM, estabelecido há 20 anos atrás, estabelece uma linguagem comum entre os equipamentos de marcas diferentes, que geralmente não são compatíveis, e entre equipamentos de imagem e computadores. Estas máquinas podem estar em hospitais, clínicas ou laboratórios. Por isso, desempenha um papel integral na evolução da medicina, garantindo os padrões de diagnósticos mais altos possíveis e o melhor desempenho. O padrão DICOM certamente definiu o cenário da medicina moderna, fornecendo as seguintes vantagens:

1. Um padrão universal da medicina digital: todos os equipamentos de aquisição de imagens digitais atuais produzem imagens DICOM e se comunicam através de redes DICOM. Portanto, o fluxo de trabalho médico atual está implicitamente controlado por uma infinidade de regras DICOM.

2. Qualidade de imagem excelente: o formato DICOM suporta até 65.536 (16 bits) de escalas de cinza para a exibição de imagens monocromáticas, além de capturar as mais sutis diferenças nas imagens médicas.

3. Suporte completo a numerosos parâmetros de aquisição de imagens e diferentes tipos de dados: além de armazenar as imagens, ar- 
mazena uma infinidade de dados relacionados à imagem como posição no espaço 3D do paciente, tamanho físico de objetos na imagem, espessura da imagem, parâmetros de exposição da imagem, e diversos outros. Estes dados enriquecem imensamente o conteúdo informacional de imagens DICOM, e facilitam o processo e interpretação dos dados da imagem em diversas maneiras.

4. Codificação completa de dados médicos: arquivos e mensagens DICOM usam mais de 2000 atributos padronizados (dicionário de dados DICOM) para transmitir diversos dados médicos desde o nome do paciente até a intensidade da cor da imagem, para o diagnóstico atual do paciente.

5. Clareza em descrever equipamentos de imagens digitais e suas funcionalidades - a espinha dorsal de qualquer projeto de imagens médicas: o DICOM define as funcionalidades de equipamentos médicos em termos muitos precisos e que não necessitam do equipamento utilizado. Ao se trabalhar com equipamentos médicos através de suas interfaces DICOM, o processo se torna muito simplificado e objetivo, deixando pequena margem para erros.

Neste trabalho, os arquivos DICOM utilizados continham imagens monocromáticas sagitais e coronais da região pulmonar com resolução de 12 bits, e diversas informações a respeito da imagem como tamanho, resolução, posição no espaço, e os dados para cada pixel da imagem. 


\section{Padrão Respiratório Temporal}

A Fig. 3.1.(a) exibe um exemplo de imagem de RM sagital e a Fig. 3.1.(b) exibe um exemplo de imagem de RM coronal. Estas duas imagens foram obtidas em instantes diferentes. No caso do pulmão, uma descrição volumétrica tridimensional não pode ser obtida por meio de RM. Como o processo de imageamento por RM é lento, é possível obter sequências temporais de imagens bidimensionais representando fatias no espaço tridimensional. A imagem em cada fatia é obtida em instantes distintos, com os pulmões em diferentes estados de inalação e exalação. Esta situação é ilustrada na Fig. 3.2 onde duas imagens, uma coronal e uma sagital, se interseccionam de forma não coerente.

Neste capítulo, apresentaremos o conceito de função respiratória padrão, que será utilizado juntamente com a transformada de Hough para determinar padrões respiratórios síncronos. Os resultados da transformada de Hough serão melhorados pela aplicação da aritmética intervalar. É conhecido que o movimento pulmonar é aproximadamente síncrono, a técnica de contornos ativos será utilizada para realizar pequenos ajustes aos padrões respiratórios encontrados pela transformada de Hough.

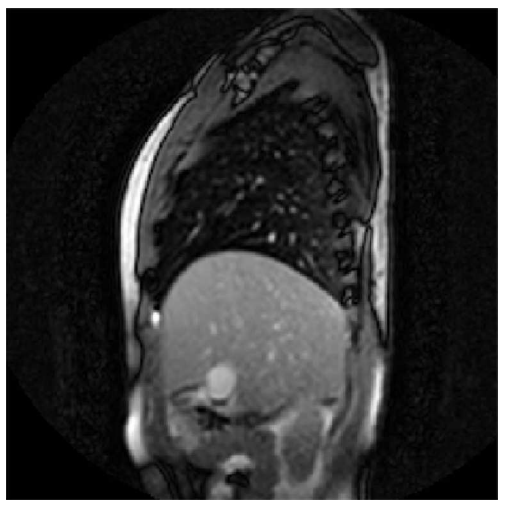

(a) imagem sagital.

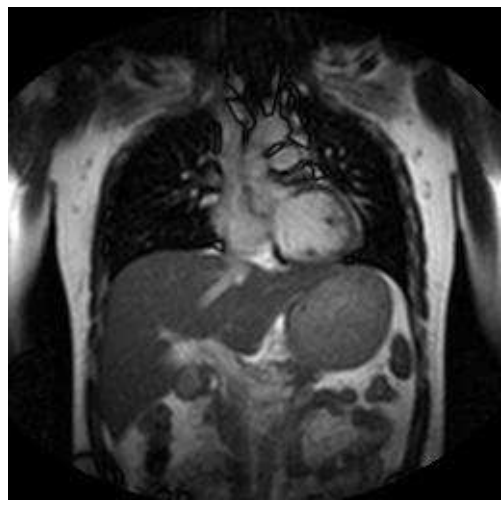

(b) imagem coronal.

Figura 3.1: Exemplos de imagens de RM, coronal e sagital. 


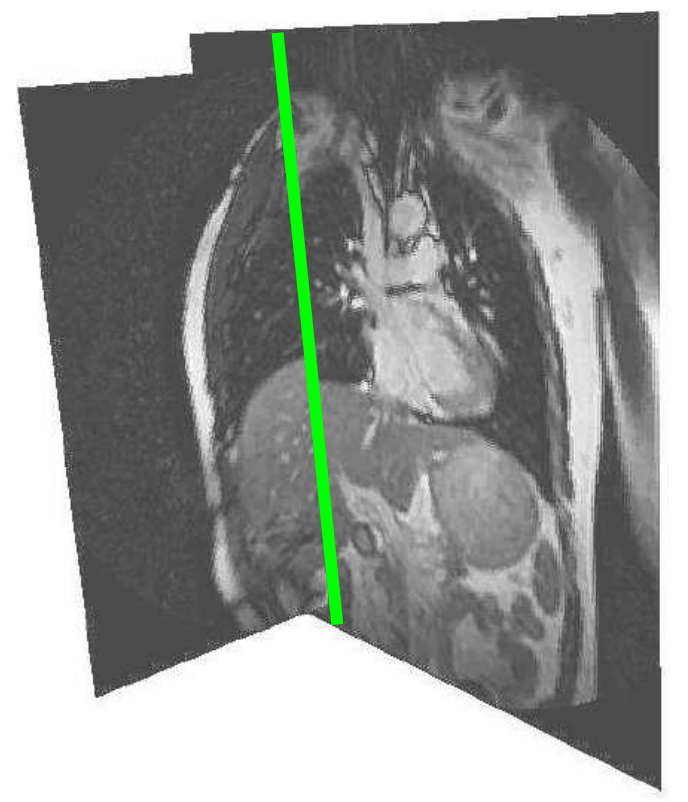

Figura 3.2: Duas imagens do mesmo pulmão que se interseccionam. A diferença de registro é mais evidente na superfície diafragmática. A intersecção entre as imagens é um segmento de linha.

\subsection{Função Respiratória Padrão}

Uma sequência temporal de imagens de RM de uma fatia do pulmão pode ser empilhada, definindo um volume espaço-temporal (STV) $I(x, y, t)$, onde $x$ e $y$ são coordenadas de cada pixel da imagem e $t$ é o tempo. A Fig. 3.3 exibe um exemplo de um STV, criada por 10 imagens coronais da mesma fatia do pulmão e obtidas em instantes distintos de tempo. Considere a definição de um plano arbitrário $\alpha$, paralelo ao eixo $t$ e ao eixo $y$, que passa por um ponto $\left(x_{s}, y_{s}\right)$. A intersecção do STV I com este plano arbitrário $\alpha$ define uma imagem 2D espaço temporal (2DSTI) como ilustrado na Fig. 3.4. A imagem 2DST $F_{s}$ corresponde à intersecção do STV I com o plano $\alpha$. A Fig. 3.5 exibe uma imagem 2DST vertical. É possível observar que um padrão de movimento está presente, especialmente pelo fato dos órgãos com movimento serem os pulmões sadios e o coração. O movimento pulmonar possui uma frequência menor e uma maior amplitude, já o movimento cardíaco possui uma frequência maior e uma menor amplitude.

Um processo direto, utilizando análise ótica de fluxo como o método do gradiente, poderia ser indicado para estimar o movimento bidimensional do pulmão, pelo fato de um campo de velocidade denso ser obtido ${ }^{[29]}$. Mas para o caso específico de imagens de RM, esta proposta não é muito adequada como é conhecido que a acurácia da estimação utilizando a análise ótica de fluxo se degrada em regiões onde os pontos em movimento sofrem modificações repentinas de intensi- 


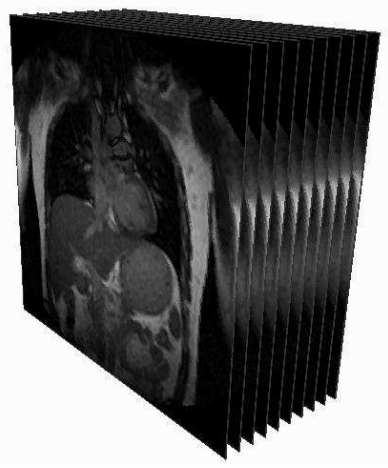

(a)

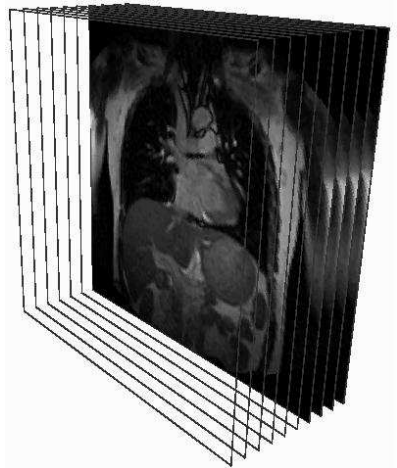

(d)

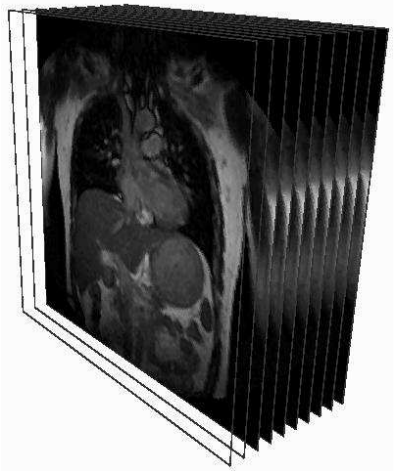

(b)

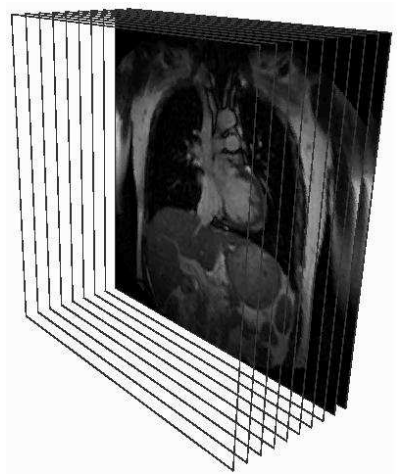

(e)

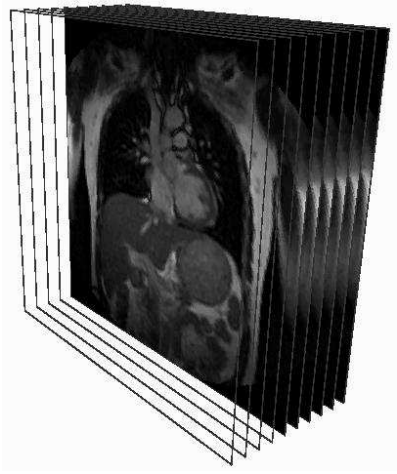

(c)

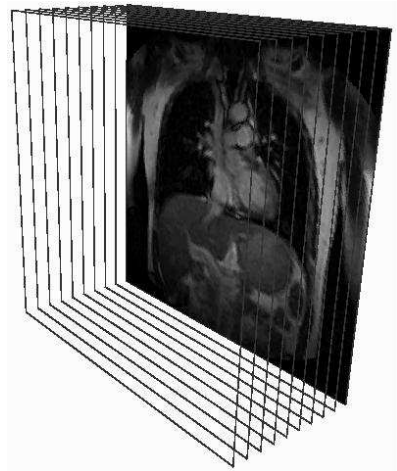

(f)

Figura 3.3: Um exemplo de STV criado por 10 imagens de RM de uma fatia coronal do pulmão.

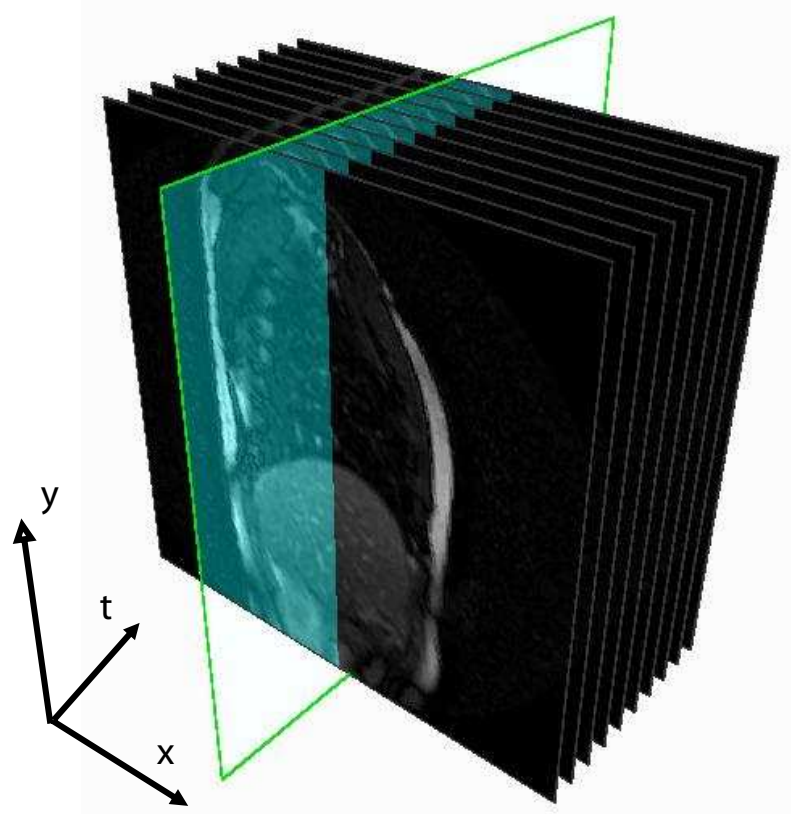

Figura 3.4: Ilustração de uma intersecção arbitrária paralela ao eixo do tempo com um STV. 


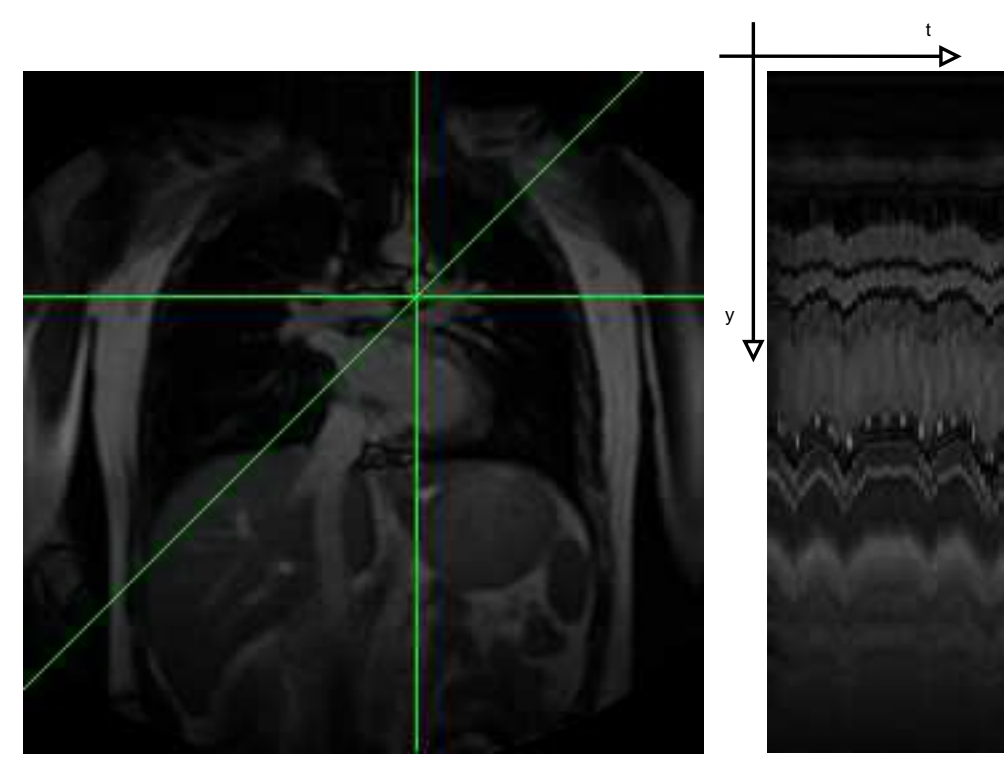

Figura 3.5: Exemplo de imagem de RM do tórax e uma imagem espaço temporal bidimensional (2DSTI) vertical.

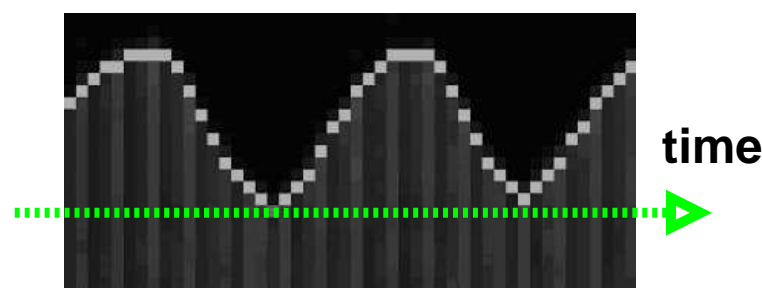

Figura 3.6: Uma função respiratória padrão $f_{s}(t)$.

dade, uma situação que é observada com frequência nas imagens de RM devido às modificações nas condições de polarização. Para ser capaz de rastrear o contorno do pulmão em sequências temporais de imagens de RM de uma determinada fatia, mesmo em quadros em que não é visível, foi feita a hipótese inicial de que todas as estruturas relacionadas ao pulmão se movem de forma quase que totalmente síncrona, e a sincronização foi feita através de um padrão chamado função respiratória padrão ${ }^{[19,30,31]}$.

Uma função respiratória padrão $f_{s}(t)$ é determinada ao redor da região diafragmática. A superfície diafragmática é mais fácil de se observar com um bom gradiente, já que o seu movimento possui uma amplitude maior quando comparado a outras estruturas torácicas. A função respiratória padrão é determinada pela entrada de dados do limite vertical do movimento do diafragma, e a curva com o maior gradiente é determinada. Uma $f_{s}(t)$ é exibida na Fig. 3.6, representando uma sequência de valores inteiros não negativos no tempo. A $f_{s}(t)$ é interna ao intervalo $\left[0, f_{\max }\right]$, onde $f_{\max }$ é a sua máxima amplitude.

Portanto, a função respiratória padrão é uma estimativa do padrão de movimento das estruturas pulmonares em uma imagem 2DST. Ela será a entrada 


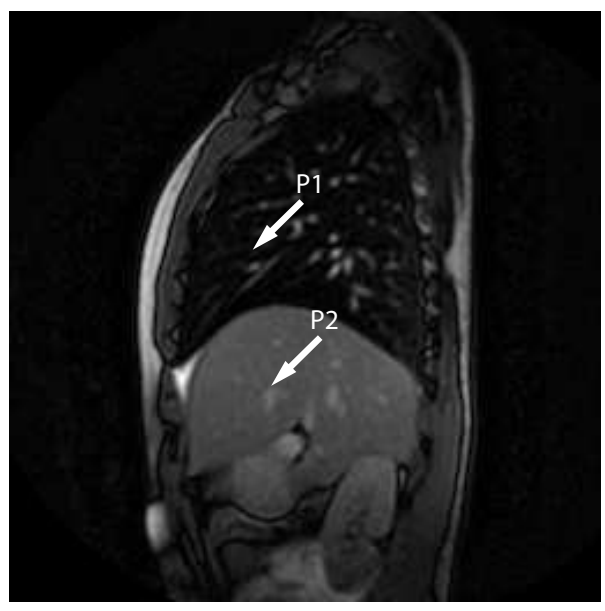

(a)

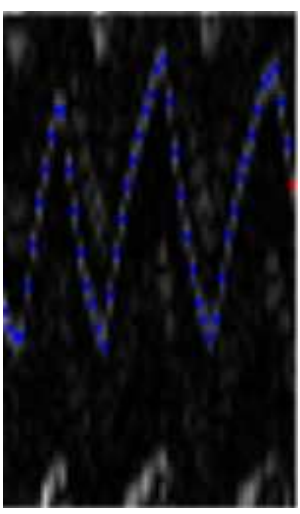

(b)

Figura 3.7: Processo realizado na obtenção da função respiração padrão. Primeiramente o usuário define uma imagem 2DST e em seguida um algoritmo detecta os maiores gradientes nesta imagem.

para a transformada de Hough determinar a presença de movimentos síncronos durante a respiração livre. A transformada de Hough será aplicada na imagem de bordas.

\subsubsection{Obtenção da Função Respiratória Padrão}

A função respiratória padrão é definida manualmente utilizando o programa desenvolvido. Em linhas gerais, o usuário define uma imagem 2DST e um algoritmo detecta os maiores gradientes nesta imagem. As seguintes etapas são realizadas no programa desenvolvido à determinação da função respiratória padrão:

1. Em primeiro lugar é realizado o carregamento da sequência a qual se deseja definir a função respiratória padrão, neste caso será utilizada uma sequência de imagens temporais coronais.

2. A seguir, são selecionados dois pontos na imagem para a definição da imagem 2DST. Ao selecionar estes dois pontos, deve-se levar em consideração qual é o movimento do diafragma, órgão utilizado como referência que possui a maior amplitude no movimento respiratório. Portanto, selecionam-se dois pontos que referem-se aproximadamente à menor e maior amplitude do movimento do diafragma, Fig. 3.7.(a).

3. Obtém-se então uma imagem 2DST com os pontos de maiores gradientes detectados, Fig. 3.7.(b). Caso alguns pontos detectados não sejam adequados, realiza-se um ajuste manual desses pontos alterando a sua posição no 


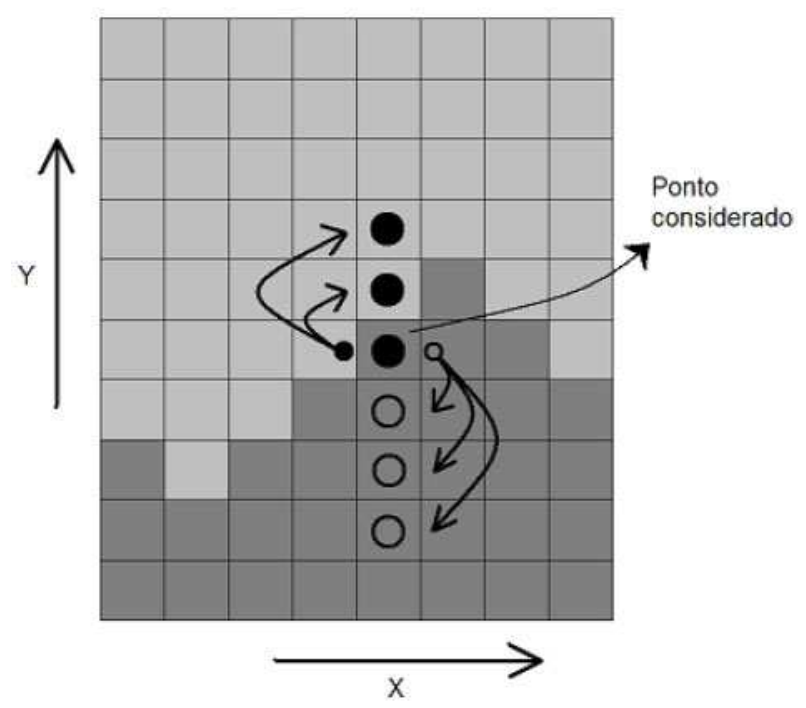

Figura 3.8: Ilustração do método de detecção de bordas. Conjuntos superior e inferior de pixels em torno do ponto considerado são usados para calcular o gradiente.

eixo vertical.

\subsection{Detector de Bordas}

Um detector de bordas visa encontrar bordas na imagem, ou simplesmente curvas e retas. Para isso, a idéia utilizada é calcular o gradiente da intensidade dos pixels. O algoritmo considera dois conjuntos de pixels para cada ponto. O primeiro conjunto é formado pelos três pontos abaixo do ponto considerado, enquanto o segundo conjunto é formado pelos dois pontos acima do ponto considerado juntamente com ele próprio (Fig. 3.8). Somam-se as intensidades dos pixels de cada conjunto e calcula-se a média das intensidades de ambos os conjuntos de pontos. Em seguida, subtraem-se os valores das médias.

O resultado é, onde há bordas, o gradiente é elevado, por causa da mudança abrupta do branco para o preto, e onde o gradiente é baixo, não houve mudanças significativas na imagem. Tal operador mostra-se muito útil aplicado a estas imagens. A imagem gerada pela RM é essencialmente preta onde é ar, e branca, onde há água, como os tecidos ou sangue. Assim, utilizando a imagem 2DST, o movimento da fronteira do pulmão é bem nítido e ao utilizar um detector de bordas teremos o contorno desejado.

A varredura é feita em toda a imagem 2DST, com o cuidado devido nos limites da própria. Assim, de acordo com o sistema de cor, pixels de fronteira estarão indicados em cores claras, enquanto regiões internas estarão indicadas por cores 


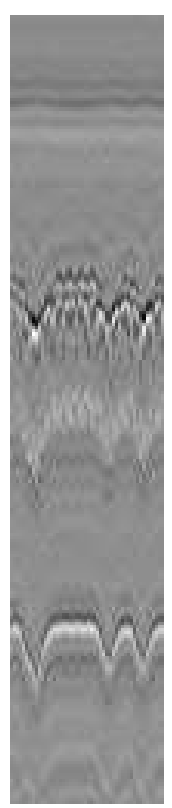

Figura 3.9: Exemplo de imagem 2DST com o detector de bordas aplicado, uma imagem aresta.

próximas à preta (Fig. 3.9). A imagem aresta corresponde à imagem 2DST com o detector de bordas aplicado.

\subsection{Transformada de Hough Modificada}

A transformada de Hough é uma técnica de extração de características utilizada em análise de imagens, visão computacional e processamento digital de imagens [32,33]. Ela é utilizada usualmente para detectar linhas retas e curvas. O objetivo da técnica é encontrar ocorrências imperfeitas de padrões dentro de uma determinada classe de formas por meio de um proceso de votação. Uma transformada de Hough modificada foi proposta por Matsushita et al. ${ }^{[31]}$ para determinar a presença de padrões respiratórios $f_{k}(t)$ em uma imagem 2DST. Supõe-se que cada ponto se movimente no tempo de acordo com a função respiratória padrão segundo uma escala e um deslocamento. Portanto, o movimento temporal de cada ponto é descrito pela seguinte equação

$$
f_{k}(t)=y=a \cdot f_{s}(t)-b
$$

onde $a$ e $b$ são a escala e o deslocamento da $f_{s}(t)$, respectivamente. A busca por padrões respiratórios $f_{k}(t)$ pode ser resumida como sendo a identificação de um grande conjunto de pares $(a, b)$ para o maior número possível de imagens 2DST para um dado STV. 


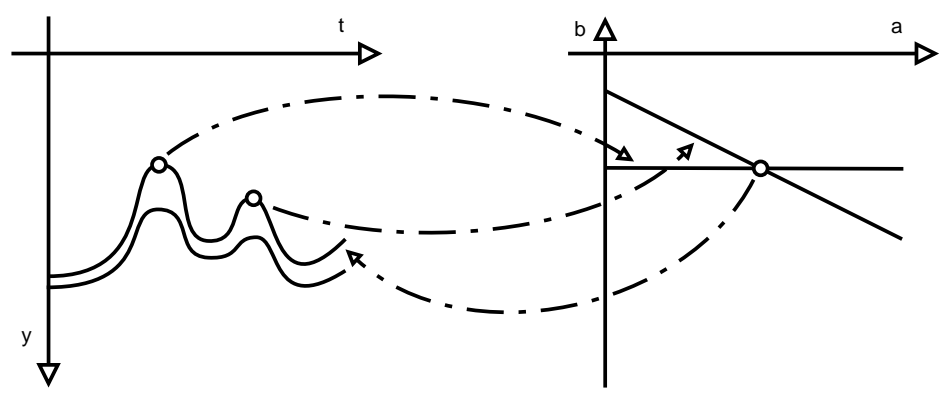

Figura 3.10: A transformada de Hough, a imagem 2DST está à esquerda e o espaço de quantização está à direita. O padrão respiratório na imagem 2DST é mapeado como uma célula no espaço de quantização.

Uma imagem de aresta é determinada a partir de uma imagem 2DST utilizando um filtro de gradiente ${ }^{[34]}$. Um padrão respiratório é completamente especificado por um par de parâmetros $(a, b)$. Para a detecção de um padrão respiratório, a transformada de Hough mapeia cada pixel aresta $(t, y)$ a partir da imagem 2DST em um espaço $(a, b)$ quantizado, onde contribuições de cada ponto característico para cada possível conjunto de $(a, b)$ são avaliadas. Para este fim, o espaço quantizado é divido em células que correspondem a um par $(a, b)$. Uma matriz multi-dimensional é utilizada para representar este espaço quantizado. Cada ponto característico $(t, y)$, ou pixel, na imagem aresta 2DST representa uma linha no espaço quantizado, as células correspondentes do acumulador são adequadamente incrementadas. Este processo é repetido para todos os pontos característicos. Todas as células no espaço quantizado mapeiam um padrão respiratório na imagem 2DST.

Desta maneira, a intensidade de cada pixel $(a, b)$ no espaço quantizado é relacionada à probabilidade de encontrar uma escala e um deslocamento para a função respiratória padrão na imagem aresta 2DST. A Fig. 3.10 exibe dois pixels da imagem 2DST que foram mapeados para duas linhas no espaço quantizado. Estas duas linhas se interseccionam em uma célula no espaço quantizado, esta célula é mapeada a um padrão respiratório na imagem 2DST. O processo de quantização determina que a célula com maior intensidade representa com maior confiança um padrão respiratório. Supondo que tal célula seja $\left(a_{1}, b_{1}\right)$, o seguinte padrão respiratório é representando

$$
y=f_{k}(t)=a_{1} \cdot f_{s}(t)-b_{1} .
$$




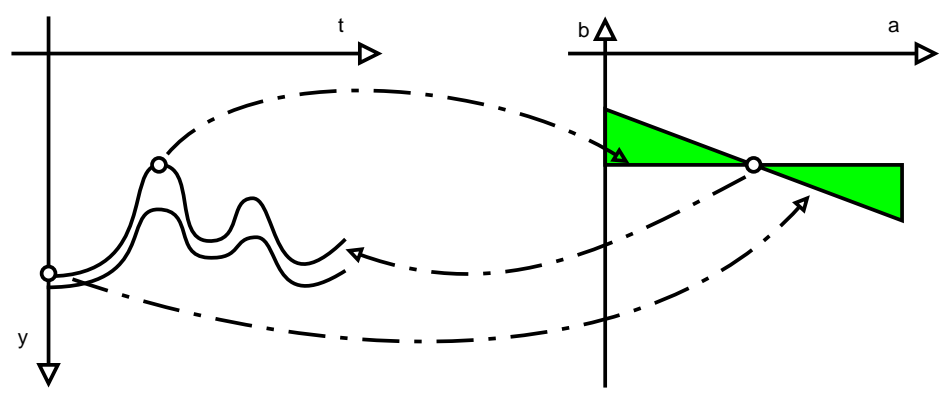

Figura 3.11: A região que precisa ser re-amostrada é exibida em verde. Esta região contém todas as linhas que passam pela célula de maior intensidade selecionada pelo algoritmo e possui coeficiente angular interno ao intervalo $\left[0, f_{\max }\right]$.

\subsubsection{Busca por outros pares (Re-amostragem negativa)}

Para proceder a busca por outros pares, é assumido que nenhuma intersecção de padrões respiratórios seja permitida, pois os órgãos não se interseccionam. Os pixels da imagem aresta 2DST que pertencem ao padrão respiratório recém encontrado são re-amostrados com valores negativos, e neste processo, todos padrões respiratórios intersectantes no padrão anteriormente achado são removidos. Este processo pode ser definido ao observar que $f_{s}(t)$ é limitado pelo intervalo $\left[0, f_{\max }\right]$, que define os limites do coeficiente angular da linha no espaço quantizado, como mostrado na expressão (3.2). Desta maneira, toda linha que passa por $\left(a_{1}, b_{1}\right)$ no espaço quantizado com coeficiente angular interno ao intervalo $\left[0, f_{\max }\right]$ precisa ser re-amostrada negativamente, ou seja, ter suas intensidade de pixels definidas como zero no espaço quantizado (veja a Fig. 3.11). A intensidade de todos os pixels pertencentes à região que foi re-amostrada negativamente, representa padrões respiratórios que interseccionam o padrão respiratório recém encontrado. Como todos padrões respiratórios intersectantes foram removidos, um novo pico no espaço quantizado pode ser encontrado e a re-amostragem com valores negativos, ou re-amostragem negativa, é novamente executada. Este processo é repetido quantas vezes for necessário, como definido pelo usuário. Este algoritmo não tem sucesso em algumas situações especiais e detecta padrões respiratórios incoerentes. Considerando o seguinte exemplo, o padrão respiratório incoerente, que não corresponde ao movimento real do órgão na região, apontado na Fig. 3.12.(a) por uma seta foi determinado pela célula de alta intensidade indicada por uma seta no espaço quantizado exibido na Fig. 3.12.(b). A seguir, a transformada de Hough modificada será explicada por meio de manipulações algébricas. 


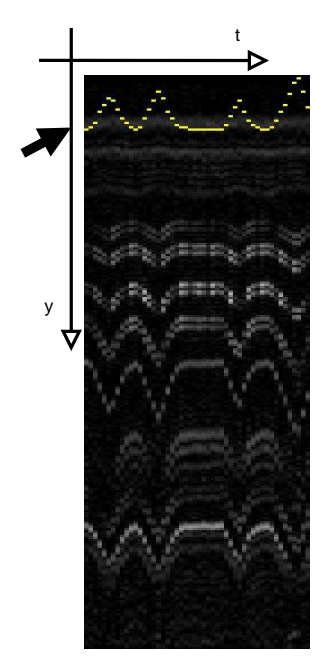

(a)

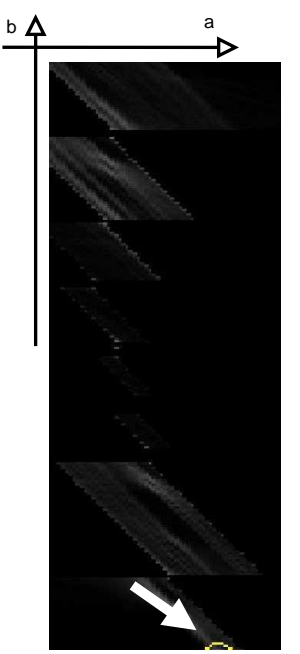

(b)

Figura 3.12: (a) Um padrão respiratório incoerente detectado pela transformada de Hough modificada é apontado por uma seta. (b) O espaço quantizado é exibido e o padrão respiratório relevante $f_{k}(t)=(a, b)$ é apontado por uma seta.

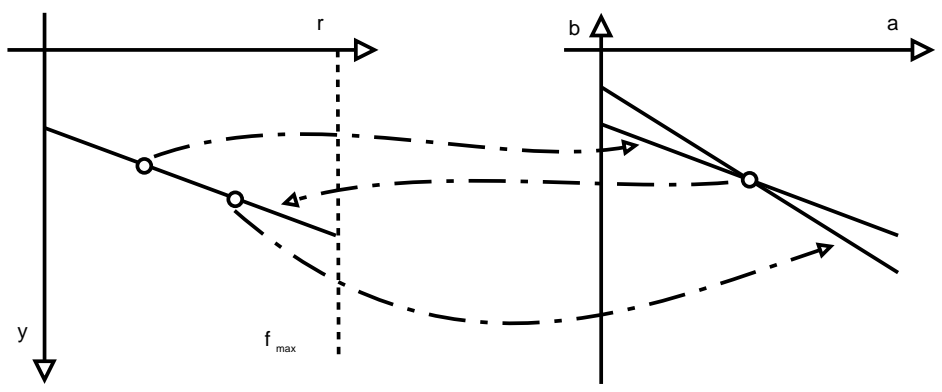

Figura 3.13: A transformada de Hough após a substituição da variável, a nova imagem está na esquerda e o espaço quantizado está na direita. Uma linha projetada como uma célula no espaço quantizado.

\subsubsection{Uma explicação sobre a Transformada de Hough Mo- dificada}

Considerando a substituição de variável, $r=f_{s}(t)$ podemos reescrever a expressão (3.1) como segue

$$
y=a \cdot r-b
$$

onde $r$ é um inteiro e pertence ao intervalo $\left[0, f_{\max }\right]$. Isto é uma transformada de Hough típica, na qual linhas retas são detectadas. A Fig. 3.13 mostra a transformada de Hough depois da substituição de variáveis. Contudo, dependendo do $f_{s}(t)$, alguns valores entre 0 e $f_{\max }$ podem não estar presentes. A substituição da variável $r=f_{s}(t)$ corresponde ao rearranjo de linhas verticais. Como afirmado anteriormente, supõe-se que a função $f_{s}(t)$ corresponde a um padrão respiratório com aproximadamente a máxima amplitude. 


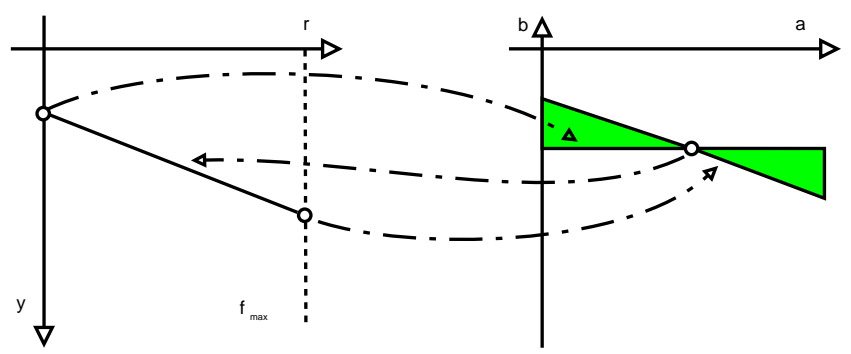

Figura 3.14: A região que deve ser re-amostrada é exibida em verde. Esta região engloba todas as linhas que atravessam a célula com maior intensidade selecionadas pelo algoritmo e que tem um coeficiente angular dentro do intervalo $\left[0, f_{\max }\right]$.

Supondo que o par $\left(a_{1}, b_{1}\right)$ tenha sido selecionado com a célula de maior intensidade. Os pontos extremos do segmento mapeado são dados por

$$
\left.\begin{array}{c}
r=0 \Rightarrow y=-b_{1} \\
r=f_{\text {max }} \Rightarrow y=a_{1} \cdot f_{\text {max }}-b_{1}
\end{array}\right\} \Longrightarrow \begin{gathered}
\left(0,-b_{1}\right) \\
\left(f_{\max }, a_{1} \cdot f_{\max }-b_{1}\right)
\end{gathered}
$$

Então, o valor mínimo para y é dado por

$$
y_{\text {min }}=\left\{\begin{array}{cc}
-b_{1} & \text { if } a_{1} \geq 0 \\
a_{1} \cdot f_{\text {max }}-b_{1} & \text { if } a_{1}<0
\end{array}\right.
$$

e o valor máximo para $y$ é dado por

$$
y_{\max }=\left\{\begin{array}{cc}
a_{1} \cdot f_{\max }-b_{1} & \text { if } a_{1} \geq 0 \\
-b_{1} & \text { if } a_{1}<0
\end{array}\right.
$$

O segmento de linha passa por $\left(a_{1}, b_{1}\right)$ e está incluso no intervalo [ $\left.y_{\min }, y_{\max }\right]$, e o padrão respiratório está também incluso nesse intervalo. A re-amostragem negativa é exibida em Fig. 3.14; todas as linhas que atravessam uma célula $\left(a_{1}, b_{1}\right)$ selecionada no espaço quantizado com coeficiente angular dentro do intervalo $\left[0, f_{\max }\right]$ deve ser negativamente re-amostrada.

\subsubsection{Transformada de Hough Modificada Intervalar (Ta- vares et al. $)^{[1]}$}

Com o objetivo de aumentar a robustez da transformada de Hough, a aritmética intervalar foi utilizada. Normalmente, os algoritmos de processamento de imagem assumem que um pixel representa uma localização exata. Na prática, a descontinuidade prevalece, no estágio de entrada os dados são obtidos a partir de um domínio discreto (RM é um exemplo). Na etapa de quantização, o al- 


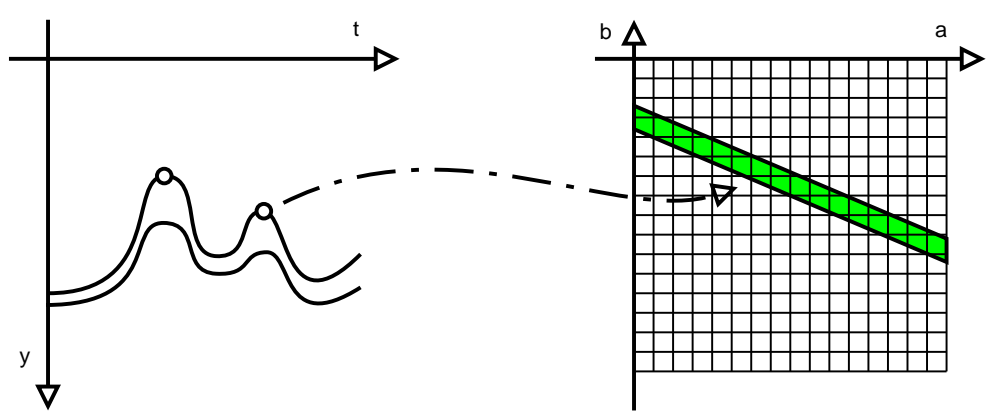

Figura 3.15: A transformada de Hough intervalar, a imagem 2DST está à esquerda e o espaço quantizado a direita. Um pixel na imagem 2DST está mapeado com uma faixa no espaço quantizado.

goritmo é computado utilizando uma matriz de acumulação que é discreta. No entanto, teoricamente, é assumido que seja contínua. Neste cenário, o algoritmo que não leva em conta a descontinuidade do sistema frequentemente fracassa com consequências graves. Cada pixel $([x],[y])$ na imagem é representado por um par de intervalos, uma faixa ${ }^{[35,36]}$, visto que na transformada de Hough modificada, cada pixel $([t],[y])$ da imagem representava apenas uma reta.

$$
([t-0.5, t+0.5],[y-0.5, y+0.5])
$$

e sua intensidade é representada por um intervalo $[I-0.5, I+0.5]$. A Fig. 3.15 mostra que cada característica do intervalo $([t],[y])$ da imagem aresta 2DST representa uma linha de banda no espaço quantizado. Considere que o valor do intervalo de deslocamento $[b]$, para um dado $[a]$, é determinado pela seguinte expressão

$$
[b]=[a] \cdot\left[f_{s}([t])\right]-[y]
$$

onde $([t],[y])$ é o intervalo característico. O valor resultante de $[b]$ corresponde a um intervalo. O intervalo do par $([a],[b])$ define um retângulo que representa a área que deve ser incrementada com o pixel $([t],[y])$ de intensidade de aresta. Normalmente, este rectângulo não se encaixa na rede do espaço quantizado. Quando uma célula completa no espaço quantizado é interna ao intervalo resultante $[b]$, então aquela célula é incrementada pela intensidade do pixel $([t],[y])$. No caso de uma intersecção parcial, a célula é incrementada por um valor proporcional à área interseccionada. Este algoritmo é muito semelhante a um algoritmo anti-aliasing [37]. O espaço quantizado resultante é muito mais suave que a abordagem anterior. A Fig. 3.16.(b)) mostra o espaço quantizado calculado pela transformada de Hough, e a Fig. 3.16.(c) mostra o espaço quantizado calculado pela transformada 


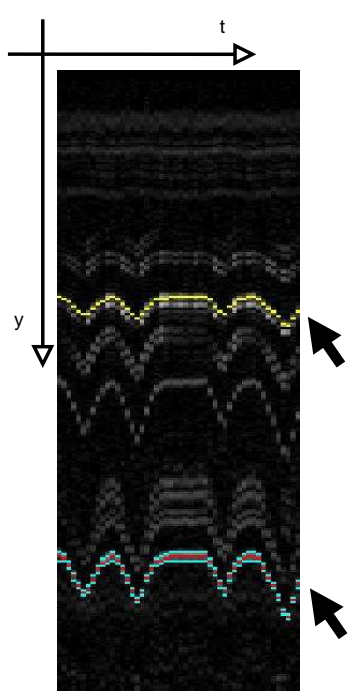

(a)

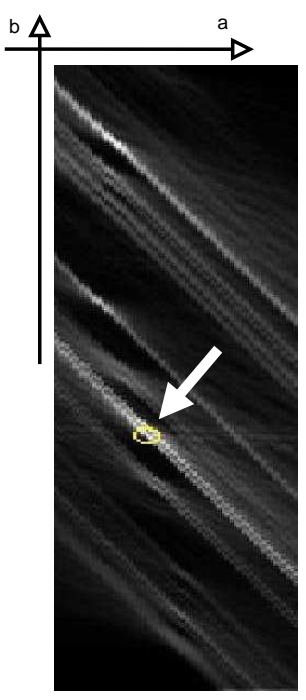

(b)

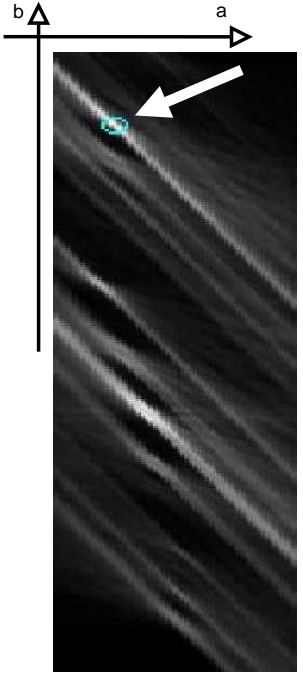

(c)

Figura 3.16: (a) A imagem 2DST e o padrão respiratório encontrado pela transformada de Hough modificada (acima), e o padrão respiratório encontrado pelo método intervalar (abaixo). (b) O espaço quantizado e o padrão respiratório relevante para a transformada de Hough modificada. (c) O espaço de quantização e o padrão respiratório relevante à transformada de Hough intervalar.

de Hough intervalar. Ambas as abordagens determinam células distintas com a maior intensidade.

A célula com maior intensidade representa uma banda de um padrão respiratório. No caso em que a banda inclui o seu pixel central, então o pixel central é selecionado. Caso contrário, o pixel com a maior interseção de área é selecionado em seu lugar. Para prosseguir com a busca de outros pares, o algoritmo de contornos ativos é aplicado ao padrão respiratório recém encontrado e, em seguida, o padrão respiratório resultante do algoritmo de contorno ativo é negativamente re-amostrado e um novo pico no espaço de quantização pode ser encontrado. É importante observar que a re-amostragem negativa é realizada considerando a distinção do mapeamento. Este processo continua até que um número razoável de padrões respiratórios tenham sido detectados.

\subsection{Algoritmo de Contornos Ativos (Snakes)}

O problema de detecção de contornos em imagens é de grande complexidade e é um desafio na área de computação. Para resolução deste problema, um modelo foi proposto por Kass et al. ${ }^{[38]}$, no qual uma curva é definida dentro do domínio da imagem e esta se move sob influência de forças internas e externas. Estas forças são definidas de modo que a curva deforme convergindo para o contorno de um objeto desejado na imagem. Este modelo foi chamado de "Snakes", ou 


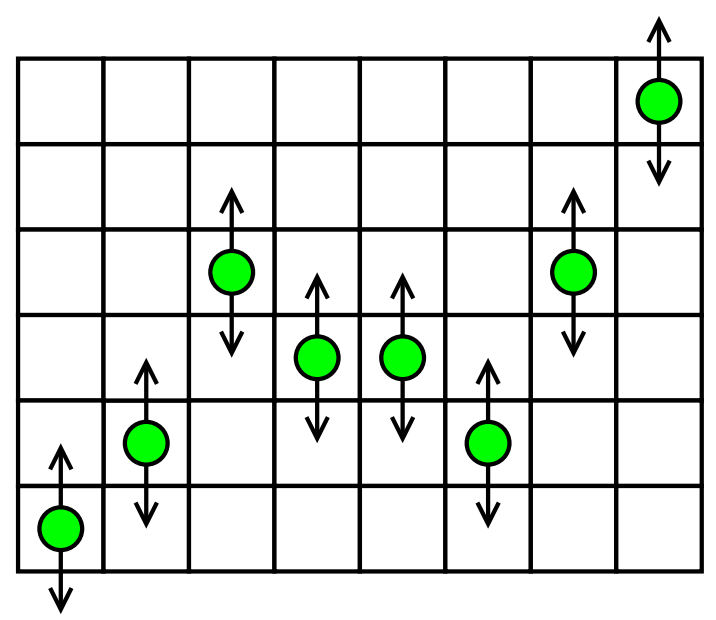

Figura 3.17: Um padrão respiratório resultante da transformada de Hough intervalar. O algoritmo de contornos ativos procura por uma posição de menor energia na adjacência vertical dos pixels pertencentes ao padrão respiratório.

contornos ativos. Neste modelo, os pontos da curva se movem de forma a atingir um mínimo de energia quando um contorno de objeto for encontrado.

Problemas com o modelo original de Kass et al. ${ }^{[38]}$ foram encontrados. A curva inicial deve estar bem próxima do contorno desejado para haver convergência. Caso contrário, a curva será atraída por um mínimo local indesejado. Outro ponto importante é a impossibilidade da curva detectar concavidades no contorno, devido ao modelo de forças externas utilizados. Além destes, problemas foram encontrados no algoritmo proposto originalmente e reportados em Amini et al. ${ }^{[39]}$. O algoritmo apresenta instabilidade e tendência dos pontos se aglomerarem em um determinado ponto.

O algoritmo "Greedy Snake" [40], foi proposto para resolver estas últimas dificuldades. O "Greedy Snake" é um algoritmo mais estável e apresenta uma melhora considerável na velocidade da convergência da curva em comparação com o método original.

\subsubsection{Aplicando ao Padrão Respiratório}

Neste trabalho, uma adaptação do algoritmo de contornos ativos foi utilizada [40]. O padrão respiratório que resultou da transformada de Hough intervalar é a condição inicial para o algoritmo de contornos ativos. Um padrão respiratório $f_{k}(t)$ é um conjunto de pixels com apenas um pixel para cada linha vertical (ver Fig. 3.17). É dado por

$$
f_{k}(t)=\left\{y_{0}, y_{1}, \cdots, y_{n}\right\}
$$


onde $0 \leq t \leq n$, tal que $n$ é o número de quadros. A função de energia a ser minimizada é definida como

$$
E\left(f_{k}(t)\right)=E_{\text {int }}\left(f_{k}(t)\right)+E_{\text {image }}\left(f_{k}(t)\right)
$$

onde $E_{\text {int }}$ é a energia interna e é definida como

$$
E_{\text {int }}\left(f_{k}(t)\right)=\frac{1}{2}\left(\alpha\left|\frac{\partial f_{k}(t)}{\partial t}\right|^{2}+\beta\left|\frac{\partial^{2} f_{k}(t)}{\partial t^{2}}\right|^{2}\right)
$$

onde $\alpha$ e $\beta$ são parâmetros positivos. $E_{\text {image }}$ é o termo que atrai o padrão respiratório aos pixels com maior intensidade na aresta da imagem. É definido como

$$
E_{\text {image }}\left(f_{k}(t)\right)=-\frac{\gamma}{\sigma\left(f_{k}(t)\right)} \cdot\left|\nabla I\left(f_{k}(t)\right)\right|
$$

onde $\gamma$ é um parâmetro positivo, $\sigma\left(f_{k}(t)\right)$ é o desvio-padrão da intensidade dos pixels que compõem o padrão respiratório no instante $t$ e $\nabla I\left(f_{k}(t)\right)$ é a média do gradiente de intensidade dos pixels da aresta que compõem o padrão respiratório no instante $t$. O gradiente de intensidade é calculado utilizando o algoritmo do detector de bordas apresentado na seção 3.2. Para maiores informações a respeito do algoritmo de contornos ativos consultar o apêndice B.

O algoritmo analisa as verticais ímpares ( $t$ número ímpar) na sequência e depois as verticais pares ( $t$ número par) na sequência. Na busca de um padrão respiratório com menor energia, a adjacência vertical de cada pixel do padrão respiratório atual é analisada. O processo é repetido até que nenhuma mudança ocorra. A Fig. 3.18 mostra o resultado do algoritmo de contornos ativos após a transformada de Hough intervalar. Foi observado empiricamente que a contribuição da componente da imagem $E_{\text {image }}\left(f_{k}(t)\right)$ tem uma maior influência no resultado final que os componentes derivados, ou seja, adotando um peso maior para o parâmetro da equação da energia da imagem, $\gamma$, foram obtidos melhores resultados. Optou-se por manter a relação $\gamma / \alpha=\gamma / \beta>1.0$ constante. Os valores adotados neste estudo foram $\alpha=0.7, \beta=0.7$ e $\gamma=1.2$. 


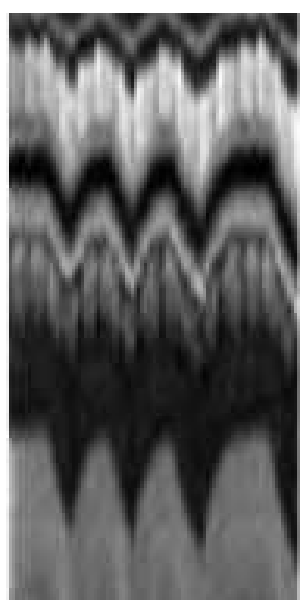

(a)

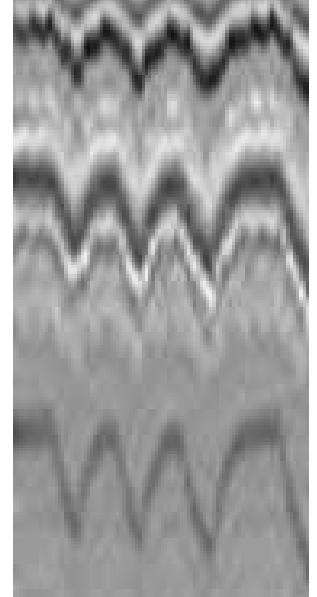

(b)

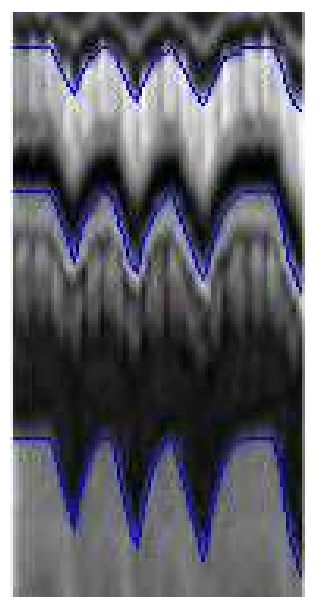

(c)

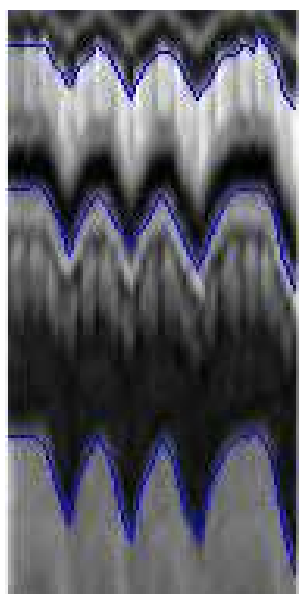

(d)

Figura 3.18: (a) A imagem 2DST original. (b) A imagem de arestas. (c) O padrão respiratório detectado pela transformada de Hough intervalar. (d) O padrão respiratório detectado pelo algoritmo de contornos ativos. 


\section{Mapeamento Coronal-Sagital}

Neste capítulo será apresentada uma técnica para realizar a correspondência de um pixel da imagem sagital para a imagem coronal e vice-versa. Um pixel em uma imagem de RM é mapeado para o espaço tridimensional utilizando a matriz de mapeamento armazenada no arquivo DICOM ${ }^{[19]}$, entretanto esta matriz não é inversível. Desta maneira, um ponto tridimensional no espaço não pode ser mapeado para uma imagem de RM. O seguinte equacionamento soluciona este problema definindo uma pseudo inversa. Os pixels contidos em uma imagem DICOM podem ser mapeados para o espaço tridimensional conforme

$$
\left[\begin{array}{c}
p_{x} \\
p_{y} \\
p_{z} \\
1.0
\end{array}\right]=\left[\begin{array}{cccc}
x_{x} \cdot \Delta_{i} & y_{x} \cdot \Delta_{j} & 0.0 & s_{x} \\
x_{y} \cdot \Delta_{i} & y_{y} \cdot \Delta_{j} & 0.0 & s_{y} \\
x_{z} \cdot \Delta_{i} & y_{z} \cdot \Delta_{j} & 0.0 & s_{z} \\
0.0 & 0.0 & 0.0 & 1.0
\end{array}\right] \cdot\left[\begin{array}{c}
i \\
j \\
0.0 \\
1.0
\end{array}\right]=[M] \cdot\left[\begin{array}{c}
i \\
j \\
0.0 \\
1.0
\end{array}\right]
$$

onde $i$ e $j$ são coluna e linha de uma imagem. $x_{x}, x_{y}$ e $x_{z}$ definem as direções do eixo $x$ no espaço tridimensional. $y_{x}, y_{y}$ e $y_{z}$ definem as direções do eixo $y$ no espaço tridimensional. $\Delta_{i}$ é o espaçamento da coluna e $\Delta_{j}$ é o espaçamento da linha. $s_{x}, s_{y}$ e $s_{z}$ correspondem ao posicionamento inicial do primeiro voxel. $p_{x}$, $p_{y}$ e $p_{z}$ correspondem às coordenadas no espaço 3D da imagem. Usualmente, as imagens coronais possuem um valor maior para $\Delta_{i}$ e $\Delta_{j}$ quando comparados aos obtidos pelas imagens sagitais da mesma pessoa.

\subsection{Intersecção do Plano Sagital x Coronal}

As imagens sagital e coronal possuem um segmento de reta comum, e considerando os pixels deste segmento de reta que se originaram das imagens sagital e coronal, respectivamente $\left(i_{c}, j_{c}\right)$ e $\left(i_{s}, j_{s}\right)$, ocupam o mesmo espaço tridimensional 


$$
P_{s}=\left[M_{s}\right] \cdot\left[\begin{array}{c}
i_{s} \\
j_{s} \\
0 \\
1
\end{array}\right]=\left[M_{c}\right] \cdot\left[\begin{array}{c}
i_{c} \\
j_{c} \\
0 \\
1
\end{array}\right]=P_{c}
$$

onde $\left[M_{s}\right]$ e $\left[M_{c}\right]$ são, respectivamente, a matriz de mapeamento sagital e coronal. É possível isolar uma das coordenadas. Dado um pixel $\left(i_{c}, j_{c}\right)$ na imagem coronal pertencente ao segmento de intersecção, o pixel correspondente na imagem sagital $\left(i_{s}, j_{s}\right)$ é dado por

$$
\left[\begin{array}{c}
i_{s} \\
j_{s} \\
0 \\
1
\end{array}\right]=\left[M_{s}\right]^{-1} \cdot\left[M_{c}\right] \cdot\left[\begin{array}{c}
i_{c} \\
j_{c} \\
0 \\
1
\end{array}\right]
$$

\subsection{A matriz inversa}

A matriz $\left[M_{s}\right]$ não possui inversa, como ela possui uma coluna completa com zeros (o mesmo é verdadeiro para a matriz $\left[M_{c}\right]$ ). Entretanto, no espaço bidimensional, a coordenada $z$ não possui nenhum significado e pode ser considerado como nada. Desta maneira, é possível modificar os valores da terceira coluna das matrizes $\left[M_{c}\right]$ e $\left[M_{s}\right]$, permitindo que ela tenha uma inversa. Considerando que $x_{x s}=x_{z s}=$ $y_{x s}=y_{y s}=0.0$ para imagens sagitais e que $x_{y c}=x_{z c}=y_{x c}=y_{y c}=0.0$ para imagens coronais, uma linha nas matrizes $\left[M_{c}\right]$ e $\left[M_{s}\right]$ também possuem apenas zeros, respectivamente a primeira e segunda linhas. As seguintes matrizes são definidas

$$
\left[M_{s}^{*}\right]=\left[\begin{array}{cccc}
0.0 & 0.0 & 1.0 & s_{x s} \\
x_{y s} \cdot \Delta_{i s} & 0.0 & 0.0 & s_{y s} \\
0.0 & y_{z s} \cdot \Delta_{j s} & 0.0 & s_{z s} \\
0.0 & 0.0 & 0.0 & 1.0
\end{array}\right]
$$


Tabela 4.1: Dados DICOM para a utilização no exemplo mencionado.

\begin{tabular}{|c|c|c|}
\hline & sagital & coronal \\
\hline$x_{x}$ & 0.0 & 1.0 \\
\hline$x_{y}$ & 1.0 & 0.0 \\
\hline$x_{z}$ & 0.0 & 0.0 \\
\hline$y_{x}$ & 0.0 & 0.0 \\
\hline$y_{y}$ & 0.0 & 0.0 \\
\hline$y_{z}$ & -1.0 & -1.0 \\
\hline$\Delta_{j}$ & 1.48 & 1.64 \\
\hline$\Delta_{j}$ & 1.48 & 1.64 \\
\hline$s_{x}$ & -60.0 & -205.7 \\
\hline$s_{y}$ & -211.0 & 5.0 \\
\hline$s_{z}$ & 191.5 & 215.7 \\
\hline \hline
\end{tabular}

$$
\left[M_{c}^{*}\right]=\left[\begin{array}{cccc}
x_{x c} \cdot \Delta_{i c} & 0.0 & 0.0 & s_{x c} \\
0.0 & 0.0 & 1.0 & s_{y c} \\
0.0 & y_{z c} \cdot \Delta_{j c} & 0.0 & s_{z c} \\
0.0 & 0.0 & 0.0 & 1.0
\end{array}\right]
$$

As matrizes $\left[M_{c}^{*}\right]$ e $\left[M_{s}^{*}\right]$ são inversíveis. O mapeamento definido pelas matrizes $\left[M_{c}^{*}\right]^{-1} \cdot\left[M_{s}\right]$ e $\left[M_{s}^{*}\right]^{-1} \cdot\left[M_{c}\right]$. O mapeamento é utilizado para determinar o segmento de reta vertical nas imagens coronais que correspondem à imagem sagital e vice-versa.

A seguir, é exibido um exemplo utilizando as matrizes com os valores alterados de acordo com a Tabela 4.1, de tal forma que seja possível realizar a inversa delas:

$$
\begin{aligned}
& {\left[M_{s}^{*}\right]=} {\left[\begin{array}{cccc}
0.0 & 0.0 & 1.0 & -60.0 \\
1.48 & 0.0 & 0.0 & -211.0 \\
0.0 & -1.48 & 0.0 & 191.5 \\
0.0 & 0.0 & 0.0 & 1.0
\end{array}\right] \text {, equivale ao plano } x=-60.0 \mathrm{~mm} } \\
& {\left[M_{c}^{*}\right]=\left[\begin{array}{cccc}
1.64 & 0.0 & 0.0 & -205.7 \\
0.0 & 0.0 & 1.0 & 5.0 \\
0.0 & -1.64 & 0.0 & 215.7 \\
0.0 & 0.0 & 0.0 & 1.0
\end{array}\right], \text { equivale ao plano } y=5.0 \mathrm{~mm} . } \\
& {\left[M_{s}^{*}\right]^{-1}=\left[\begin{array}{ccccc}
0.0 & 0.67 & 0.0 & 142.6 \\
0.0 & 0.0 & -0.67 & 129.4 \\
1.0 & 0.0 & 0.0 & 60.0 \\
0.0 & 0.0 & 0.0 & 1.0
\end{array}\right] }
\end{aligned}
$$




$$
\begin{gathered}
{\left[M_{c}^{*}\right]^{-1}=\left[\begin{array}{cccc}
0.61 & 0.0 & 0.0 & 125.4 \\
0.0 & 0.0 & -0.61 & 131.5 \\
0.0 & 1.0 & 0.0 & -5.0 \\
0.0 & 0.0 & 0.0 & 1.0
\end{array}\right]} \\
{\left[M_{c}^{*}\right]^{-1} *\left[M_{c}\right]=\left[\begin{array}{cccc}
1.0 & 0.0 & 0.0 & 0.0 \\
0.0 & 1.0 & 0.0 & 0.0 \\
0.0 & 0.0 & 1.0 & 0.0 \\
0.0 & 0.0 & 0.0 & 1.0
\end{array}\right]} \\
{\left[M_{s}^{*}\right]^{-1} *\left[M_{s}\right]=\left[\begin{array}{llll}
1.0 & 0.0 & 0.0 & 0.0 \\
0.0 & 1.0 & 0.0 & 0.0 \\
0.0 & 0.0 & 1.0 & 0.0 \\
0.0 & 0.0 & 0.0 & 1.0
\end{array}\right] .}
\end{gathered}
$$

Observa-se que o resultado do produto entre a matriz inversa da matriz alterada e a matriz não altera é igual a matriz identidade, tanto para a matriz coronal, como para a matriz sagital.

\subsection{Cálculo da Intersecção das Imagens}

Para a intersecção dos planos, as posições no espaço de cada uma das imagens deve ser a mesma, de tal forma que:

$$
P_{s}=\left[M_{s}^{*}\right] \cdot\left[\begin{array}{c}
i_{s} \\
j_{s} \\
0 \\
1
\end{array}\right]=\left[M_{c}^{*}\right] \cdot\left[\begin{array}{c}
i_{c} \\
j_{c} \\
0 \\
1
\end{array}\right]=P_{c}
$$

De onde vem a relação principal para o cálculo da intersecção:

$$
\left[\begin{array}{c}
i_{c} \\
j_{c} \\
\operatorname{nada} \\
1
\end{array}\right]=\left[M_{c}^{*}\right]^{-1} \cdot\left[M_{s}^{*}\right] \cdot\left[\begin{array}{c}
i_{s} \\
j_{s} \\
0 \\
1
\end{array}\right] .
$$




$$
\left[\begin{array}{c}
i_{s} \\
j_{s} \\
n a d a \\
1
\end{array}\right]=\left[M_{s}^{*}\right]^{-1} \cdot\left[M_{c}^{*}\right] \cdot\left[\begin{array}{c}
i_{c} \\
j_{c} \\
0 \\
1
\end{array}\right]
$$

A matriz já calculada representa a mudança de coordenadas de uma imagem para a outra, como os dois planos são perpendiculares, só existe uma única linha ou coluna que atenderá à condição exibida na mudança:

$$
\begin{aligned}
& {\left[M_{c}^{*}\right]^{-1} \cdot\left[M_{s}\right]=\left[\begin{array}{cccc}
0.0 & 0.0 & 0.61 & 88.8 \\
0.0 & 0.90 & 0.0 & 14.7 \\
1.48 & 0.0 & 0.0 & -216.0 \\
0.0 & 0.0 & 0.0 & 1.0
\end{array}\right]} \\
& {\left[M_{s}^{*}\right]^{-1} \cdot\left[M_{c}\right]=\left[\begin{array}{cccc}
0.0 & 0.0 & 0.67 & 145.5 \\
0.0 & 1.10 & 0.0 & -15.1 \\
1.64 & 0.0 & 0.0 & -145.7 \\
0.0 & 0.0 & 0.0 & 1.0
\end{array}\right]}
\end{aligned}
$$

A resolução se mostra da seguinte forma:

$$
\begin{gathered}
{\left[\begin{array}{c}
i_{c} \\
j_{c} \\
n a d a \\
1.0
\end{array}\right]=\left[\begin{array}{c}
88.8 \\
14.7+0.90 \cdot j_{s} \\
-216.0+1.48 \cdot i_{s} \\
1.0
\end{array}\right]} \\
{\left[\begin{array}{c}
i_{s} \\
j_{s} \\
n a d a \\
1.0
\end{array}\right]=\left[\begin{array}{c}
145.9 \\
-15.1+1.10 \cdot j_{c} \\
-145.7+1.64 \cdot i_{c} \\
1.0
\end{array}\right] .}
\end{gathered}
$$

Como consequência, as imagens sagitais estão contidas na mesma coordenada $i_{c}=88.8$ e vice-versa $\left(i_{s}=145.9\right)$. Ambas as imagens têm 256 pixels, mas os pixels das imagens sagitais $\left(\Delta_{s j}=1.48\right)$ tem uma dimensão menor quando comparadas com os pixels das imagens coronais $\left(\Delta_{c j}=1.64\right)$. Fig. 4.1 mostra o segmento de linha comum nas imagens sagitais e coronais.

Considere as imagens temporais no espaço bidimensional para as sequências sagitais e coronais obtidas no $i_{c}=89$ (imagem coronal) e $i_{s}=146$ (imagem 


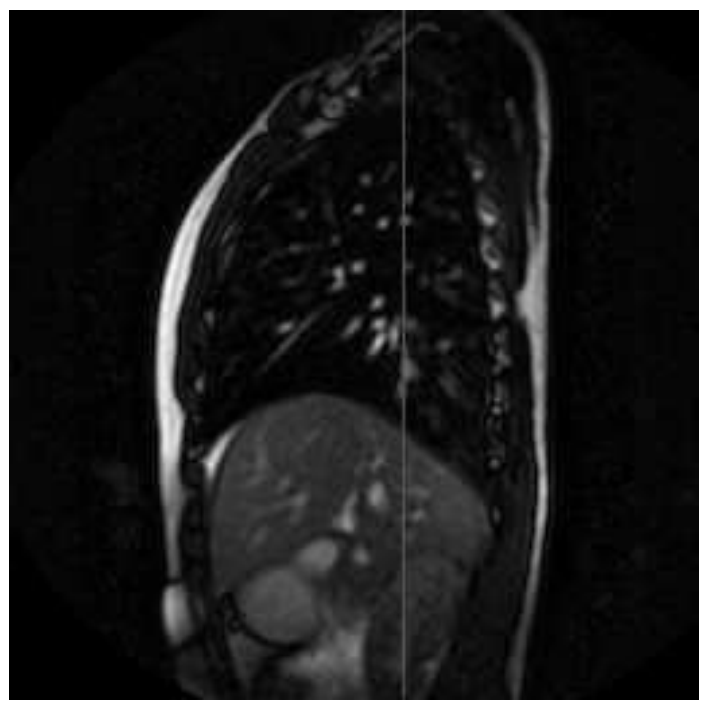

(a) Imagem sagital.

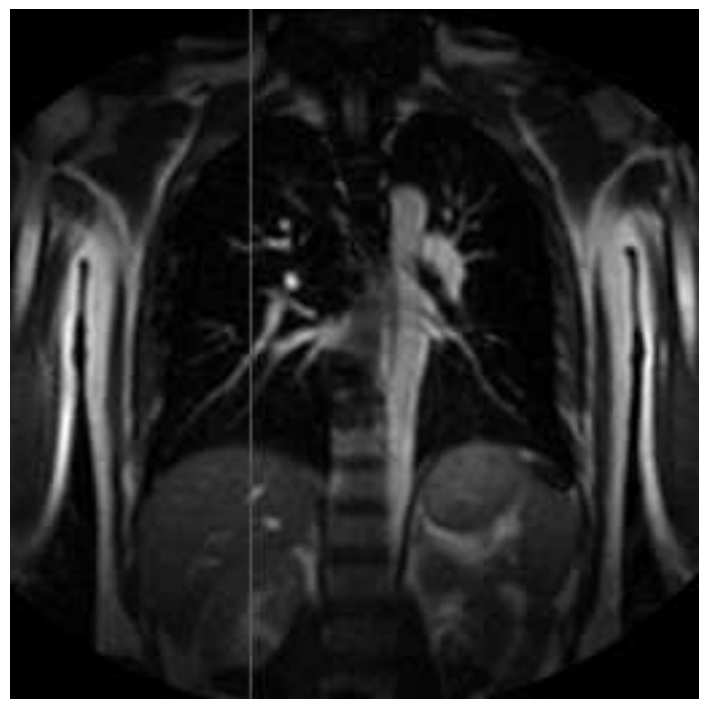

(b) Imagem coronal.

Figura 4.1: O segmento de linha comum exibido nas imagens coronal e sagital. O segmento de linha vertical comum é localizado na $i_{c}=89$ (imagem coronal) e $i_{s}=146$ (imagem sagital).

sagital). As Figs. 4.2.(a) e 4.2.(b) mostram essas imagens. A imagem coronal deve ser cortadas entre pixels 15 e 244 (Fig. 4.2.(c) mostra a imagem coronal cortada). 


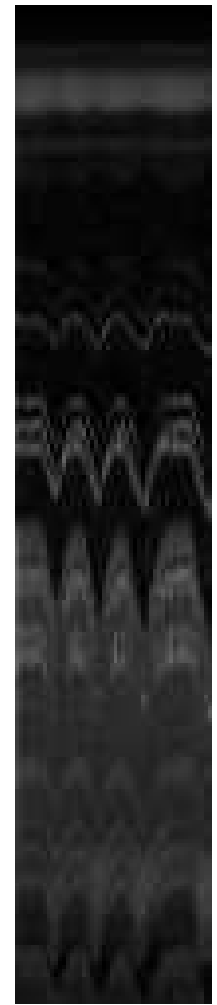

(a) Sequência coronal.

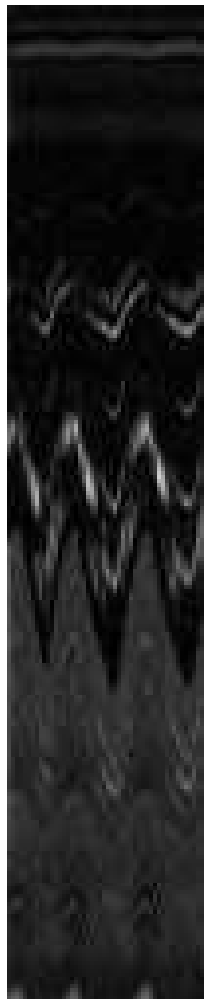

(b) Sequência sagital.

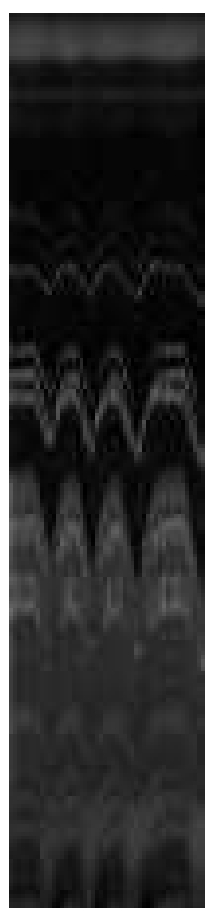

(c) Sequência coronal cortada.

Figura 4.2: O segmento de linha comum em função do tempo: imagens (a) coronal, (b) sagital e (c) coronal cortada. 


\section{$5 \quad$ Registro Temporal}

O sistema proposto procura por uma imagem na sequência coronal que registra uma imagem sagital fornecida, e vice-versa. O sistema proposto consiste em três módulos principais como exibido na Fig. 5.1. No primeiro módulo, é determinado o mapeamento sagital-coronal. Este mapeamento define a intersecção entre as imagens sagital e coronal. No segundo módulo, imagens 2DST coronal e sagital na intersecção são obtidas e a transformada de Hough intervalar modificada é aplicada para determinar padrões respiratórios. E no terceiro módulo, os padrões respiratórios encontrados são utilizados para registrar as imagens sagital e coronal.

Como mostrado na Fig. 3.5, em uma imagem de RM do peito, os pulmões e o coração são órgãos que se movimentam. O movimento do pulmão tem maior amplitude e menor frequência quando comparado ao movimento do coração. Inicialmente, a transformada de Hough intervalar determina a presença de padrões síncronos à função respiratória padrão. O algoritmo de contornos ativos pósprocessa os resultados obtidos pela transformada de Hough para que padrões assíncronos sejam encontrados. Esta é uma melhoria em relação ao trabalho proposto por Tavares et al. ${ }^{[1]}$. O algoritmo proposto neste trabalho é mostrado na Fig. 5.2. O algoritmo de contornos ativos é integrado como uma etapa ao algoritmo da transformada de Hough intervalar.

Uma estrutura pulmonar que intersecciona a sequência de imagens sagital e coronal no segmento de reta comum, pode ser utilizada pelo algoritmo de registro temporal. As superfícies definidas pelo diafragma e contorno superior ("apex") foram utilizadas neste trabalho. O diafragma possui um movimento de maior amplitude e um bom gradiente. O inflar e desinflar dos alvéolos durante a exalação e inalação provoca uma tensão superficial que diminui e aumenta de uma maneira que produz a histerese característica do pulmão. A histerese significa que a inalação segue uma relação diferente de pressão por volume quando comparada com a exalação ${ }^{[41]}$. 


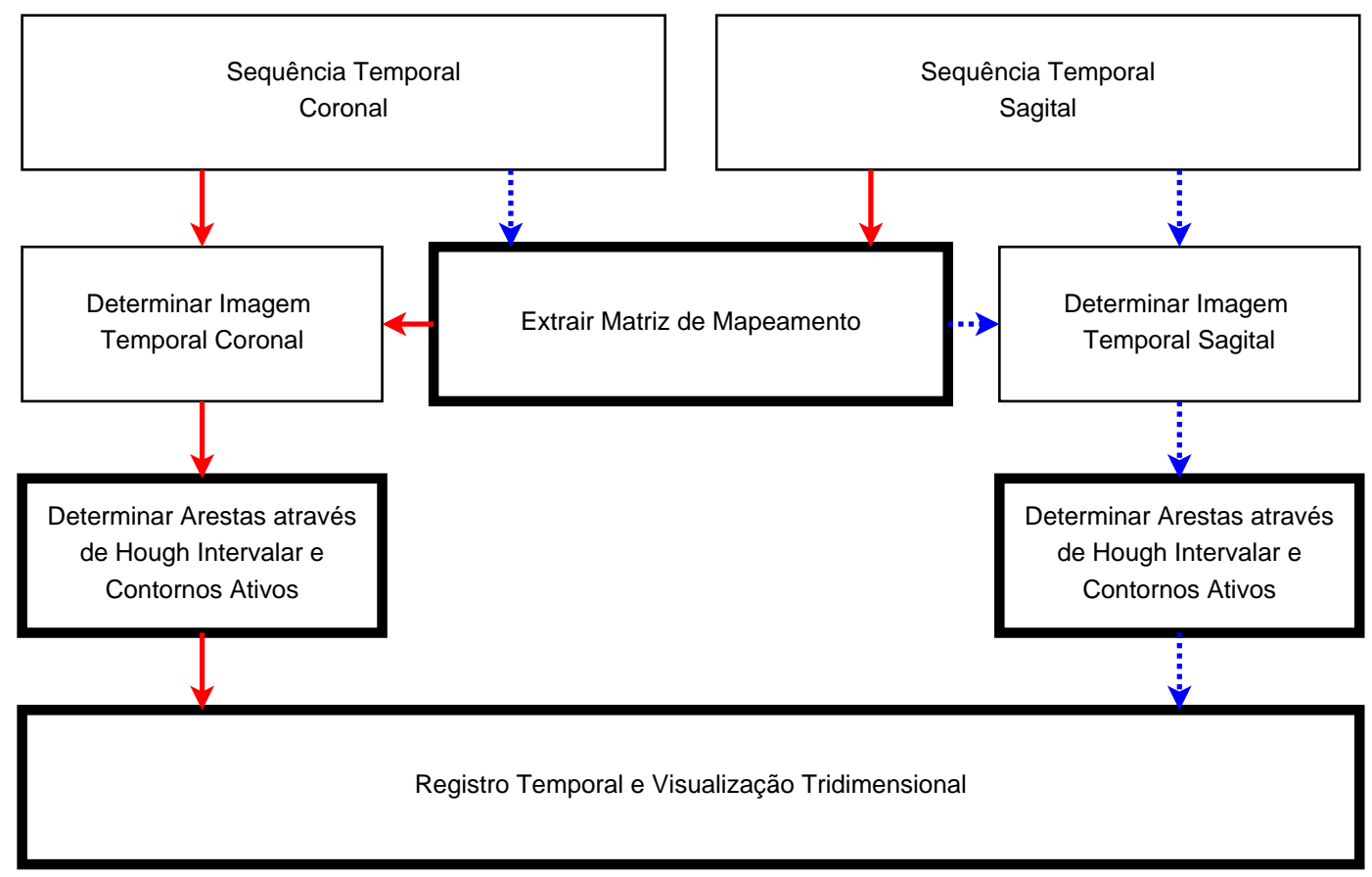

Figura 5.1: A arquitetura do sistema desenvolvido com os três módulos principais: extrair a matriz de mapeamento, determinar arestas através de Hough intervalar e contornos ativos e registro temporal e visualização tridimensional.

Considere o exemplo exibido na Fig. 5.3 onde a superfície diafragmática de três imagens do pulmão (uma coronal e duas sagitais) possuem o mesmo nível segundo o segmento de reta comum. Entretanto, as Figs. 5.3.(a) e 5.3.(c) estão na fase de inalação, e a Fig. 5.3.(d) está na fase de exalação. As imagens 2DST das Figs. 5.3.(b) e 5.3.(e) correspondem ao segmento de reta comum às imagens coronal e sagital. As Figs. 5.4.(a) e 5.4.(b) exibem que a superfície diafragmática das imagens coronal e sagital possuem o mesmo nível no segmento de reta comum. A Fig. 5.4.(a) exibe o caso em que ambas as imagens estão na mesma fase respiratória.

A fase respiratória associada à imagem pode ser detectada facilmente pelo processamento da função respiratória padrão extraída da sequência de imagens. Também foi observado que a influência do contorno superior ("apex") é mínima, pois possui uma pequena amplitude de movimento.

A transformada de Hough é um algoritmo baseado na intensidade da imagem gradiente, então o número de padrões respiratórios necessário para determinar a superfície diafragmática pode variar. O contorno superior do pulmão ("apex") possui uma intensidade menor quando comparada com o diafragma, consequentemente, o número de padrões respiratórios a serem detectados, para que o contorno superior seguramente esteja no conjunto de padrões detectados, é muito maior.

Poucas estruturas pulmonares internas interseccionam a imagem 2DST das 


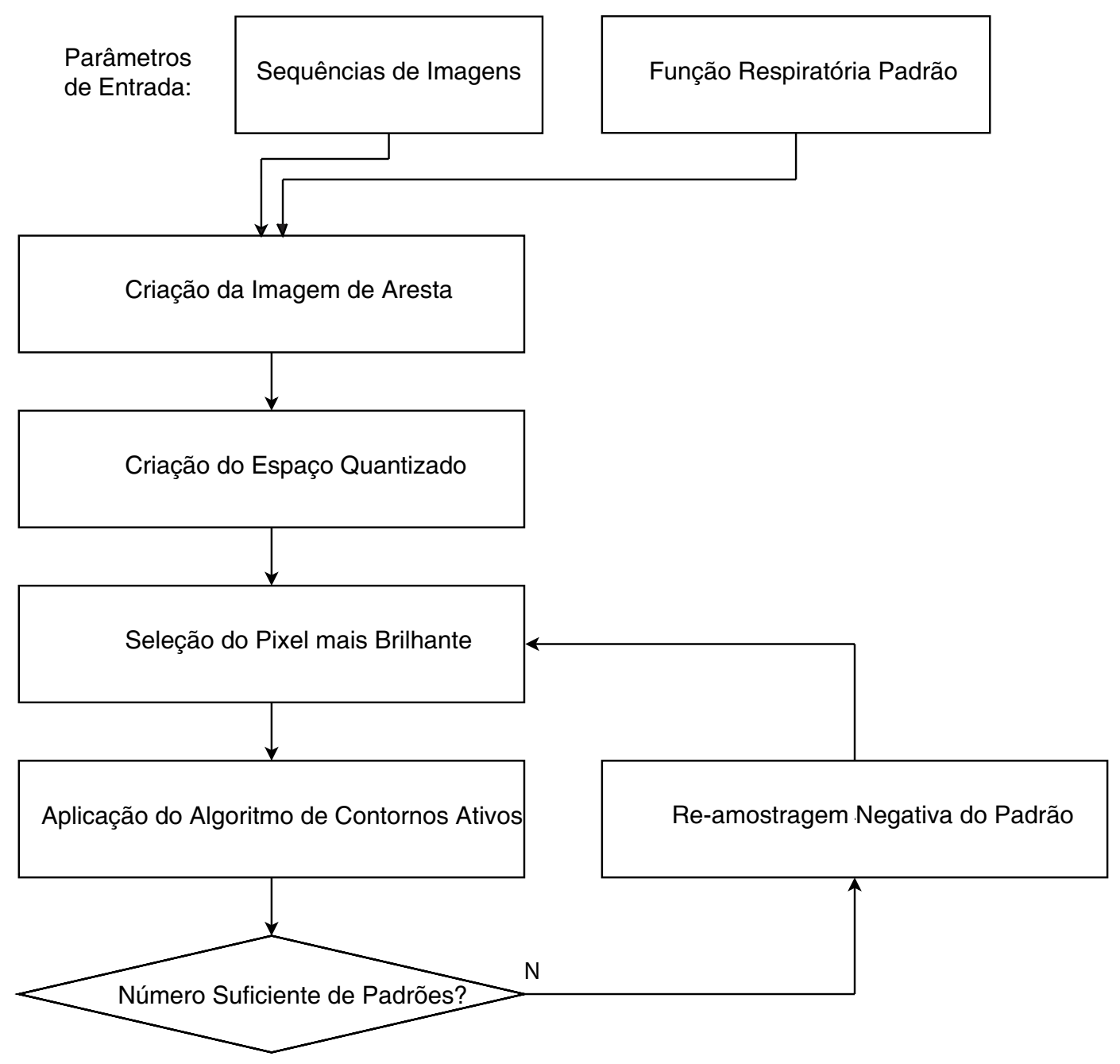

Figura 5.2: Determinação de arestas pelos módulos de Hough intervalar e contornos ativos. A transformada de Hough intervalar corresponde aos seguintes módulos: criação da imagem da aresta, criação do espaço quantizado, seleção do pixel mais brilhante e re-amostragem negativa do padrão respiratório. 


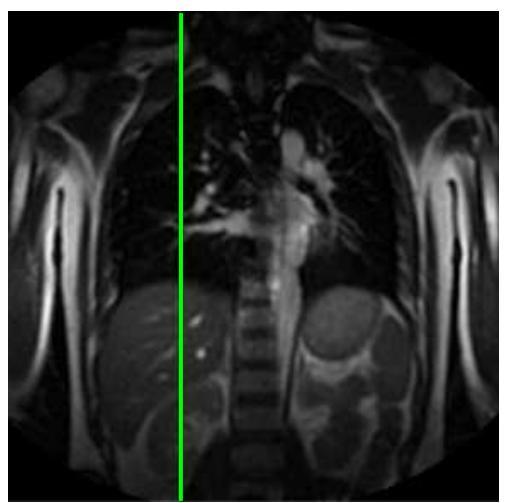

(a)

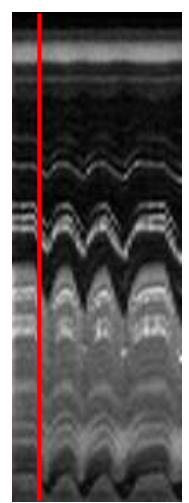

(b)

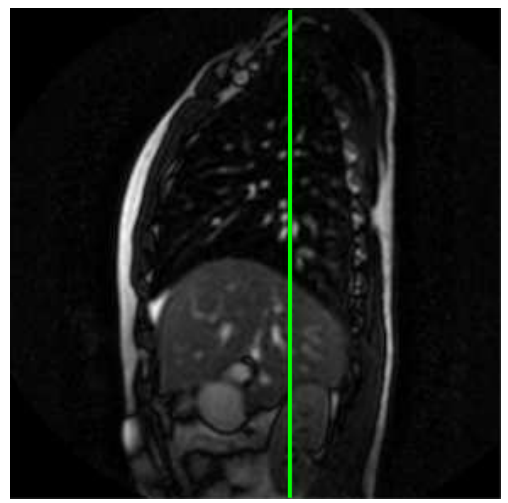

(c)

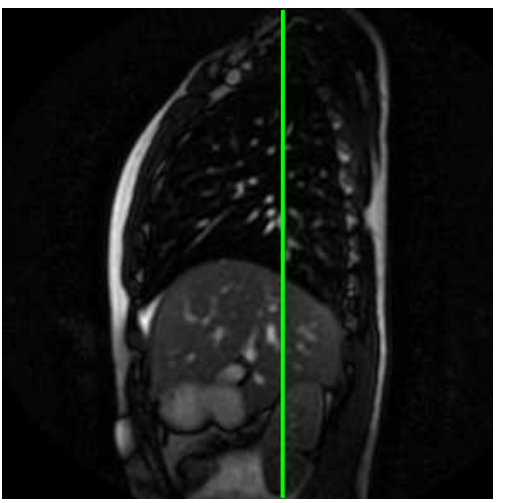

(d)

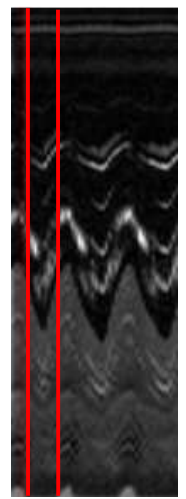

(e)

Figura 5.3: (a) Imagem coronal com uma linha vertical exibindo a posição da sequência sagital exibida em (c) e (d). (b) Imagem 2DST da sequência coronal com a linha vertical exibindo o instante da imagem exibida em (a). (c)-(d) Imagens sagitais com uma linha vertical exibindo a posição da sequência coronal exibida em (a). (e) Imagem 2DST da sequência sagital com duas linhas verticais exibindo os instantes das imagens exibidas em (c) e (d).

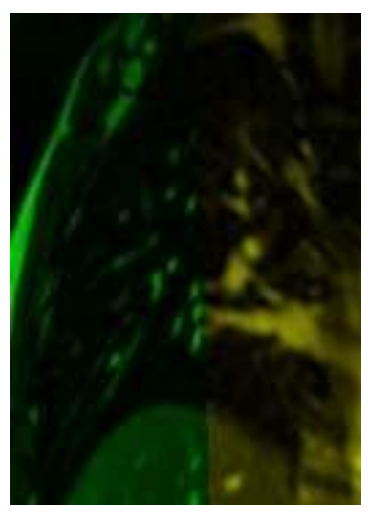

(a)

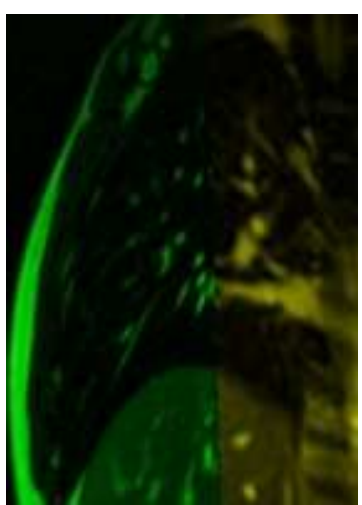

(b)

Figura 5.4: (a) Composição 3D da imagem coronal exibida na Fig. 5.3.(a) e da imagem sagital exibida na Fig. 5.3.(c). Ambas as imagens estão na mesma fase inalatória. (b) Composição tridimensional da imagem coronal exibida na Fig. 5.3.(a) e da imagem sagital exibida na Fig. 5.3.(d). As imagens estão em fases respiratórias distintas. 


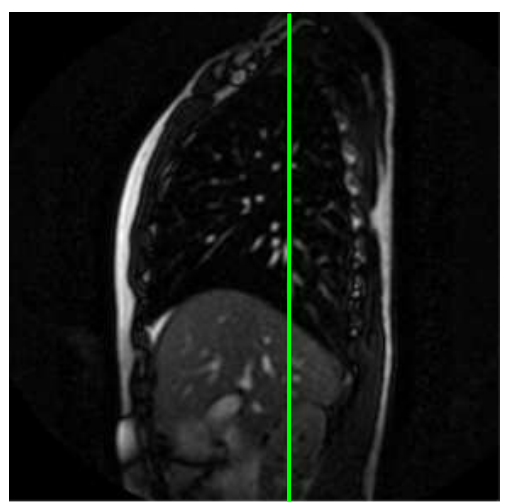

(a)

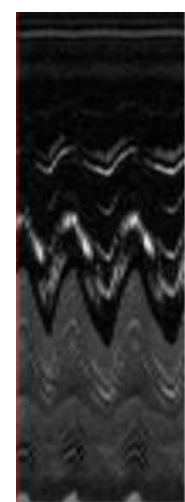

(b)

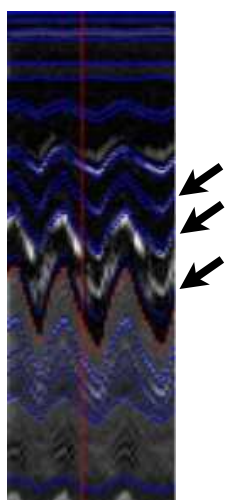

(c)

Figura 5.5: (a)Uma imagem sagital exibindo o local em que a imagem 2DST foi obtida. (b) Imagem 2DST. (c) 21 padrões respiratórios detectados. As setas indicam alguns padrões respiratórios detectados pela transformada de Hough que são a composição de estruturas internas diversas.

imagens sagitais. As artérias e brônquios são principalmente perpendiculares às imagens sagitais ${ }^{[13]}$. A Fig. 5.5.(a) exibe uma imagem sagital com uma linha vertical onde a imagem 2DST foi retirada. Vários padrões respiratórios são externos ao pulmão, e não são utilizados no registro temporal. A transformada de Hough modificada detecta a presença de padrões respiratórios em situações definidas pela composição de estruturas pulmonares internas diversas. A Fig. 5.5.(c) exibe com setas alguns padrões respiratórios destas estruturas pulmonares internas. Entretanto, o registro de estruturas internas é uma atividade muito mais complexa que não foi realizada neste trabalho. É possível observar que o contorno superior ("apex") e a superfície diafragmática se movimentam com uma diferença de fase de $180^{\circ}$.

Os padrões respiratórios a serem utilizados no registro temporal foram selecionados manualmente. A superfície diafragmática e o contorno superior ("apex") criam padrões respiratórios identificáveis nas imagens 2DST. Estes dois padrões respiratórios e a fase respiratória precisam coincidir para que haja um registro correto. Adicionalmente, os padrões respiratórios originados exclusivamente de estruturas pulmonares internas podem ser utilizados no registro temporal, mesmo se a estrutura não puder ser identificada no outro tipo de imagem (coronal ou sagital). 


\section{$6 \quad$ Resultados e Discussões}

As sequências de imagens de RM utilizadas no experimento foram obtidos pelo Symphony (1.5T) feito pela Siemens, utilizando o método trueFISP (Fast Imaging with Steady State Precession). As imagens de RM foram obtidas a partir de seis indivíduos saudáveis não fumantes. A tabela 6.1 mostra algumas características das imagens obtidas dos indivíduos. As imagens iniciais em conjuntos de dados dinâmicos foram adquiridas no estado transiente da magnetização, assim elas têm intensidade de sinal e contraste diferentes. A análise considerou todas as imagens adquiridas, incluindo as imagens iniciais. A Fig. 6.1 mostra um exemplo do resultado em que a transformada de Hough intervalar descobriu 21 padrões respiratórios e apenas 3 ou 4 padrões respiratórios foram, respectivamente, selecionados nas imagens 2DST coronais e sagitais.

Stevo et al. ${ }^{[5]}$ compararam linhas verticais das imagens 2DST utilizando duas abordagens diferentes: pixel por pixel e transformada discreta de Fourier. As mesmas sequências temporais exibidas na Fig. 5.3 são usadas para explicar alguns resultados obtidos pela abordagem de comparação pixel a pixel. A Fig. 6.2.(a) mostra um gráfico com os pixels no eixo horizontal e com a diferença de intensidade dos pixels no eixo vertical. Há 50 gráficos sobrepostos e cada gráfico compara o segmento intersectante da $7^{\mathrm{a}}$ imagem coronal (representada pela linha vermelha

Tabela 6.1: Caracterização das sequências de imagens de RM coronal e sagital utilizadas nos experimentos obtidos a partir de seis indivíduos saudáveis. Todas as sequências tem $256 \times 256$ pixels, tempo de repetição de $2.33 \mathrm{~ms}$, tempo de eco de $1.16 \mathrm{~ms}$, a espessura de corte de $10 \mathrm{~mm}$ e o número de imagens em cada sequência é de 50

\begin{tabular}{ccccc}
\hline Ind. & fov - cor $(\mathrm{mm})$ & fov - sag $(\mathrm{mm})$ & tempo total $(\mathrm{s})$ & idade \\
\hline A & $420 \times 420$ & $380 \times 380$ & 17 & 31 \\
\hline B & $420 \times 420$ & $380 \times 380$ & 11 & 31 \\
\hline C & $420 \times 420$ & $380 \times 380$ & 11 & 24 \\
\hline D & $450 \times 450$ & $450 \times 450$ & 27 & 58 \\
\hline E & $420 \times 420$ & $380 \times 380$ & 11 & 50 \\
\hline F & $450 \times 450$ & $450 \times 450$ & 11 & 28 \\
\hline
\end{tabular}




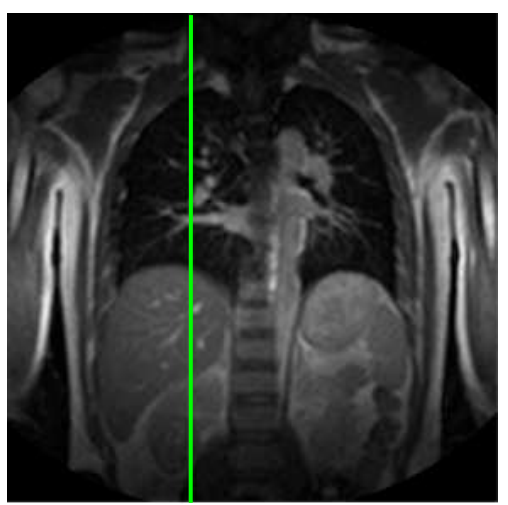

(a)

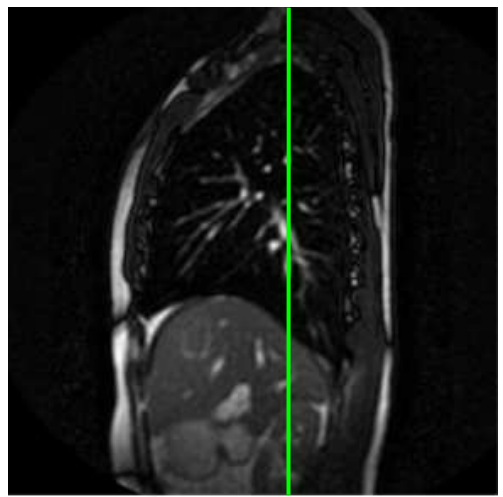

(c)

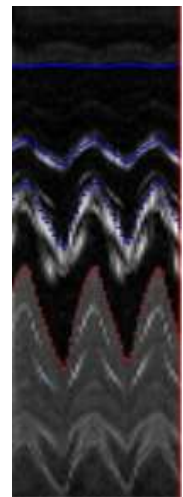

(d)

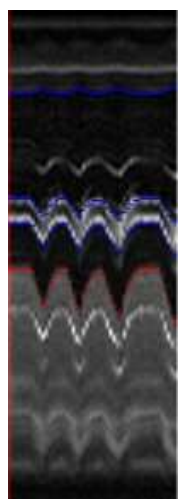

(b)

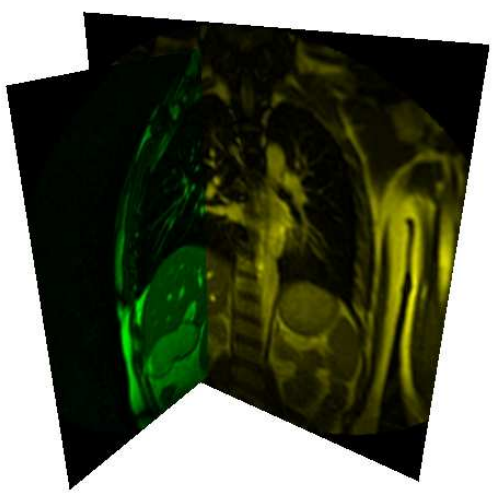

(e)

Figura 6.1: (a)-(b) A imagem coronal tem uma linha vertical mostrando onde uma imagem 2DST foi obtida. A transformada de Hough intervalar encontrou 21 padrões respiratórios e apenas 3 padrões foram selecionados para o registro temporal (c)-(d) A imagem sagital tem uma linha vertical que mostra onde uma imagem 2DST foi obtida. A transformada de Hough intervalar encontrou 21 padrões respiratórios e apenas 4 padrões respiratórios foram selecionados para o registro temporal. (e) Resultado do registro temporal. 


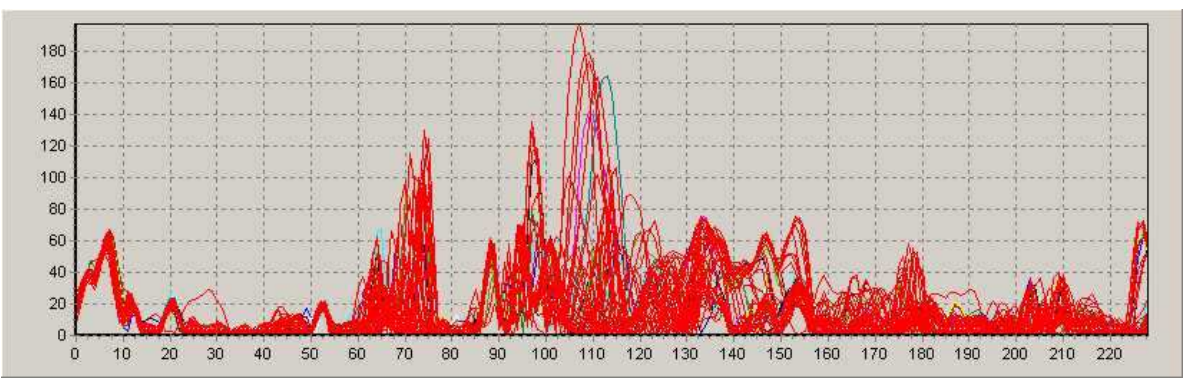

(a) Gráficos para todas as 50 imagens sagitais e as suas diferenças entre as intensidades dos pixels quando comparada à $7^{\mathrm{a}}$ imagem coronal.

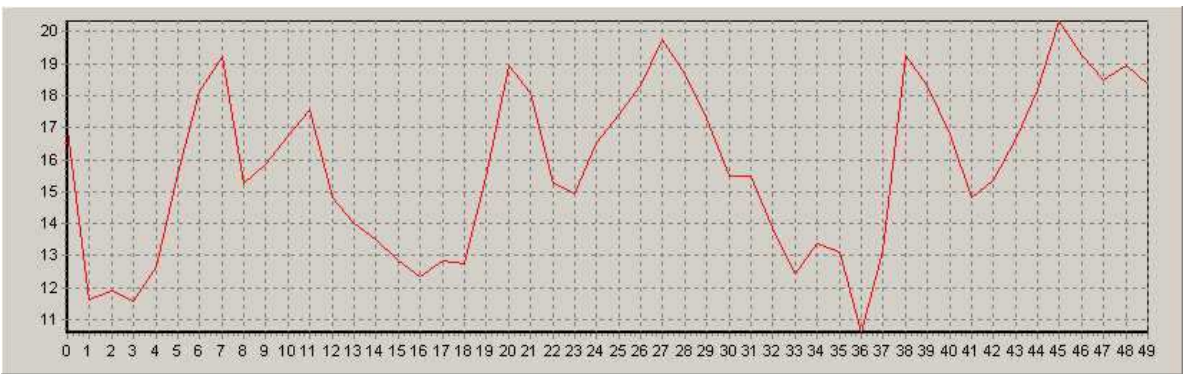

(b) Média da diferença de intensidade dos pixels para todas as 50 imagens sagitais quando comparadas à $7^{\text {a }}$ imagem coronal.

Figura 6.2: Gráficos exibindo a diferença de intensidade dos pixels de toda imagem sagital na sequência temporal em relação a $7^{\text {a }}$ imagem coronal.

na Fig. 5.3.(b)) com o segmento intersectante de uma imagem sagital contida na sua sequência temporal de imagens. Cada gráfico representa a diferença entre a intensidade de pixels de uma forma pixel a pixel. É possível de se observar que todos os pixels entre as linhas 0 a 60 exibiram quase nenhuma variação no tempo. As sequências coronais e sagitais apresentam algumas diferenças na intensidade dos pixels como consequência das suas configurações.

Sejam duas imagens 2DST, uma coronal e a outra sagital, e definindo as intensidades dos pixels destas imagens como $I_{s}\left(t_{s}, y\right)$ and $I_{c}\left(t_{c}, y\right)$. Então a média da diferença de intensidade dos pixels pode ser definida pela seguinte equação

$$
e=\sum_{y}^{n}\left\|I_{s}\left(t_{s}, y\right)-I_{c}\left(t_{c}, y\right)\right\| / n
$$

onde $e$ é a média da diferença de intensidade dos pixels, ou média da distância dos pixels, e $n$ é o número de pixels intersectantes. A Fig. 6.2.(b) mostra um gráfico onde 50 imagens sagitais são representadas no eixo horizontal e o eixo vertical representa a média da diferença de intensidade dos pixels. O gráfico representa a média das diferenças da intensidade dos pixels entre a $7^{\mathrm{a}}$ imagem coronal e todas as 50 imagens sagitais. Neste exemplo, a $36^{\mathrm{a}}$ imagem sagital tem 


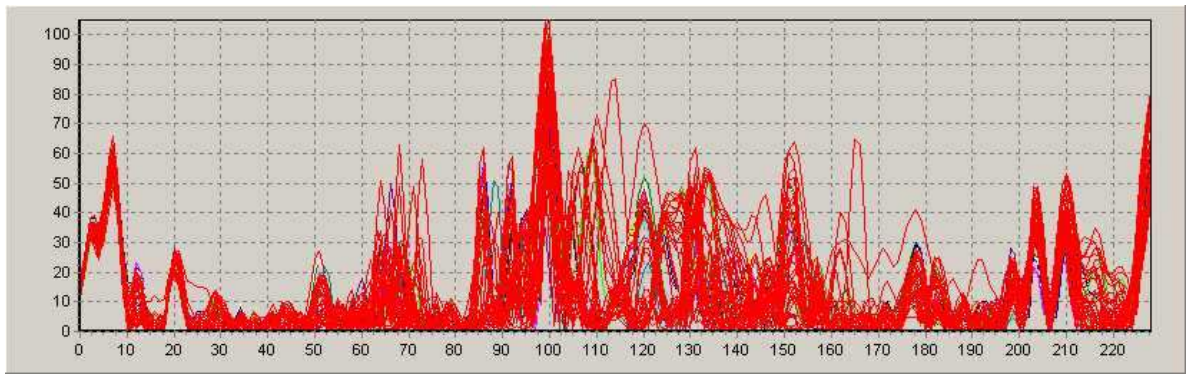

(a) Gráficos para todas as 50 imagens coronais e as as suas diferenças entre as intensidades dos pixels quando comparada à $36^{\mathrm{a}}$ imagem sagital.

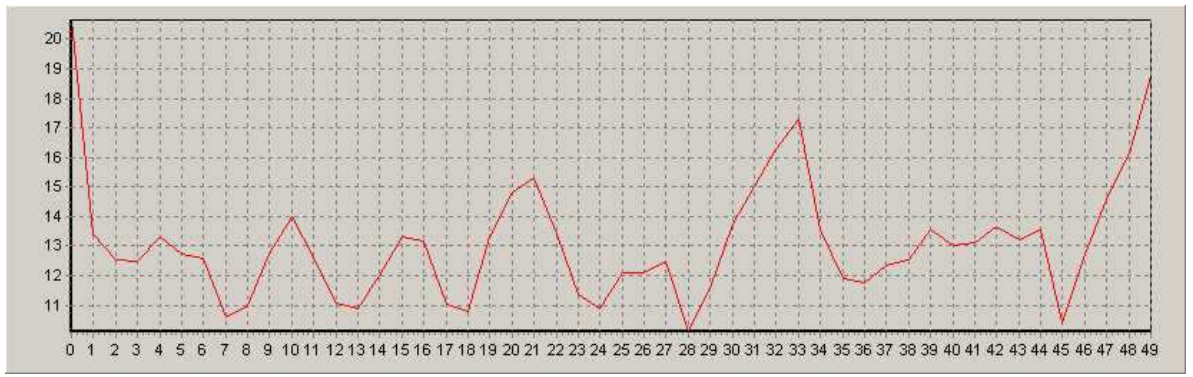

(b) Média da diferença de intensidade dos pixels para todas as 50 imagens coronais quando comparadas à $36^{\mathrm{a}}$ imagem sagital.

Figura 6.3: Gráficos exibindo a diferença de intensidade dos pixels de toda imagem coronal na sequência temporal em relação a $36^{a}$ imagem sagital.

a menor média da diferença de intensidade dos pixels, e nenhuma idéia a respeito da existência de outras possibilidades pode ser estabelecida.

Similarmente, as Figs. 6.3.(a) e 6.3.(b) exibem gráficos comparando a $36^{\mathrm{a}}$ imagem sagital com todas as 50 imagens coronais na sequência temporal. A Fig. 6.3.(b) exibe que a $28^{\mathrm{a}}$ e a $45^{\mathrm{a}}$ imagens possuem uma média da diferença da intensidade dos pixels menor que a $7^{\mathrm{a}}$ imagem, e o par com a menor média da diferença da intensidade dos pixels é a $28^{\mathrm{a}}$ coronal e a $36^{\mathrm{a}}$ sagital. Entretanto, o par da $7^{\mathrm{a}}$ coronal e $36^{\mathrm{a}}$ sagital, obtido anteriormente do gráfico da Fig. 5.3.(b), também é uma possibilidade. As Figs. 6.5.(a) e 6.5.(b) exibem a composição tridimensional de ambos os pares das imagens. Porém, em algumas situações específicas, não é possível determinar um par de imagens com uma média da diferença da intensidade dos pixels de valor razoável. E além do mais, não é possível determinar se a imagem desejada está entre duas imagens. A transformada de Fourier discreta obteve resultados semelhantes a estes.

Estes resultados do método de comparação pixel a pixel, mostram que o mapeamento de similaridade não é comutativo. A $7^{\text {a }}$ imagem coronal é mais similar a 36 imagem sagital, porém, no sentido oposto não é válida esta afirmação. A $36^{\mathrm{a}}$ imagem sagital é mais similar à $28^{\mathrm{a}}$ imagem coronal. As Figs. 6.4.(a) e 


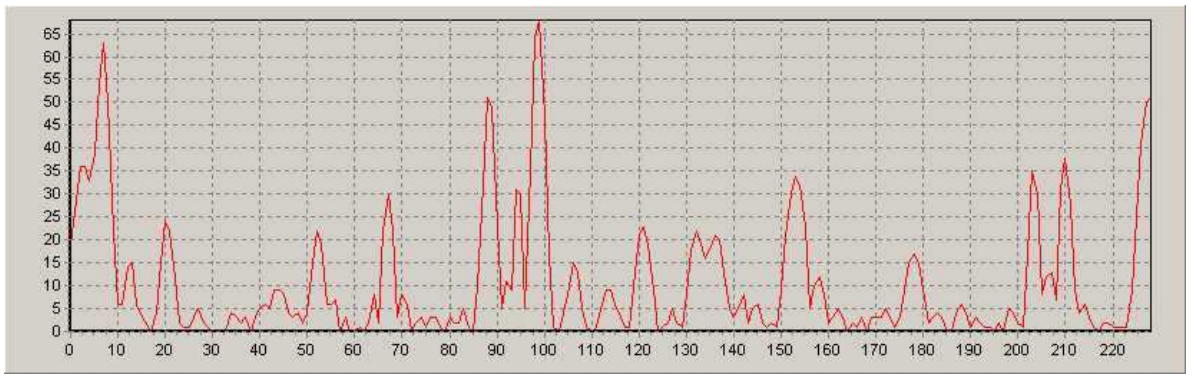

(a) Gráfico comparando a diferença entre as intensidades dos pixels entre a $36^{\mathrm{a}}$ imagem sagital e a $7^{\text {a }}$ imagem coronal.

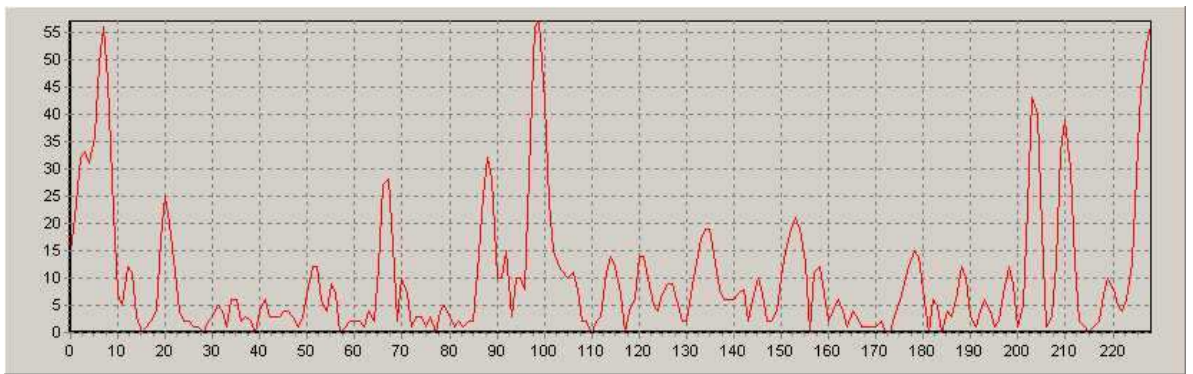

(b) Gráfico comparando a diferença entre as intensidades dos pixels entre a $36^{a}$ imagem sagital e a $28^{\mathrm{a}}$ imagem coronal.

Figura 6.4: Gráficos de comparação entre as $7^{\mathrm{a}}$ e $28^{\mathrm{a}}$ imagens coronais e a 36 imagem sagital.

6.4.(b) exibem um gráfico com a distância entre os pixels entre a $36^{\mathrm{a}}$ imagem sagital e, respectivamente, a $7^{\mathrm{a}}$ e $28^{\mathrm{a}}$ imagens.

A Fig. 6.6 mostra três gráficos que foram obtidos utilizando a abordagem proposta. Nele é representada a diferença entre o nível diafragmático de uma imagem coronal (sagital) específica e o padrão respiratório determinado na sequência temporal de imagens sagitais (coronais). As mesmas situações analisadas nas Figs. 6.2(a)-(b), Figs. 6.3(a)-(b) e Figs. 6.4(a)-(b) é representado aqui. Quando o gráfico intersecta o eixo $x$ ocorre um casamento entre os padrões respiratórios associados à superfície diafragmática. A fase respiratória é muito nítida nestes gráficos resultantes. Considerando o gráfico associado com a $7^{a}$ imagem coronal, o registro ocorre com as imagens sagitais 3 e 36. Verifica-se também um possível registro entre as imagens sagitais 17 e 18. As Figs. 6.7.(a)-(f) exibem alguns pares de registro adicionais.

O algoritmo de registro temporal proposto neste trabalho possui resultados melhores que o algoritmo proposto por Stevo et al. ${ }^{[5]}$. A abordagem proposta por Stevo et al. ${ }^{[5]}$ são baseadas em um registro considerando apenas a intensidade dos pixels que são fortemente afetados pelos efeitos de desfocamento e "fantasmas". O algoritmo de registro temporal proposto aqui utiliza informações de alto nível 


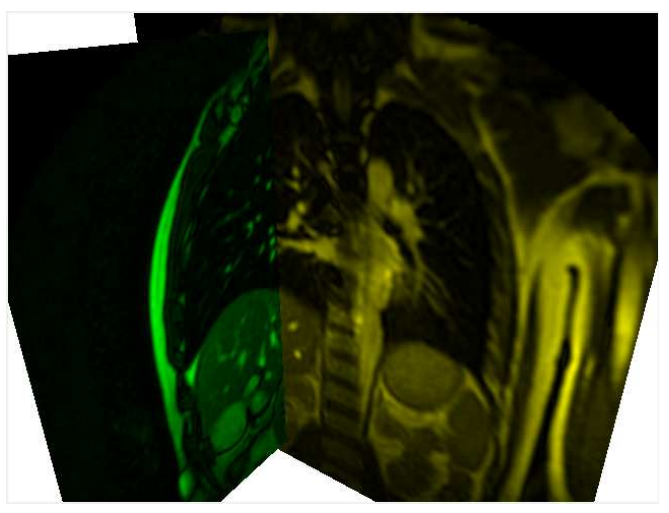

(a)

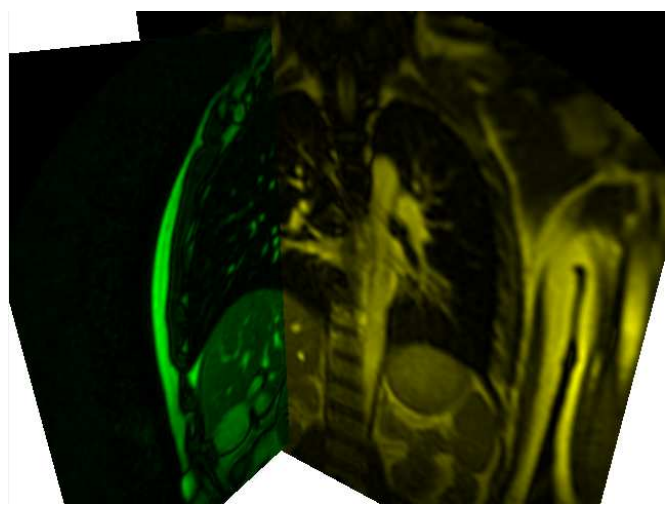

(b)

Figura 6.5: Composição tridimensional dos pares das imagens obtidas a partir do método de comparação de pixel a pixel proposto por Neylor et al. ${ }^{[5]}$. (a) A $36^{a}$ imagem sagital e a $7^{a}$ imagem coronal. (b) A $36^{a}$ imagem sagital e a $28^{a}$ imagem coronal.

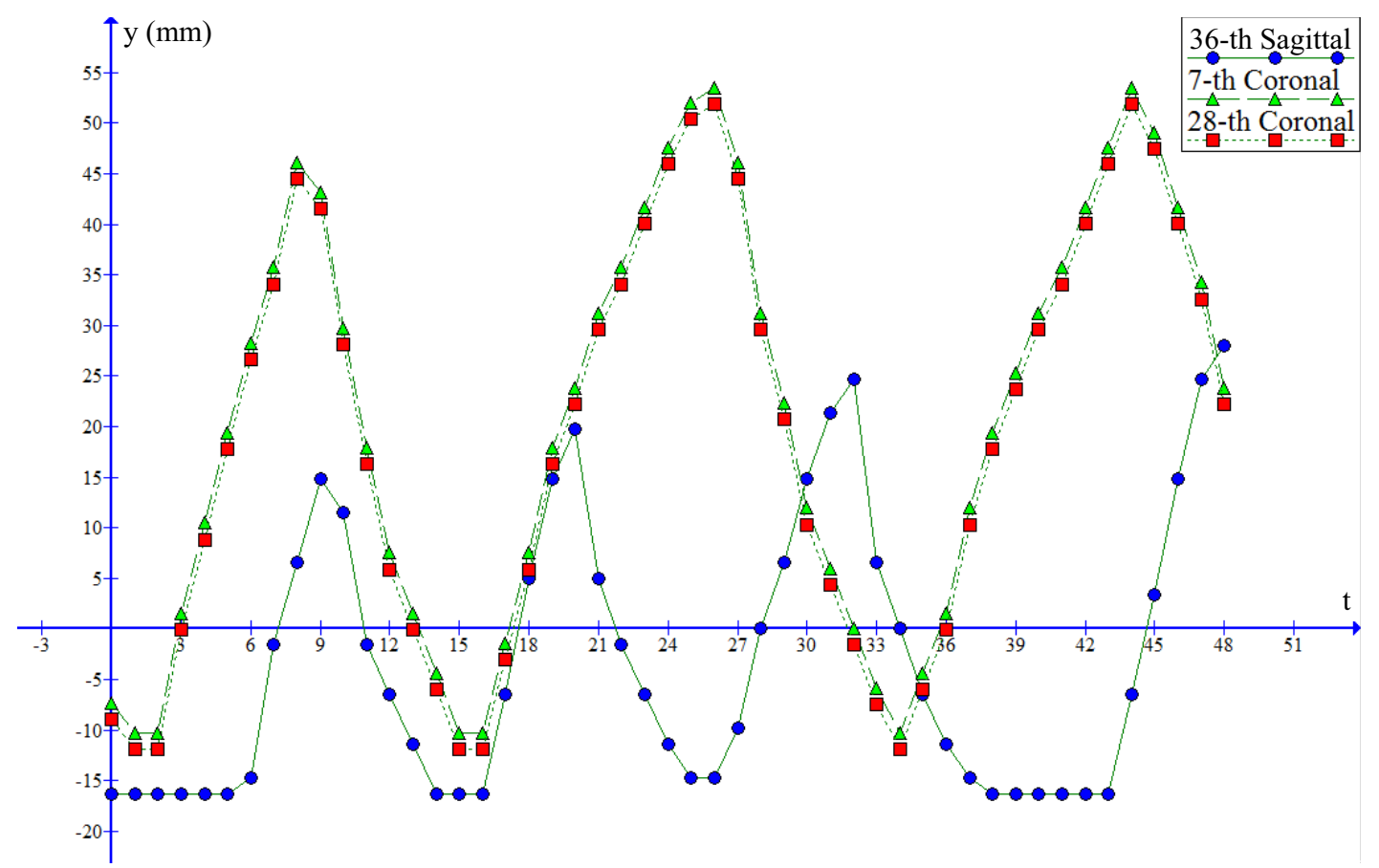

Figura 6.6: Cada gráfico representa a diferença entre um valor constante representando o padrão respiratório associado à superfície diafragmática de uma imagem sagital (coronal) específica ( $37^{a}$ sagital, $7^{a}$ coronal e $28^{a}$ coronal) e o padrão respiratório associado à superfície diafragmática de uma sequência temporal de imagens coronais (sagitais). 


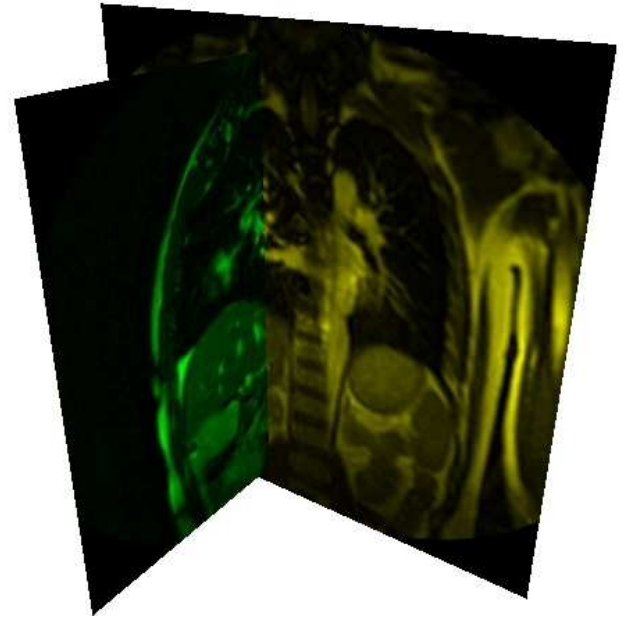

(a)

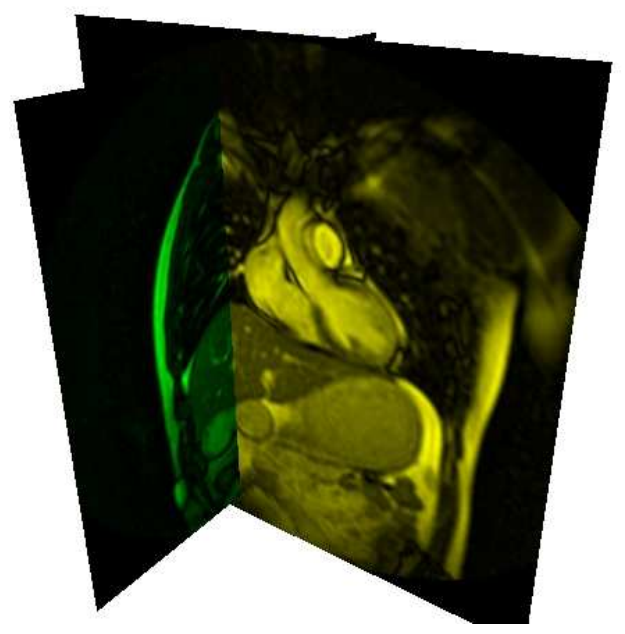

(c)

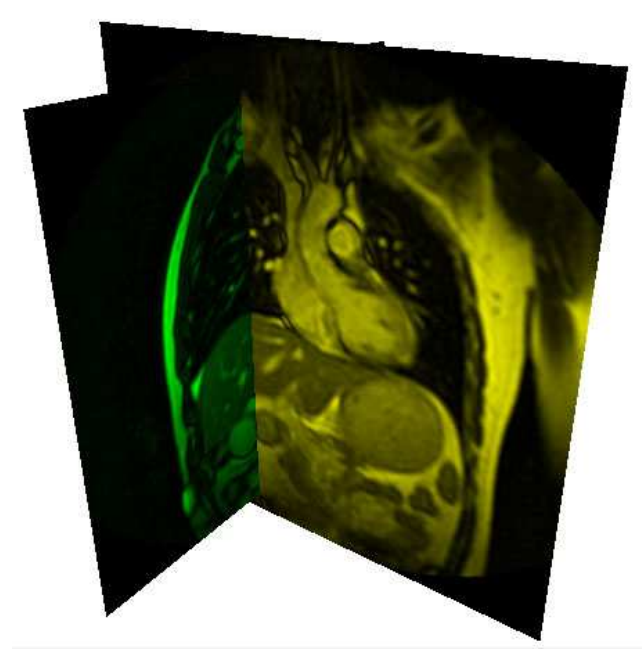

(e)

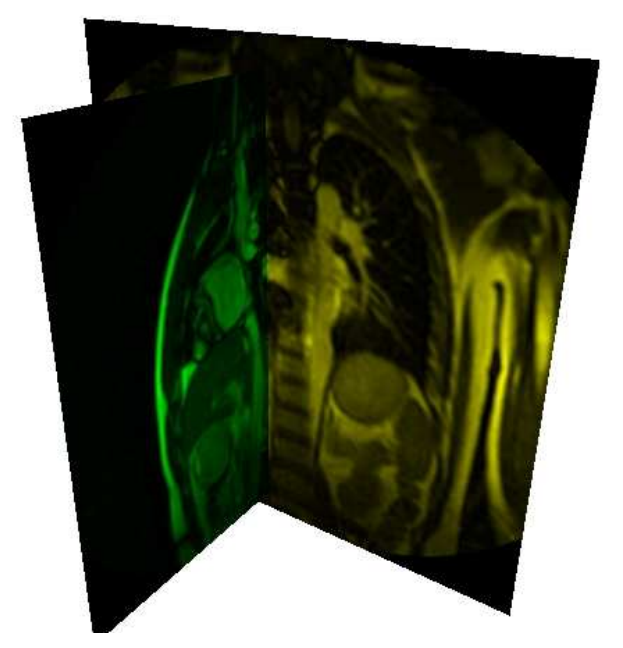

(b)

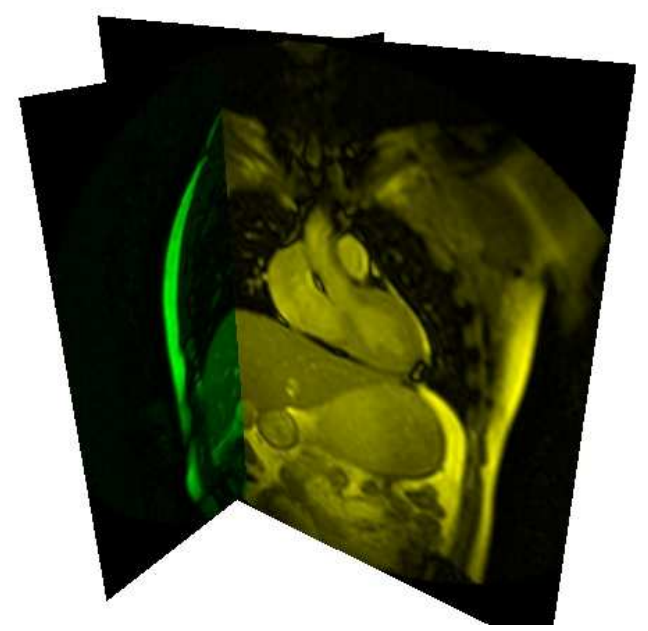

(d)

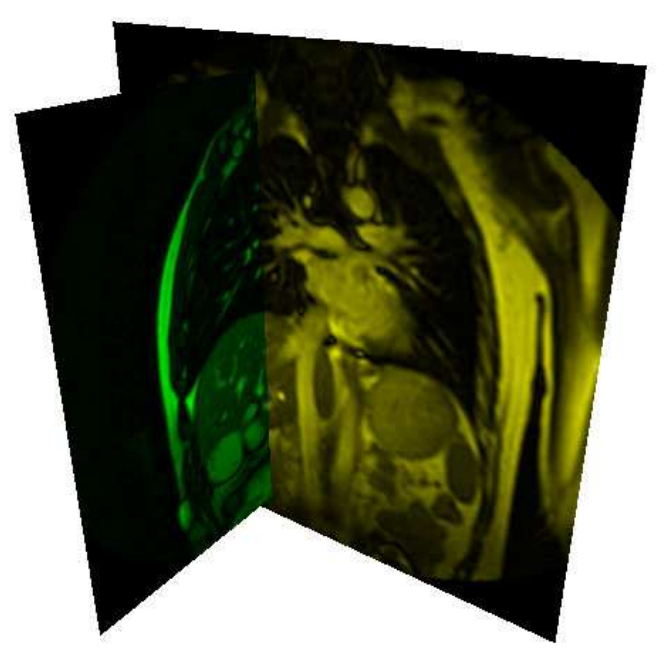

(f)

Figura 6.7: (a)-(f) Exemplos de pares de registro resultantes do algoritmo proposto. 


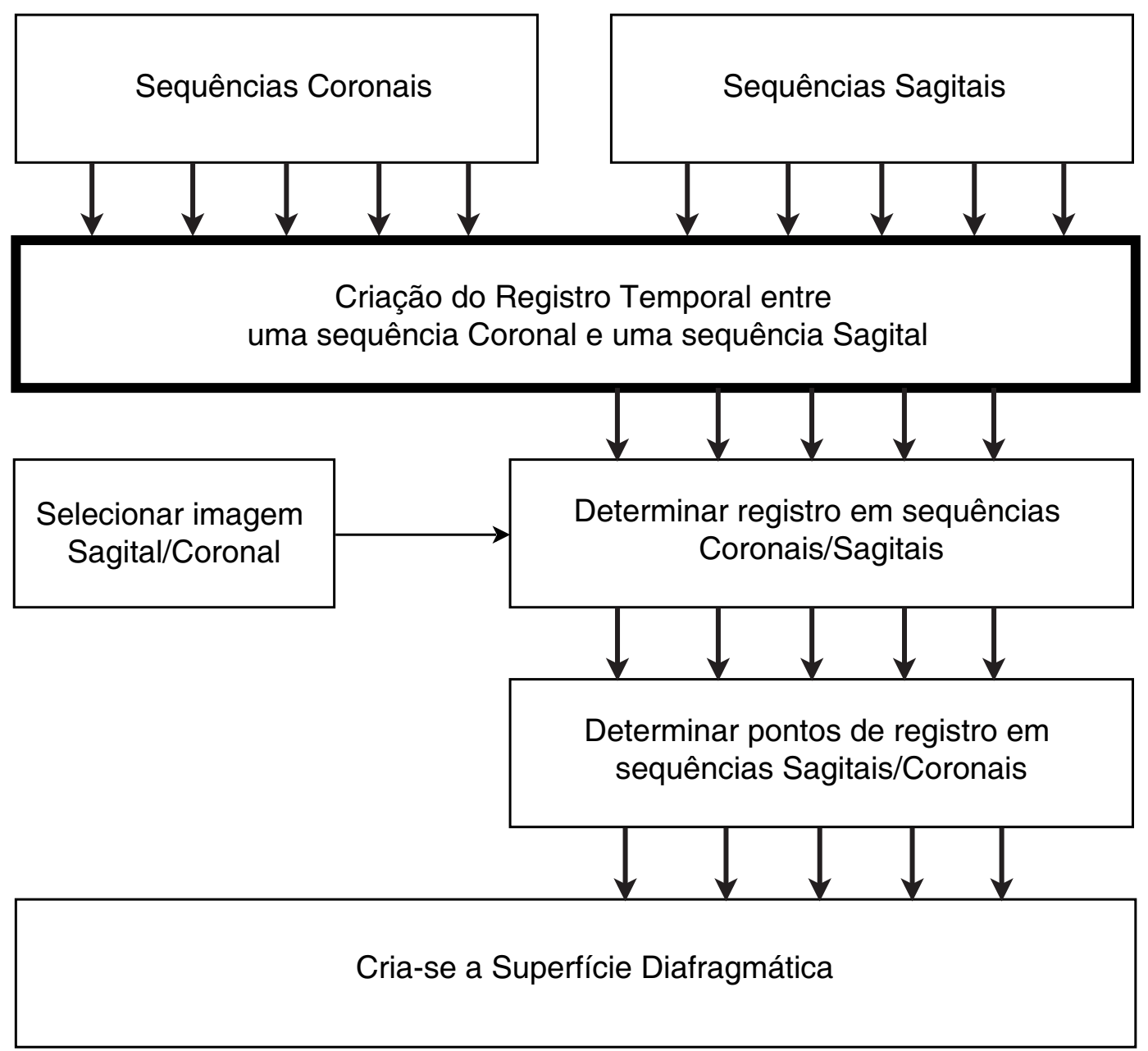

Figura 6.8: Determinação da superfície diafragmática através do registro múltiplo entre sequências coronais e sagitais. O algoritmo do registro múltiplo consiste em: seleção de uma sequência e imagem base, localização dos pontos da sequência base que interseccionam outras sequências e obtenção dos pontos intersectantes das melhores imagens correspondentes.

a respeito das estruturas do pulmão e determina imagens que exclusivamente façam uma composição excelente. A abordagem proposta detectou um grande número de pares de registro, permitindo assim a determinação de um possível par de registro entre duas imagens consecutivas na sequência temporal.

Considerando que possuímos 25 sequências de imagens sagitais e 31 sequências de imagens coronais para um mesmo indivíduo, obtidas em instantes de tempo diferentes, e cada sequência possui 50 imagens sequenciais. O algoritmo para registro entre sequências foi aplicado $25 \times 31=775$ vezes combinando as sequências sagitais e coronais. É importante salientar que alguns pares de sequências não possuem a superfície diafragmática, e portanto não existe registro para este par. A superfície diafragmática será reconstruída pela aplicação do algoritmo registro múltiplas vezes. Inicialmente seleciona-se uma sequência sagital (ou coronal), e determina-se o registro temporal entre todas as 31 sequências coronais (ou 25 
sequências sagitais). Posteriormente, aplica-se o algoritmo de registro para cada uma das 31 sequências coronais (ou 25 sequências sagitais) combinando com as outras 25 sequências sagitais (ou 31 sequências coronais). A Fig. 6.8 exibe uma breve descrição deste algoritmo. As Figs. 6.9 (a)-(d) mostram quatro superfícies diafragmáticas tendo como base 4 imagens coronais sequenciais. Nestas superfícies obtidas, foram utilizadas como base imagens coronais que possuíam alguns pontos da superfície diafragmática detectados com imprecisão, ocasionando uma superfície diafragmática tridimensional com uma quantidade elevada de imperfeições, como pode ser observado nas Figs. 6.9 (a)-(d). As Figs. 6.10 (a)-(d) mostram quatro superfícies diafragmáticas tendo como base 4 imagens sagitais sequenciais. Nestas superfícies obtidas observa-se que os resultados são de melhor qualidade, já que nas imagens sagitais utilizadas como base foi possível de se obter todos os pontos de registro da superfície diafragmática. As Figs. 6.11 (a)-(d) exibem a superfície diafragmática da Fig. 6.10 (c) juntamente com a sua imagem sagital base e uma imagem coronal que possui o melhor registro para aquela intersecção.

Vários autores fazem suposições sólidas sobre a regularidade do movimento respiratório e parametrizam esse movimento como um deslocamento ou período unidimensional, muito semelhante à função respiratória padrão proposta aqui. Embora a respiração mostre claramente um carácter repetitivo, a redução da deformação de órgãos respiratórios em um parâmetro ignora toda a complexa variabilidade dos órgãos e, em alguns casos, pode ser uma aproximação muito grosseira. Isto leva a artefatos nas imagens reconstruídas e consideráveis incerte$\operatorname{zas}^{[42-44]}$.

Siebenthal ${ }^{[45]}$ rastreou estruturas vasculares do fígado presentes em imagens sagitais durante os ciclos de respiração completa, e usou uma fatia "navigator" que continha vasos transversais que são distribuídos por toda a fatia do fígado e que são facilmente rastreáveis. Ele acompanhou o movimento das estruturas vasculares do fígado no espaço bidimensional. Vários autores usaram uma abordagem semelhante para rastrear as estruturas internas do pulmão nas sequências de imagens obtidas a partir de TC ${ }^{[10,46-48]}$, e não foi possível de se encontrar uma abordagem semelhante para as imagens do pulmão obtidos a partir de RM.

A abordagem proposta aqui tem a convicção de que o padrão respiratório associado à superfície diafragmática e ao limite superior estão registrados na fase de respiração correta. Quando disponível em ambas as imagens (coronal e sagital), algumas estruturas internas do pulmão também apresentam um casamento. Uma desvantagem é o fato de, atualmente, os padrões respiratórios resultantes da transformada de Hough intervalar serem manualmente filtrados. 

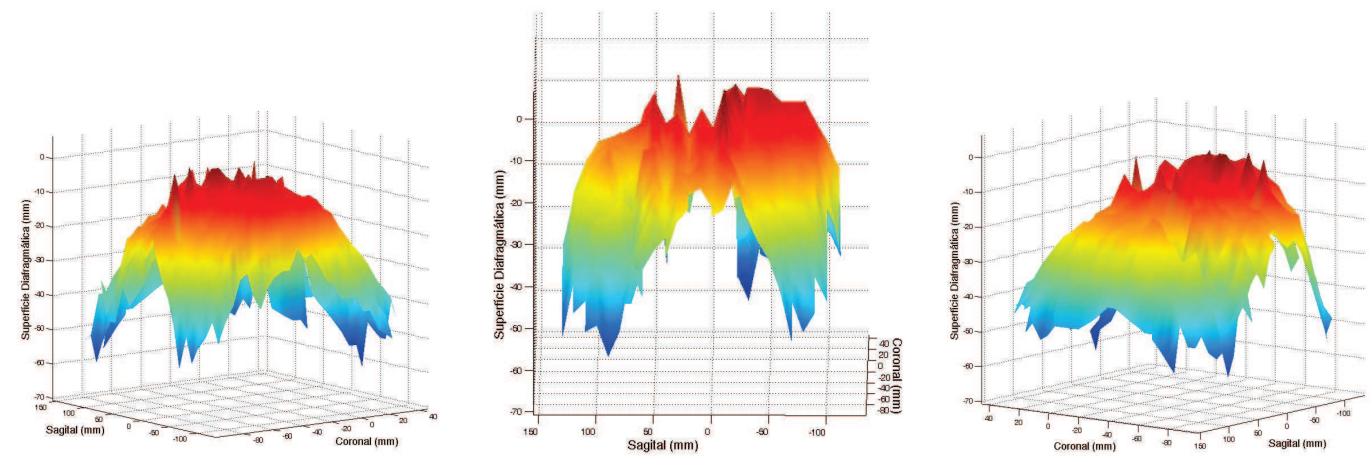

(a)
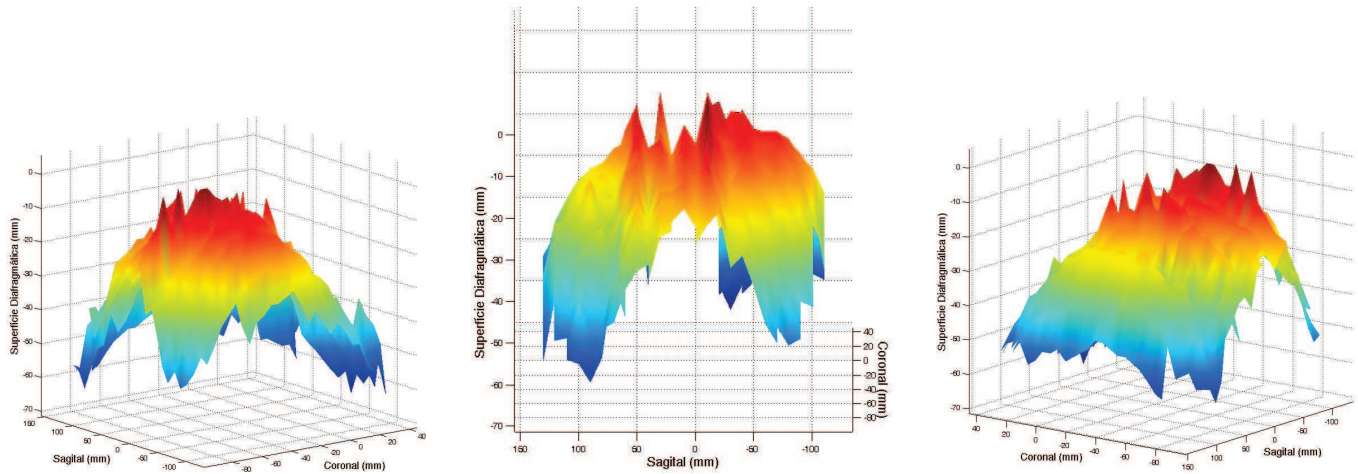

(b)
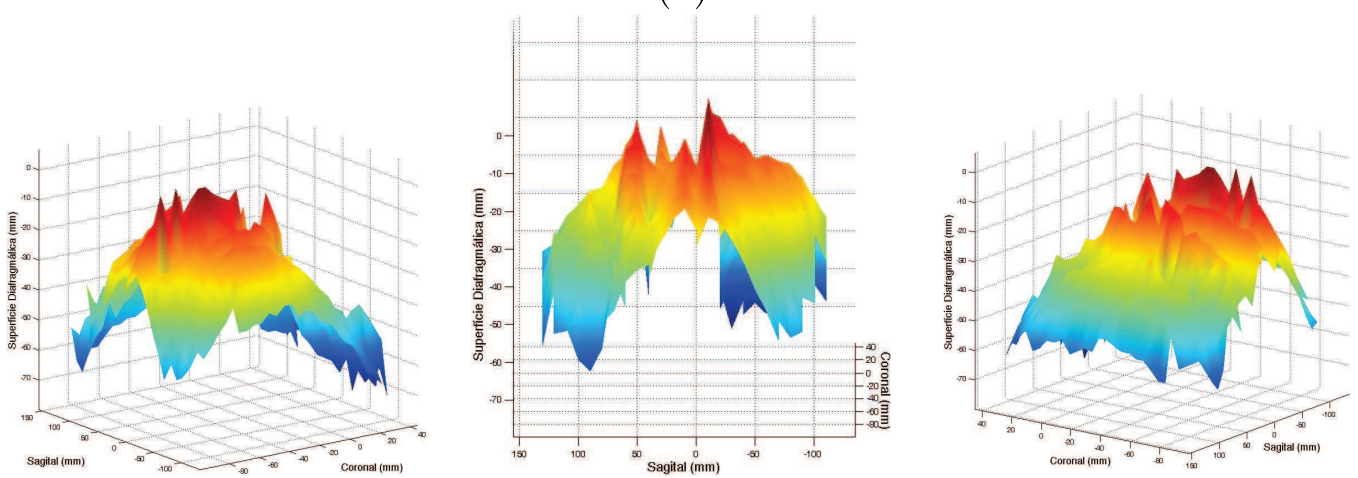

(c)
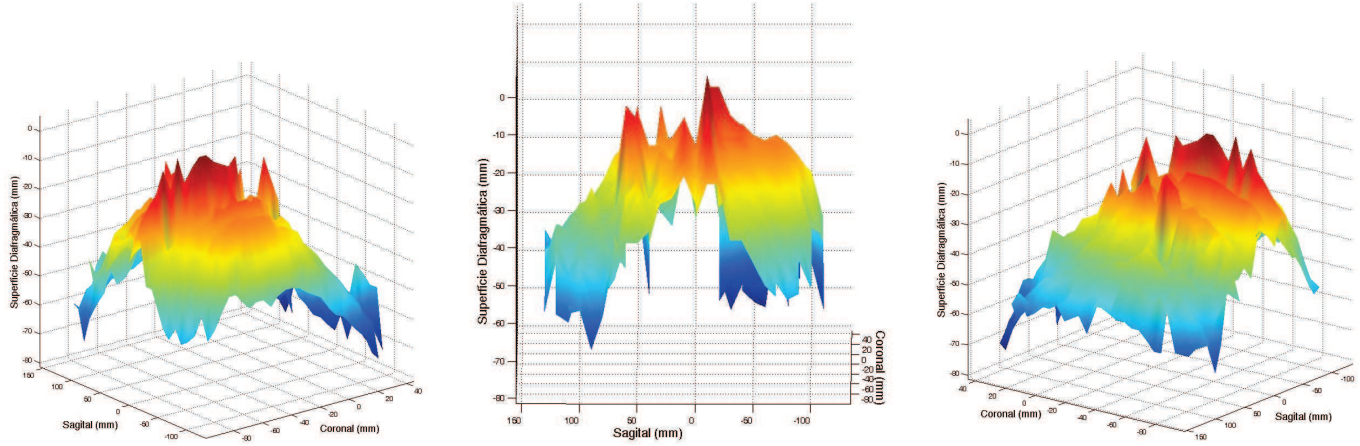

(d)

Figura 6.9: (a)-(d) Sequência de superfícies diafragmáticas tendo como base 4 imagens coronais sequenciais. A escala de cores representa o nível diafragmático. 

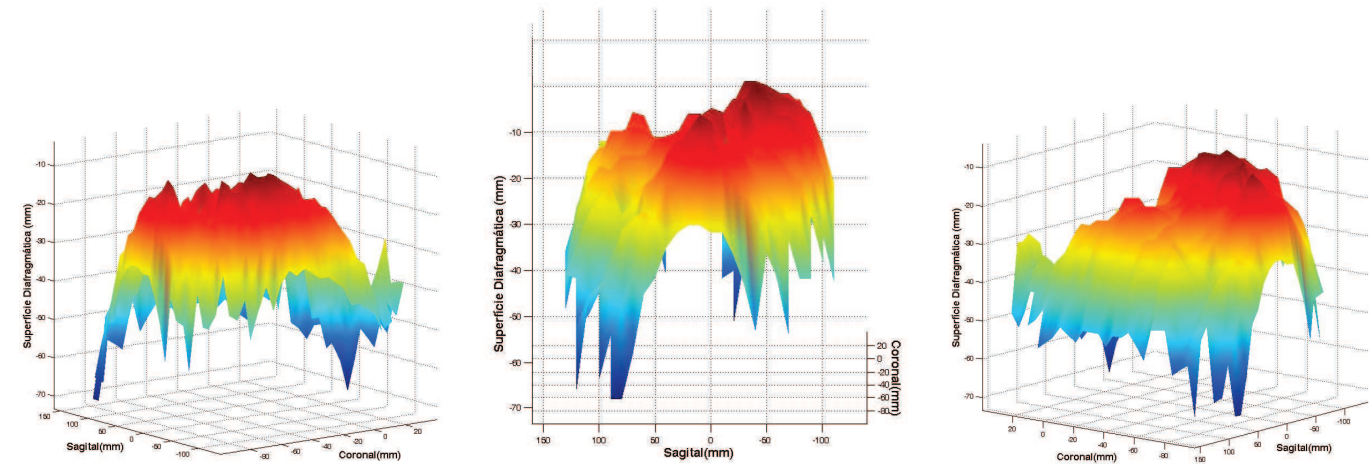

(a)
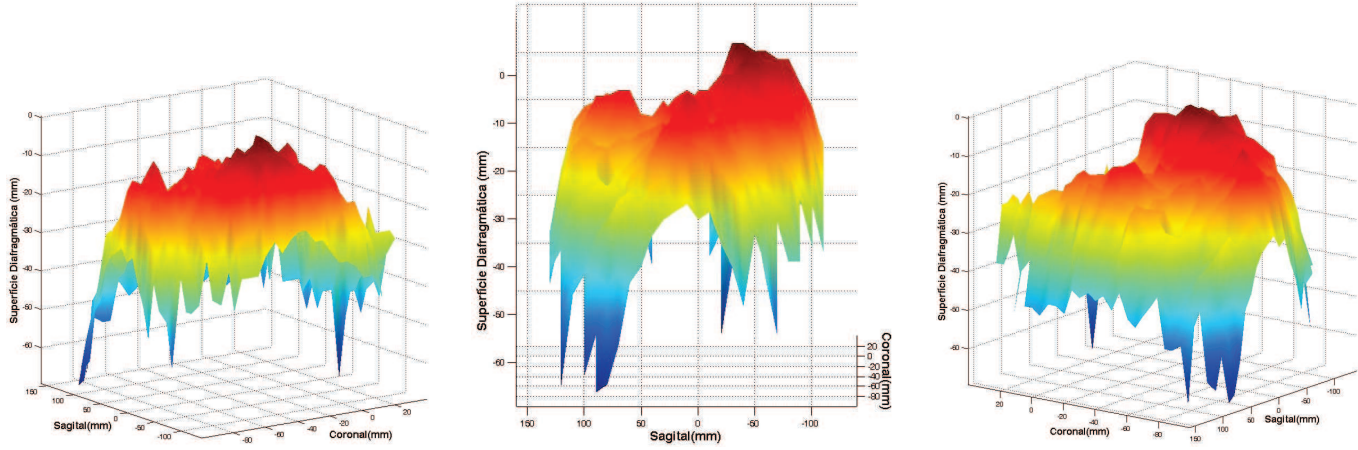

(b)
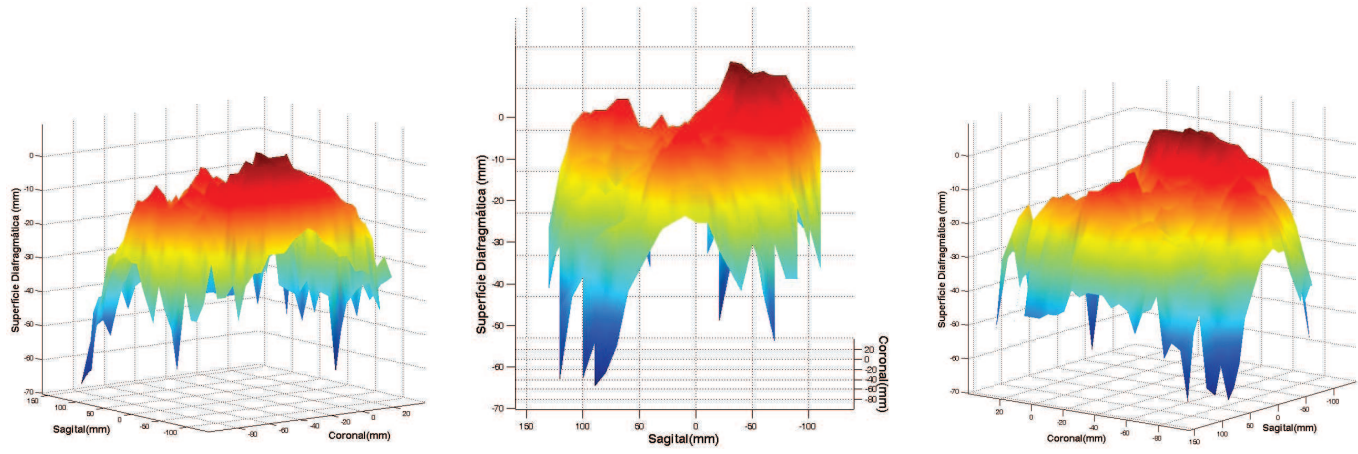

(c)
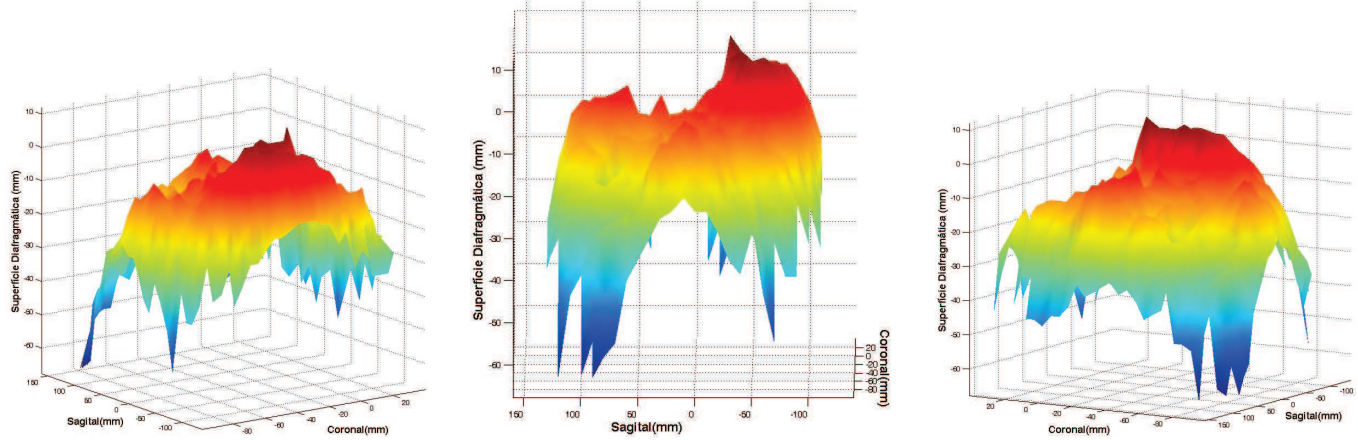

(d)

Figura 6.10: (a)-(d) Sequência de superfícies diafragmáticas tendo como base 4 imagens sagitais sequenciais. A escala de cores representa o nível diafragmático. 


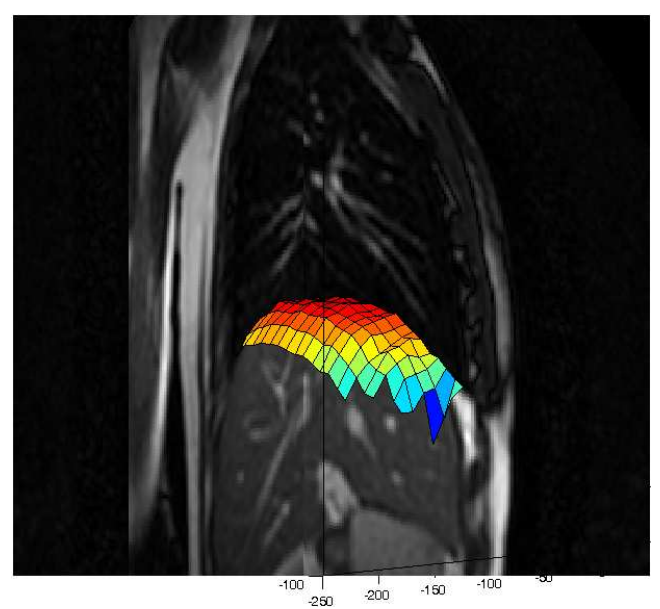

(a)

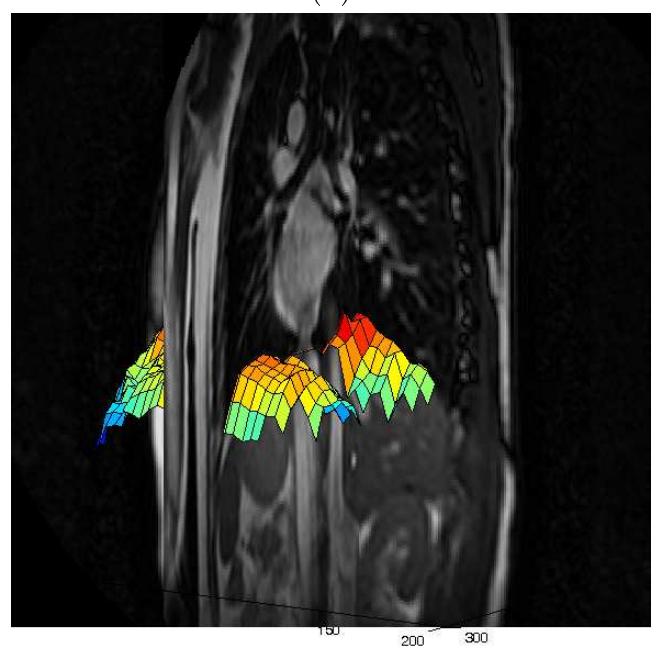

(c)

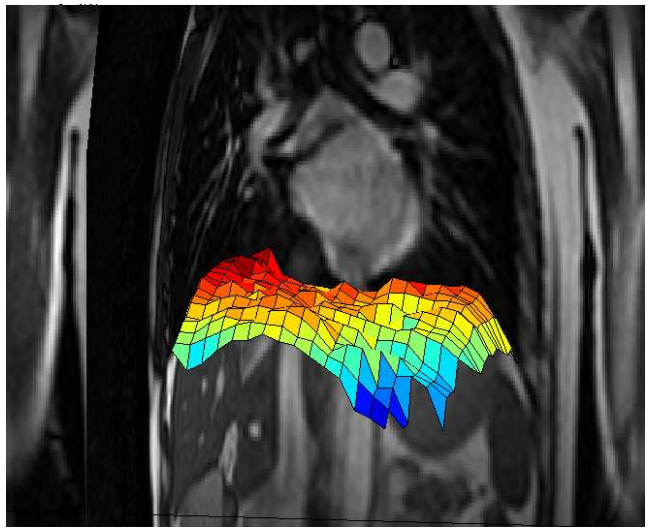

(b)

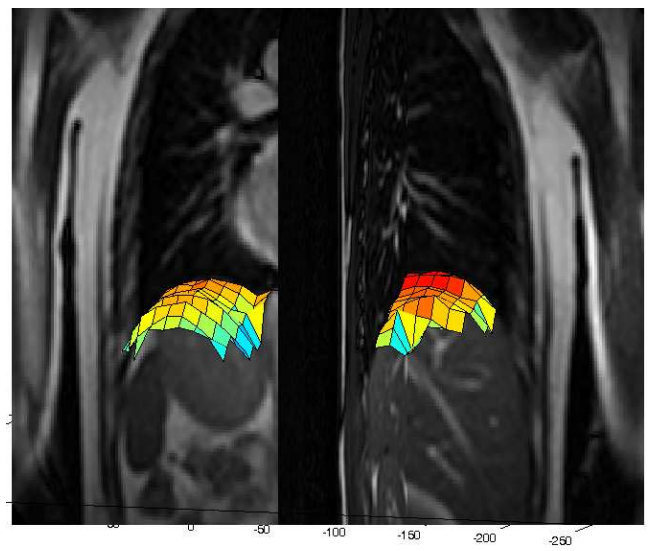

(d)

Figura 6.11: (a)-(d) Superfície diafragmática da Fig. 6.10 (c) juntamente com a sua imagem sagital base e uma imagem coronal que possui o melhor registro para aquela intersecção. 


\section{$7 \quad$ Conclusões}

Um método para a reconstrução animada tridimensional do pulmão utilizando imagens de RM sagitais e coronais adquiridas durante a respiração livre é proposto neste trabalho. Vários cortes sagitais e coronais são constituídos. Um requisito importante para a técnica de imagem desenvolvida foi a capacidade de manipular e visualizar a variabilidade do movimento do órgão.

A transformada de Hough intervalar em combinação com o algoritmo de contornos ativos "Snakes" determinou vários padrões respiratórios. Os padrões respiratórios associados ao diafragma e o limite superior (Apex) foram determinados.

Verificou-se que mesmo em situações em que um registro perfeito não existe, é possível determinar o nível diafragmático intermediário associado ao registro temporal. Portanto, comprovou-se eficaz o registro temporal baseado na comparação das superfícies do diafragma e do limite superior quando o pulmão está em fases de respiração compatíveis.

O casamento "diafragmático" entre duas imagens corresponde ao instante em que os padrões respiratórios associados à superfície diafragmática se correspondem. Assim, ao comparar os algoritmos de registro utilizando a comparação pixel a pixel e a transformada de Fourier com os algoritmos de registro utilizando a transformada de Hough, nota-se que a proposta baseada na transformada de Hough permite determinar múltiplos casamentos "diafragmáticos", se eles existirem. Também é possível determinar a ausência destes casamentos, e nesta situação o registro pode ser interpolado se o casamento "diaframático" existir e estiver entre duas imagens da sequência. As outras duas propostas identificam apenas o melhor casamento segundo a métrica adotada, e o melhor casamento pode não corresponder a um casamento "diafragmático".

Estas características do algoritmo de registro proposto, permitem a sua aplicação em sequência de modo a reconstruir a geometria da superfície diafragmática no tempo. 


\section{Apêndice A - Aritmética Intervalar}

Uma imagem digital, independente do formato, é formada por pixels e tem uma limitação de resolução. Isto é, não se consegue maior precisão do que a representada pelos pixels. Quando se captura uma imagem real e a transforma em uma imagem digital, a imagem gerada terá seu número de pixels e, portanto, resolução máxima definidos. Porém, o pixel acaba representando um intervalo da imagem real. O valor que ele apresenta não necessariamente é o valor de todo o intervalo que ele representa. Desta forma, por não representar corretamente a realidade, o pixel deve ser tratado como um intervalo, e a sua intensidade de cor é de um ponto dentro deste intervalo.

Além disso, trabalhar com intervalos tem outra vantagem sobre operações em ponto flutuante. Arredondamentos errados e não esperados podem afetar o resultado final. Utilizando intervalos, é possível de se controlar todas as operações feitas. Assim, a proposta feita é a utilização da aritmética intervalar para que a análise englobe, em todas as suas operações, ou, ao menos nas relevantes, tais erros. A seguir, serão apresentadas definições e operações básicas e principais da aritmética intervalar.

As operações em aritmética intervalar básicas são definidas como:

$$
\begin{gathered}
{[a, b]+[c, d]=[a+c, b+d]} \\
{[a, b]-[c, d]=[a-c, b-d]} \\
{[a, b] *[c, d]=[\min (a * c, a * d, b * c, b * d), \max (a * c, a * d, b * c, b * d)]} \\
\frac{[a, b]}{[c, d]}=\left[\min \left(\frac{a}{c}, \frac{a}{d}, \frac{b}{c}, \frac{b}{d}\right), \max \left(\frac{a}{c}, \frac{a}{d}, \frac{b}{c}, \frac{b}{d}\right)\right], \text { para } 0 \notin[c ; d]
\end{gathered}
$$


Porém, caso as operações internas sejam realizadas em ponto flutuante, não há garantia de que o arredondamento aplicado aos limites seja feito de forma que conserve o intervalo inteiro, e correto, dentro desses limites. Assim, o método de Aritmética de Intervalo Arredondado (Rounded-Interval Arithmetic) ${ }^{[49]}$ garante que o resultado final computado sempre contenha o intervalo exato, da seguinte forma:

$$
\begin{gathered}
{[a, b]+[c, d]=\left[a+c-\epsilon_{l}, b+d+\epsilon_{u}\right]} \\
{[a, b]-[c, d]=\left[a-c-\epsilon_{l}, b-d+\epsilon_{u}\right]} \\
{[a, b] *[c, d]=\left[\min (a * c, a * d, b * c, b * d)-\epsilon_{l}, \max (a * c, a * d, b * c, b * d)+\epsilon_{u}\right]} \\
\frac{[a, b]}{[c, d]}=\left[\min \left(\frac{a}{c}, \frac{a}{d}, \frac{b}{c}, \frac{b}{d}\right)-\epsilon l, \max \left(\frac{a}{c}, \frac{a}{d}, \frac{b}{c}, \frac{b}{d}\right)+\epsilon u\right], \text { para } 0 \notin[c ; d]
\end{gathered}
$$

Onde, $\epsilon_{l}$ e $\epsilon_{u}$ são as unidades na última posição (units-in-last-place), denotadas por ulpl e ulpu para cada número em ponto flutuante resultante de operações em ponto flutuante, dando os limites superior e inferior. Ao realizar operações comuns usando Aritmética de Intervalo Arredondado, o limite inferior é estendido, caso necessário, ao número em ponto flutuante imediatamente menor, o qual é menor por ulpl. De forma similar, o limite superior é estendido por ulpu para incluir o número imediatamente maior. Assim, o intervalo resultante é ampliado em $u l p l+u l p u$, e o resultado será confiável para as próximas operações.

Definição da intersecção de dois intervalos

$$
[a ; b] \cap[c ; d]= \begin{cases}\emptyset, & \text { se } \mathrm{a}>\mathrm{d} \text { ou } \mathrm{b}<\mathrm{c} \\ {[\max (a, c) ; \min (b, d)],} & \text { caso contrário. }\end{cases}
$$

Definição da união entre dois intervalos com intersecção vazia 


$$
[a ; b] \cup[c ; d]=[\min (a, c) ; \max (b, d)]
$$

E a comparação entre dois intervalos, $[a ; b]$ e $[c ; d]$ pode resultar em três possibilidades:

- Certamente iguais: se $a=c e b=d$.

- Possivelmente iguais: se a intersecção entre eles for não nula.

- Certamente não iguais: se a intersecção entre eles for vazia.

O exemplo a seguir mostra que expressões algébricas equivalentes podem dar resultados diferentes no intervalo aritmético. Considere a seguinte expressão

$$
f(x)=\frac{x}{1-x} \quad x \neq 1
$$

e para $[x]=[2,3]$, então

$$
f([x])=\frac{[2,3]}{1-[2,3]}=[-3,-1] .
$$

Para $x \neq 0$,podemos reescrever $f(x)$ como

$$
f_{1}(x)=\frac{x}{1-x}=\frac{1}{\frac{1}{x}-1} \quad x \neq 0
$$

O cálculo utilizando aritmética intervalar $[2,3]$ tem como resultado

$$
f_{1}([x])=\frac{1}{\frac{1}{[2,3]}-1}=\left[-2,-\frac{3}{2}\right] \neq[-3,-1]
$$

A razão para isso é baseado no fato de que a aritmética intervalar não segue as mesmas regras da aritmética para números reais. 


\section{Apêndice B - Algoritmo de Contornos Ativos (Snakes)}

\section{B.1 Formulação Clássica}

Um contorno ativo sofre influência de forças internas, que fazem com que a curva fique suave, de forças externas, que consistem de forças da imagem, fazendo com que a curva seja atraída por bordas, linhas ou terminações, e de restrições externas.

A energia definida para este contorno, de modo que o seu mínimo corresponda ao contorno final desejado, representando o contorno ativo como uma curva paramétrica $v(s)=(x(s), y(s))$, onde $s$ é o comprimento do arco, é:

$$
\begin{aligned}
E_{\text {snake }}^{*} & =\int_{0}^{1} E_{\text {snake }}(v(s)) d s \\
& =\int_{0}^{1} E_{\text {int }}(v(s))+E_{\text {image }}(v(s))+E_{\text {con }}(v(s)) d s
\end{aligned}
$$

onde $E_{\text {int }}$ representa a energia interna devido à curvatura ou descontinuidades, $E_{\text {image }}$ corresponde às forças de imagem e $E_{\text {cont }}$ às forças de restrição externas.

A energia interna da curva spline pode ser dada por:

$$
E_{\text {int }}=\frac{1}{2} \alpha(s)\left|v_{s}(s)\right|^{2}+\frac{1}{2} \beta(s)\left|v_{s s}(s)\right|^{2} .
$$

Esta equação apresenta dois termos importantes. O termo de primeira ordem aumenta com a descontinuidade da curva e o termo de segunda ordem cresce com o aumento da curvatura. Os coeficientes $\alpha$ e $\beta$ são os pesos atribuídos para cada um desses termos, a fim de se controlar a importância de cada um.

A energia de imagem faz a curva ser atraída para características específicas da imagem como linha, bordas e terminações. A energia da imagem é a soma 
destes três termos, com seus respectivos pesos

$$
E_{\text {image }}=w_{\text {line }} E_{\text {line }}+w_{\text {edge }} E_{\text {edge }}+w_{\text {term }} E_{\text {term }} .
$$

A energia interna é o termo regularizante. Definindo $E_{\text {ext }}=E_{\text {image }}+E_{\text {con }}$, a integral da energia fica como:

$$
\int_{0}^{1} E_{\text {ext }}(v(s))+\frac{1}{2}\left(\alpha(s)\left|v_{s}(s)\right|^{2}+\beta(s)\left|v_{s s}(s)\right|^{2}\right) d s
$$

Se for adotado $\alpha(s)=\beta$ e $\beta(s)=\beta$ como constantes, e substituindo os termos correspondentes na equação acima, um par de equação independentes de Euler é obtido,

$$
\begin{aligned}
& \alpha x_{s s}+\beta x_{s s s s}+\frac{\partial E_{e x t}}{\partial x}=0 \\
& \alpha y_{s s}+\beta y_{s s s s}+\frac{\partial E_{e x t}}{\partial y}=0 .
\end{aligned}
$$

No caso de $\alpha$ e $\beta$ não serem constantes, será utilizado a função discretizada da equação (B.3). Dessa forma, temos que:

$$
E_{\text {snake }}^{*}=\sum_{i=1}^{n} E_{\text {int }}(i)+E_{\text {ext }}(i) .
$$

Definindo o vetor $v_{i}=\left(x_{i}, y_{i}\right)$, que é a discretização de $v(s)$ e utilizando as diferenças finitas: $\frac{\partial v_{i}}{\partial i}=\frac{v_{i}-v_{i-1}}{2 h^{2}}$ e $\frac{\partial^{2} v_{i}}{\partial i^{2}}=\frac{v_{i-1}-2 v_{i}+v_{i+1}}{2 h^{4}}$, temos que $E_{\text {int }}$ :

$$
E_{\text {int }}(i)=\alpha_{i} \frac{\left|v_{i}-v_{i-1}\right|^{2}}{2 h^{2}}+\beta_{i} \frac{\left|v_{i-1}-2 v_{i}+v_{i+1}\right|^{2}}{2 h^{4}}
$$

onde definimos $v(0)=v(n)$.

Sendo $f_{x}(i)=\frac{\partial E_{e x t}}{\partial x_{i}}$ e $f_{y}(i)=\frac{\partial E_{e x t}}{\partial y_{i}}$, as equações de Euler discretizadas ficam:

$$
\begin{aligned}
& \alpha_{i}\left(v_{i}-v_{i-1}\right)-\alpha_{i+1}\left(v_{i+1}-v_{i}\right)+\beta_{i-1}\left[v_{i-2}-2 v_{i-1}+v_{i}\right] \\
& -2 \beta_{i}\left[v_{i-1}-2 v_{i}+v_{i+1}\right]+\beta_{i+1}\left[v_{i}-2 v_{i+1}+v_{i+2}\right] \\
& +\left(f_{x}(i), f_{y}(i)\right)=0 .
\end{aligned}
$$

Na forma de matriz, a equação pode ser escrita como: 


$$
A x+f_{x}(x, y)=0
$$

$$
A y+f_{y}(x, y)=0
$$

onde A é a matriz dos coeficientes $\alpha$ e $\beta$ e é pentadiagonal. A evolução temporal do "snake" pode então ser obtida pela seguinte equação:

$$
\begin{aligned}
& x_{t}=(A+\gamma I)^{-1}\left(x_{t-1}-f_{x}\left(x_{i-1}, y_{t-1}\right)\right) \\
& y_{t}=(A+\gamma I)^{-1}\left(y_{t-1}-f_{y}\left(x_{i-1}, y_{t-1}\right)\right) .
\end{aligned}
$$

onde $x_{t}$ e $y_{t}$ são as iterações dos vetores de posição e o fator $\gamma$ é o tamanho do passo temporal. A inversão da matriz pentadiagonal $A+\gamma I$ pode ser obtida com complexidade $O(n)$ através de decomposição LU.

A abordagem padrão ao problema utiliza $w_{\text {line }}=0$ e $w_{\text {term }}=0$ para $E_{\text {image }}$. $E_{c o n}$ também é adotada como zero. A energia externa $E_{\text {ext }}$ fica:

$$
E_{\text {ext }}=w_{\text {edge }} E_{\text {edge }}=-w_{\text {edge }}|\nabla I(x, y)|^{2}
$$

\section{B.2 Greedy Snake}

O método "Greedy Snake" apresenta uma abordagem diferente para a solução de contornos ativos. O método corrige problemas de instabilidade na implementação original de Kass et al. ${ }^{[38]}$ e apresenta uma maior eficiência computacional. O algoritmo não garante a localização de um mínimo global, mas apresenta melhores resultados comparado a outros métodos.

A nova energia para ser minimizada neste método é:

$$
\begin{aligned}
E_{\text {snake }} & =\int_{0}^{1}\left(E_{\text {int }}+\gamma(s) E_{\text {image }}\right) d s \\
& =\int_{0}^{1}\left(\alpha(s) E_{\text {cont }}+\beta(s) E_{\text {curv }}+\gamma(s) E_{\text {image }}\right) d s
\end{aligned}
$$

onde $E_{\text {cont }}$ é a energia interna relacionada à continuidade da curva e $E_{\text {curv }}$ é a energia interna relacionada à curvatura. A $E_{\text {image }}$ é a energia relacionada a imagem, correspondente à equação (B.4). 
A cada iteração do algoritmo, a vizinhança de cada ponto da curva é examinada e o ponto que possui menor energia é escolhido como o novo ponto da curva para próxima iteração. Se for utilizado o índice $j$ para enumerar os pontos da vizinhança, e $i$ para o $i^{\text {ésimo }}$ ponto da curva, poder-se-á reescrever a equação da energia a ser minimizada:

$$
E_{\text {snake }}=\sum_{i=0}^{N-1}\left(\alpha(s) E_{\text {cont }}\left(v_{i}, j\right)+\beta(s) E_{\text {curv }}\left(v_{i}, j\right)+\gamma(s) E_{\text {image }}\left(v_{i}, j\right)\right) .
$$

O primeiro termo, a energia de continuidade, é definida como a diferença entre a média da distância entre os pontos e os dois pontos considerados: $d_{a v r}-$ $d_{v(i)-v(i+1, j)}$. Desta forma a curva não possui a têndencia de encolher como no método clássico, mas mantém a mesma propriedade de favorecer a continuidade de primeira ordem. O valor da energia deve ser normalizada, fornecendo:

$$
E_{\text {cont }}(v(i), j)=\frac{\left|d_{\text {avr }}-d_{v(i)-v(i+1, j)}\right|}{\max \left\{\left|d_{a v r}-d_{v(i)-v(i+1, j)}\right|\right\}} .
$$

A energia de curvatura utilizada é a mesma obtida pelas diferenças finitas no método clássico, desta vez normalizada. Na nova notação, a energia é:

$$
E_{\text {curv }}(v(i), j)=\frac{|v(i-1)-2 v(i, j)+v(i+1)|}{\max \{|v(i-1)-2 v(i, j)+v(i+1)|\}} .
$$

O termo $E_{\text {image }}$ provém da magnitude do gradiente $(I)$, que também deve ser normalizado. A normalização é feita em relação à amplitude dos valores do gradiente, para obter maior sensibilidade na variação da magnitude. O termo da magnitude é negativo para que os pontos com grandes gradientes possuam menor energia.

$$
E_{\text {image }}(v(i), j)=\frac{I(v(i), j)}{\max (I(v(i), j))-\min (I(v(i), j))}
$$




\section{Referências}

1 TAVARES, R. S.; TSUZUKI, M. S. G.; GOTOH, T.; KAGEI, S.; IWASAWA, $\mathrm{T}$. Lung movement determination in temporal sequences of $\mathrm{mr}$ images using hough transform and interval arithmetics. In: Proceedings of the 7th IFAC Symposium on Modelling and Control in Biomedical Systems. [S.l.: s.n.], 2009. p. $192-197$.

2 MOORE, K. L.; DAlley, A. F. Anatomia Orientada para a Clínica. Brazil: Guanabara Koogan, 2001.

3 KILLNER, G. I. Radiações Eletromagnéticas - Revista Escola. 2010. http://revistaescola.abril.com.br/img/plano-de-aula/ensino-medio/ radiacao- $1 . j p g$.

4 NóBREGA, A. I. da. Técnicas em Ressônancia Magnética Nuclear. Brazil: Atheneu, 2006.

5 STEVO, N.; CAMPOS, R.; TAVARES, R. S.; TSUZUKI, M. S. G.; GOTOH, T.; KAGEI, S.; IWASAWA, T. Registration of temporal sequences of coronal and sagittal images obtained from magnetic resonance. In: Proceedings of the COBEM 2009 - 20 ${ }^{\text {th }}$ International Congress of Mechanical Engineering. [S.l.: s.n.], 2007.

6 MORI, S.; KONDO, C.; SUZUKI, N.; YAMASHITA, H.; HATTORI, A.; KUSAKABE, M.; ENDO, M. Volumetric cine imaging for cardiovascular circulation using prototype 256-detector row computed tomography scanner (4-dimensional computed tomography) a preliminary study with a porcine model. Journal of Computer Assisted Tomography, v. 29, p. 26-30, 2005.

7 LUJAN, A. E.; LARSEN, E. W.; BALTER, J. M.; HAKEN, R. K. T. A method for incorporating organ motion due to breathing into $3 \mathrm{~d}$ dose calculations. Medical Physics, v. 26, p. 715-720, 1999.

8 HERK, M. van. Errors and margins in radiotherapy. Seminars in Radiation Oncology, v. 14, p. 52-64, 2004.

9 KEALL, P. J.; JOSHI, S.; VEDAM, S. S.; SIEBERS, J. V.; KINI, V. R.; MOHAN, R. Four-dimensional radiotherapy planning for dmlc-based respiratory motion tracking. Medical Physics, v. 32, p. 942-951, 2005.

10 SARRUT, D.; DELHAY, B.; VILlard, P.-F.; BOLDEA, V.; BEUVE, M.; CLARYSSE, P. A comparison framework for breathing motion estimation methods from 4d imaging. IEEE Transactions on Medical Imaging, v. 26, p. 1636-1648, 2007.

11 MANGARD, M.; HAMMERSBERG, P. Optimised detail detectability in computerised tomography. Journal of X-Ray Science and Technology, v. 8, p. 51-73, 1998. 
12 HATABU, H.; ALSOP, D. C.; LISTERUD, J.; BONNET, M.; GEFTER, W. B. $t 2^{*}$ and proton density measurement of normal human lung parenchyma using submillisecond echo time gradient echo magnetic resonance imaging. European Journal of Radiology, v. 29, p. 245-252, 1999.

13 KAUCZOR, H. U. MRI of the lung. Berlim: Springer-Verlag, 2009.

14 IWASAWA, T.; KAGEI, S.; GOTOH, T.; YOSHIIKE, Y.; MATSUSHITA, K.; KURIHARA, H.; SAITO, K.; MATSUBARA, S. Magnetic resonance analysis of abonormal diaphragmatic motion in patients with emphysema. European Respiratory Journal, v. 19, p. 225-331, 2002.

15 CLUZEL, P.; SIMILOWSKI, T.; CHARTRAND-LEFEBVRE, C.; ZELTER, M.; DERENNE, J. P.; GRENIER, P. A. Diaphragm and chest wall: assessment of the inspiratory pump with $\mathrm{mr}$ imaging-preliminary observations. Radiology, v. 215 , p. $574-583,2000$.

16 GAUTHIER, A. P.; VERBATICK, S.; ESTENN, M.; SEGEBARTG, C.; MACKLEM, P. T.; PAIVA, M. Three dimensional reconstruction of the in vivo human diaphragm shape at different lung volumes. J Appl Physiol., v. 76, p. 495-50, 1994.

17 GIERADA, D. S.; CURTIN, J. J.; ERICKSON, S. J.; PROST, R. W.; STRANDT, J. A.; GOODMAN, L. R. Diaphragmatic motion: fast gradientrecalled-echo $\mathrm{mr}$ imaging in healthy subjects. Radiology, v. 194, p. 879-884, 1995 .

18 NAKAMURA, C.; ASAKURA, A.; TSUZUKI, M. S. G.; GOTOH, T.; KAGEI, S.; IWASAWA, T. Three dimensional lung modeling from sequential $\mathrm{mr}$ images based on respiratory motion analysis. IEICE Technical Report, v. 105, p. 33-38, 2005.

19 TSUZUKI, M. S. G.; TAKASE, F. K.; GOTOH, T.; KAGEI, S.; ASAKURA, A.; IWASAWA, T.; INOUE, T. Animated solid model of the lung constructed from unsynchronized mr sequential images. Computer Aided Design, v. 41, p. 573-585, 2009.

20 HANEISHI, H.; MASUDA, Y.; UE, H. Dynamic 3d image analysis of thoracoabdominal region. IEICE Technical Report, v. 125, p. 293-297, 2009.

21 OECHSNER, M.; PRACHT, E. D.; STAEB, D.; ARNOLD, J. F. T.; KÖSTLER, H.; HAHN, D.; BEER, M.; JAKOB, P. M. Lung imaging under free-breathing conditions. Magnetic Resonance in Medicine, v. 61, p. 723-727, 2009 .

22 SINGH, M.; CHENG, I.; MANDAL, M. 4d alignment of bidirectional dynamic mri sequences. In: $30^{\text {th }}$ Annual International IEEE EMBS Conference. Vancouver: [s.n.], 2008. p. 5893-5896.

23 PLATHOW, C.; SCHOEBINGER, M.; FINK, C.; LEY, S.; PUDERBACH, M.; EICHINGER, M.; BOCK, M.; MEINZER, H. P.; KAUCZOR, H. U. Evaluation of lung volumetry using dynamic three-dimensional magnetic resonance imaging. Invest Radiol., v. 40, p. 173-179, 2005. 
24 FAttini, C. A.; DAngelo, J. G. Anatomia Humana Básica. Brazil: Atheneu, 2002.

25 STAndRInG, S. Gray's Anatomy: The Anatomical Basis of Clinical Practice. United Kingdom: Elsevier, 2005.

26 KUPERMAN, V. Magnetic Resonance Imaging: Physical Principles and Applications. United States of America: Academic Press, 2000.

27 DiAGNOSTICS, G. E. H. M. Medcyclopaedia. 2010. http://www. medcyclopaedia.com.

28 PIANYKH, O. S. Digital Imaging and Communications in Medicine (DICOM): A Practical Introduction and Survival Guide. United States of America: Springer, 2008.

29 SimOnCELli, E. P.; ADELSON, E. H.; HEEGER, D. J. Probability distributions of optical flow. In: Proceedings Computer Vision and Pattern Recognition 91. [S.1.: s.n.], 1991. p. 310-315.

30 ASAKURA, A.; GOTOH, T.; KAGEI, S.; IWASAWA, T.; INOUE, T. Computer aided system for respiratory motion analysis of the lung region by sequential mr images. Medical Imaging Technology, v. 23, p. 39-46, 2005.

31 MATSUSHITA, K.; ASAKURA, A.; KAGEI, S.; GOTOH, T.; IWASAWA, T.; INOUE, T. Shape tracking on chest $\mathrm{mr}$ sequence images using respiratory patterns. The Journal of the Institute of Image Electronics Engineers of Japan, v. 33, p. 1115-1122, 2004.

32 DUDA, R. O.; HART, P. E. Use of the hough transformation to detect lines and curves in pictures. Communications of the Association for Computing Machinery, v. 15, 1972.

33 KIRYATI, N.; ELDAR, Y.; BRUCKSTEIN, A. M. A probabilistic hough transform. Pattern Recognition, v. 24, p. 303-316, 1991.

34 HEATH, M.; SARKAR, S.; SANOCKI, T.; BOWYER, K. Comparison of edge detectors: a methodology and initial study. Computer Vision and Image Understanding, v. 69, p. 38-54, 1998.

35 HANSEN, E. Interval arithmetic in matrix computations, part i. J. SIAM Numer. Anal., v. 2, p. 308-320, 1965.

36 HANSEN, E.; SMITH, R. Interval arithmetic in matrix computations, part ii. J. SIAM Numer. Anal., v. 4, p. 1-9, 1967.

37 PORTER, T.; DUFF, T. Compositing digital images. SIGGRAPH Comput. Graph., ACM, New York, NY, USA, v. 18, p. 253-259, 1984. ISSN 0097-8930.

38 KASS, M.; WITKIN, A.; TERZOPOULOS, D. Snakes: active contour models. International Journal of Computer Vision, v. 1, p. 321-331, 1987.

39 AMINI, A. A.; TEHRANI, S.; WEYMOUTH, T. E. Using dynamic programming for minimizing the energy of active contours in the presence of hard constraints. In: Int. Conf. Computer Vision. [S.l.: s.n.], 1988. p. 95-99. 
40 WILLIAMS, D. J.; SHAH, M. A fast algorithm for active contours and curvature estimation. Computacional Visual Graphical Image Processing, v. 1, p. $14-26,1992$.

41 SANTHANAM, A.; PATTANAIK, S.; FIDOPIASTIS, C.; ROLLAND, J. P.; DAVENPORT, P. Physically-based deformation of high-resolution 3d lung models for augmented reality based medical visualization. In: $M I C C A I-A M I-$ ARCS international workshop on augmented environments for medical imaging and computer-aided surgery. Rennes (St. Malo France): [s.n.], 2004.

42 VEDAM, S. S.; KEALL, P. J.; KINI, V. R.; MOSTAFAVI, H.; SHUKLA, H. P.; MOHAN, R. Acquiring a four-dimensional computed tomography dataset using an external respiratory signal. Physics In Medicine And Biology, v. 48, p. 45-62, 2003.

43 FITZPATRICK, M. J.; STARKSCHALL, G.; ANTOLAK, J. A.; FU, J.; SHUKLA, H.; KEALL, P. J.; KLAHR, P.; MOHAN, R. Displacement-based binning of time-dependent computed tomography image data sets. Medical Physics, v. 33, p. 235-246, 2006.

44 WEISS, E.; WIJESOORIYA, K.; DILL, S. V.; KEALL, P. J. Tumor and normal tissue motion in the thorax during respiration: Analysis of volumetric and positional variations using 4 d ct. Int. J. Radiat. Oncol. Biol. Phys., v. 67, p. 296-307, 2007.

45 SIEBENTHAL, M. von. Analysis and modelling of respiratory liver motion using 4DMRI. Tese (Doutorado) — Eidgenössische Technische Hochschule ETH Zürich, 2008.

46 COSElmon, M. M.; BALTER, J. M.; MCSHAN, D. L.; KESSLER, M. L. Mutual information based ct registration of the lung at exhale and inhale breathing states using thin-plate splines. Medical Physics, v. 31, p. 2942-2948, 2004.

47 RIETZEL, E.; CHEN, G. T. Y. Deformable registration of 4d computed tomography data. Medical Physics, v. 21, p. 4423-4430, 2006.

48 CASTIllo, R.; CASTIllo, E.; GUERRA, R.; JOHNSON, V. E.; MCPHAIL, T.; GARG, A. K.; GUERRERO, T. A framework for evaluation of deformable image registration spatial accuracy using large landmark point sets. Physics in Medicine And Biology, v. 54, p. 1849-1870, 2009.

49 ABRAMS, S. L.; CHO, W.; HU, C. Y.; MAEKAWA, T.; PATRIKALAKIS, N. M.; SHERBROOKE, E. C. Efficient and reliable methods for rounded interval arithmetic. Computer Aided Design, v. 30, p. 657-665, 1998. 